Andrews University

Digital Commons @ Andrews University

2015

\title{
Programa de Capacitacion Para Involucrar al Nuevo Creyente en la Testificacion en la Asociacion de Allegheny West
}

Walter Castro

Andrews University

Follow this and additional works at: https://digitalcommons.andrews.edu/dmin

Part of the Practical Theology Commons

\section{Recommended Citation}

Castro, Walter, "Programa de Capacitacion Para Involucrar al Nuevo Creyente en la Testificacion en la Asociacion de Allegheny West" (2015). Professional Dissertations DMin. 491.

https://dx.doi.org/10.32597/dmin/491

https://digitalcommons.andrews.edu/dmin/491

This Project Report is brought to you for free and open access by the Graduate Research at Digital Commons @ Andrews University. It has been accepted for inclusion in Professional Dissertations DMin by an authorized administrator of Digital Commons @ Andrews University. For more information, please contact repository@andrews.edu. 


\begin{abstract}
PROGRAMA DE CAPACITACIÓN PARA INVOLUCRAR AL NUEVO CREYENTE EN LA TESTIFICACIÓN EN LA ASOCIACIÓN DE ALLEGHENY WEST
\end{abstract}

\author{
por \\ Walter Castro
}

Asesor: Jorge Mayer 


\section{ABSTRACT OF GRADUATE STUDENT RESEARCH}

Dissertation

Andrews University

Seventh-day Adventist Theological Seminary

\section{Title: PROGRAMA DE CAPACITACIÓN PARA INVOLUCRAR AL NUEVO CREYENTE EN LA TESTIFICACIÓN EN LA ASOCIACIÓN DE ALLEGHENY WEST}

Name of researcher: Walter Castro

Name and degree of faculty adviser: Jorge Mayer, DMin

Date completed: May, 2015

\section{Problem}

The purpose of this study was to analyze the results of a training program for the new believers of the Allegheny West Conference of the Seventh-day Adventist Church. The AWC was established in 1967, and for more than 30 years there was no Hispanic presence throughout its vast territory that covers almost four states. When they managed to establish some Hispanic groups of believers, it was neither because of soul winning, nor because of a clear established witnessing plan, nor a large evangelistic effort or a strategic evangelistic plan to reach a new area. The records indicate that most of these groups were established by Adventists who simply moved from elsewhere. 


\section{Methodology}

The following study researched the biblical foundations that support the training of believers for witnessing. Principles and counsel by Ellen White were analyzed in reference to the involvement of every believer in the art of witnessing for Christ. In addition, a study was conducted in contemporary literature that studies and recommends how a new believer can and should be involved quickly in witnessing as part of their new life in Christ.

Also, a theorical and practical training was developed for the new believers of the AWC. This program was implemented in all the preaching centers of this Conference for a period of one year, although results were collected for four years just to gather more information for a better implementation of this program in the future.

Later on, the program was analyzed and evaluated to reach conclusions that would help us better understand the results of implementing a deliberate program of spiritual growth and the active participation of new believers in witnessing.

\section{Results and Conclusion}

The implementation of the training program for new believers was completed in December of 2013. The program succeeded in tripling the membership of the Hispanics in AWC, seven new congregations were planted and the tithe increased significantly. During this period, more than 200 new believers received training and were subsequently involved in many leadership positions at the local churches.

Because of this training program, the small groups became active and vital in all the local churches. The church growth program implemented in AWC confirmed the 
importance of instructing all new believers on how to be better witnesses of Christ. Besides, the program shed light as to what would be the factors that might encourage more steady growth at the local churches, especially in places with lack of leadership. The results observed regarding the training program for newly baptized in AWC confirmed the importance of not discarding any human being. Anyone surrendered to Christ, trained and enabled, can continue the work that He himself entrusted to his twelve apprentices more than 2,000 years ago. 


\section{SÍNTESIS}

PROGRAMA DE CAPACITACIÓN PARA INVOLUCRAR AL NUEVO CREYENTE EN LA TESTIFICACIÓN EN LA ASOCIACIÓN DE ALLEGHENY WEST

por

Walter Castro

Asesor: Jorge Mayer 


\title{
SÍNTESIS DE TESIS DOCTORAL
}

Doctorado en Ministerio

\author{
Andrews University \\ Seventh-day Adventist Theological Seminary
}

\section{Título: PROGRAMA DE CAPACITACIÓN PARA INVOLUCRAR AL NUEVO CREYENTE EN LA TESTIFICACIÓN EN LA ASOCIACIÓN DE ALLEGHENY WEST}

Nombre del investigador: Walter Castro

Nombre y título del asesor: Jorge Mayer, DMin

Fecha de culminación: Mayo, 2015

\section{Problema}

El propósito de este estudio fue analizar los resultados de un programa de capacitación para los nuevos creyentes de la Asociación del Oeste de Allegheny, o como se la conoce en inglés, Allegheny West Conference (AWC). La Asociación del Oeste de Allegheny fue establecida en 1967, y por más de 30 años no existió presencia hispana a lo largo de su vasto territorio que cubre casi cuatro estados. Cuando finalmente se lograron establecer algunos grupos de hispanos creyentes, no fue por gananacia de almas, ni por un plan de testificación claramente establecido, por una gran tarea evangelística, o 
la planificación estratégica para penetrar en una zona. Los registros nos indican que en su mayoría, estos grupos se establecieron simplemente por adventistas que se mudaron de otros lugares.

\section{Metodología}

La siguiente investigación realizó un estudio de los fundamentos bíblicos que apoyan el entrenamiento de creyentes para la testificación. Se analizaron los principios y consejos de Elena de White con referencia al involucramiento de cada creyente en el arte de testificar por Cristo. Además, se realizó un estudio en la literatura contemporánea que estudia y recomienda cómo un nuevo creyente puede y debe involucrarse rápidamente en la testificación como parte de su nueva vida en cristo.

Además, se preparó una estrategia de entrenamiento teórico-práctico para los nuevos creyentes de la Asociación del Oeste de Allegheny (Allegheny West Conference, AWC). Este programa se implementó en todos los centros de predicación de esta asociación por un período de un año, aunque los resultados fueron recogidos a lo largo de cuatro años para juntar más información y poder mejorar la implementación de este programa en el futuro.

Luego fue analizado y evaluado para llegar a conclusiones que nos ayudarían a comprender mejor los resultados al implementar un programa intencional de crecimiento espiritual y participativo en la testificación para nuevos creyentes.

$$
\text { Resultados y Conclusión }
$$

La implementación del programa de capacitación para nuevos creyentes fue terminada en Diciembre de 2013. El programa tuvo éxito en los siguientes aspectos: Se 
triplicó la membresía de los hispanos en la AWC, se lograron plantar siete nuevas congregaciones y el diezmo aumentó significativamente. Durante este período, más de 200 nuevos creyentes recibieron capacitación y luego fueron involucrados en diversas posiciones de liderazgo en las iglesias locales. 
Andrews University

Seventh-day Adventist Theological Seminary

\title{
PROGRAMA DE CAPACITACIÓN PARA INVOLUCRAR AL NUEVO CREYENTE EN LA TESTIFICACIÓN EN LA ASOCIACIÓN DE ALLEGHENY WEST
}

\author{
Tesis \\ Presentada en Cumplimiento Parcial \\ de los Requisitos Para el Título de \\ Doctor en Ministerio \\ por \\ Walter Castro \\ Mayo del 2015
}


(C) Copyright by Walter Castro 2015

All Rights Reserved 


\section{PROGRAMA DE CAPACITACIÓN PARA INVOLUCRAR AL NUEVO CREYENTE EN LA TESTIFICACIÓN EN LA ASOCIACIÓN DE ALLEGHENY WEST}

\section{Tesis}

Presentada en Cumplimiento Parcial de los Requisitos Para el Título de

Doctor en Ministerio

por

Walter Castro
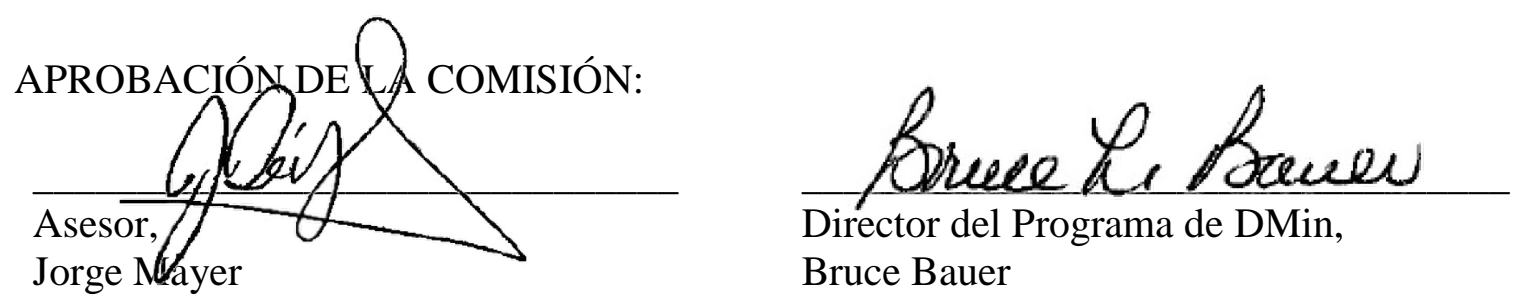

Director del Programa de DMin, Bruce Bauer
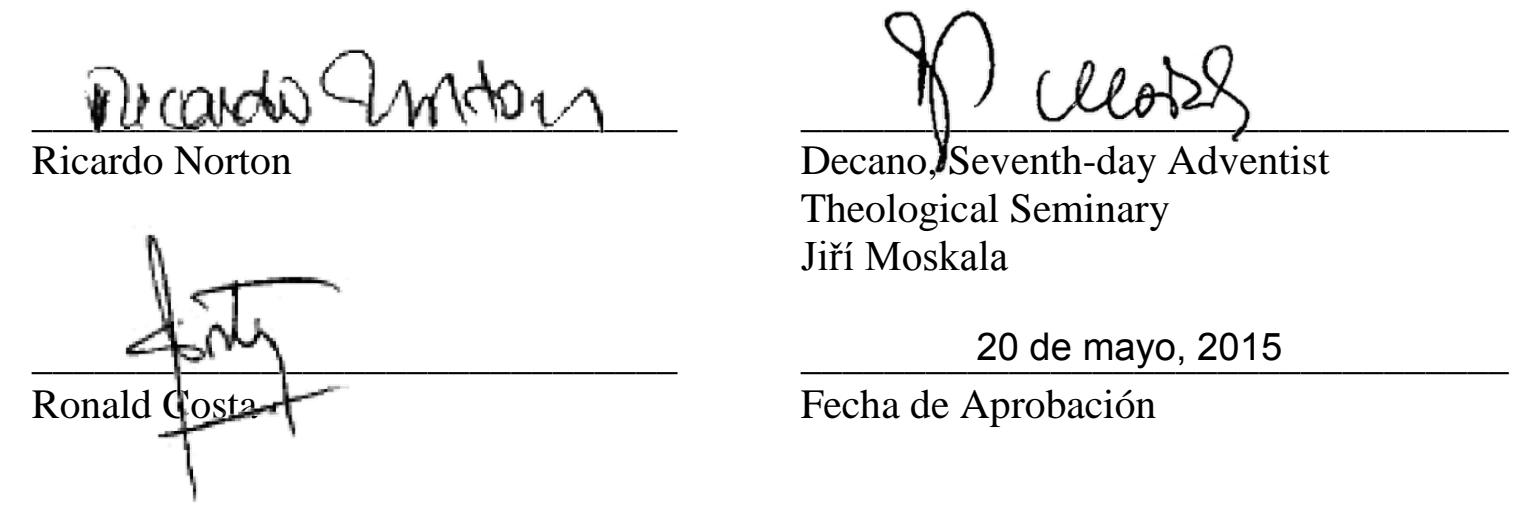

Decano, Seventh-day Adventist

Theological Seminary

Jiří Moskala

20 de mayo, 2015

Fecha de Aprobación 


\section{AGRADECIMIENTO}

Agradezco al Dr. Jorge Mayer; asesor, consejero y líder, por todas sus oportunas recomendaciones. Gracias a su vasta experiencia y dedicación a las escuelas de entrenamiento laico, este proyecto recibió ajustes que son prácticos y vitales para una correcta capacitación. Gracias por ser un ejemplo de dedicación y amor desinteresado digno de imitar para toda la hermandad en el vasto territorio de la Unión del Sur (Southern Union of Seventh-day Adventist Church). 


\section{ÍNDICE DE CONTENIDO}

LISTA DE TABLAS $\ldots \ldots \ldots \ldots \ldots \ldots \ldots \ldots \ldots \ldots \ldots \ldots \ldots$ vii

RECONOCIMIENTOS $\ldots \ldots \ldots \ldots \ldots \ldots \ldots \ldots \ldots \ldots \ldots$ viii

\section{Capítulo}

I. INTRODUCCIÓN $\ldots \ldots \ldots \ldots \ldots \ldots \ldots \ldots \ldots \ldots \ldots$

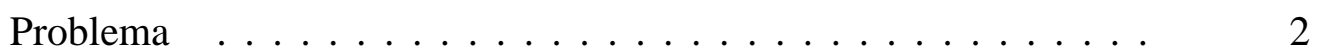

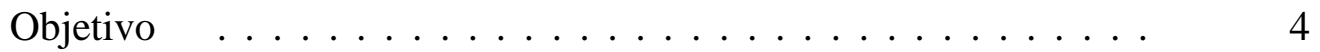

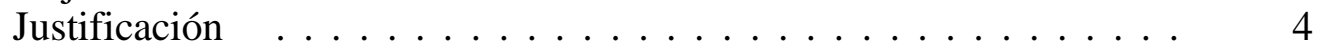

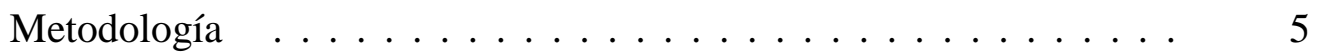

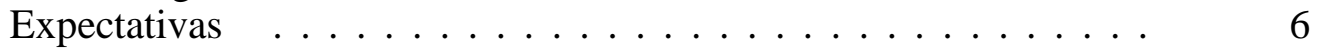

Descripción del proyecto $\ldots \ldots \ldots \ldots \ldots \ldots \ldots$

II. FUNDAMENTOS TEOLÓGICOS PARA LA CAPACITACIÓN DEL CREYENTE EN LA TESTIFICACIÓN $\ldots \ldots \ldots \ldots \ldots \ldots$

Conceptos bíblicos $\ldots \ldots \ldots \ldots \ldots \ldots \ldots \ldots \ldots$

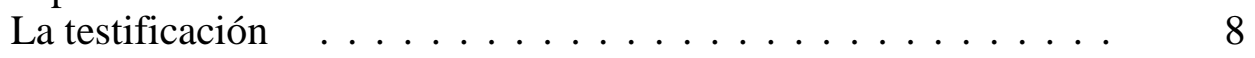

Una mejor comprensión del término testificación . . . . . . 9

Jesús y la testificación . . . . . . . . . . . . . . . 10

La capacitación para testificar $\quad \ldots \ldots \ldots \ldots \ldots \ldots$

Jesús como capacitador ejemplar _ . . . . . . . . . . . 11

Elementos básicos en la capacitación de Jesús . . . . . . . . 13

El evangelismo . . . . . . . . . . . . . . . 15

El evangelio como las buenas nuevas de Jesús $\quad \ldots \ldots \ldots \quad 16$

El evangelio debe ser compartido $\ldots \ldots \ldots \ldots \ldots$

El llamado a la testificación $\ldots \ldots \ldots$. . . . . . . 17

Adaptaciones necesarias para testificar $\quad \ldots \ldots \ldots . \ldots .619$

Principios de testificación en el ministerio de Jesús _ . . . . . . . 21

El principio de la iniciativa $\ldots \ldots \ldots \ldots \ldots \ldots . \ldots \ldots$

El principio de cruzar barreras $\ldots \ldots \ldots \ldots . \ldots 23$

El principio de escuchar $\ldots \ldots \ldots \ldots \ldots \ldots . \ldots \ldots$

El principio de ofrecer asistencia espiritual _ . . . . . . . 25

El principio de no apresurar la cosecha . . . . . . . . . . 25

La testificación en el libro de Hechos _ . . . . . . . . . . . 26

El compromiso con la testificación en los Apóstoles _ . . . . 27

Estrategias de testificación _ . . . . . . . . . . . . 27

El amor como base de la testificación $\ldots \ldots \ldots \ldots \ldots$ 
El amor como resumen de la ley $\ldots \ldots \ldots \ldots$

El amor al prójimo $\ldots \ldots \ldots \ldots \ldots \ldots \ldots \ldots$

La compatibilidad del amor $\ldots \ldots \ldots \ldots \ldots \ldots$

III. LA CAPACITACIÓN DEL RECIÉN BAUTIZADO PARA LA TESTIFICACIÓN EN LA LITERATURA CONTEMPORÁNEA $\ldots .33$

La capacitación del nuevo creyente $\quad \ldots \ldots \ldots \ldots$. . . . . . 34

Los beneficios de la capacitación $\quad \ldots \ldots \ldots \ldots$. . . . . . . 35

Consecuencias de la falta de capacitación $\quad \ldots \ldots \ldots \ldots$

La capacitación del nuevo creyente para la testificación . . . . . 37

La indispensabilidad de la capacitación para la testificación $\quad \ldots \quad 38$

El primer amor y la habilidad para testificar . . . . . . . . 40

El desarrollo de relaciones para testificar $\ldots \ldots \ldots \ldots . \ldots 42$

El estudio de la biblia para testificar $\ldots \ldots \ldots \ldots$. . . . . 43

La oración personal para poder testificar $\ldots \ldots \ldots \ldots$. . . . . 44

La actitud de servicio para testificar $\ldots \ldots \ldots \ldots \ldots$

El testimonio personal $\ldots \ldots \ldots \ldots \ldots \ldots \ldots$

La testificación y el marco social del nuevo creyente . . . . . . . 50

El círculo de influencia del nuevo creyente $\ldots \ldots \ldots \ldots . . \ldots 50$

Las barreras sociales y la testificación _. . . . . . . . . 53

Amigos y familiares como el marco social inmediato . . . . . . 58

La testificación a amigos y familiares en las redes sociales _ . . . 60

El Espíritu Santo como compañero en la testificación . . . . . . . 64

Acompaña con poder para testificar _. . . . . . . . . . 65

Acompaña con poder para convertir $\quad \ldots \ldots \ldots \ldots \ldots . \ldots 6$

IV. PROGRAMA DE ENTRENAMIENTO PARA NUEVOS

CREYENTES ....................

Realidad del territorio y perfil de la Asociación del Oeste de

Allegheny $\ldots \ldots \ldots \ldots \ldots \ldots \ldots \ldots \ldots \ldots \ldots \ldots \ldots$

Breve reseña histórica de AWC $\ldots . \ldots \ldots \ldots$

Breve reseña del arribo de hispanos a Ohio . . . . . . . . . 70

Breve reseña del arribo de hispanos a Virginia y West

Virginia ................... 71

Breve reseña del arribo de hispanos a Pennsylvania . . . . 72

Pioneros del adventismo hispano en AWC . . . . . . . . 73

Descripción del programa de entrenamiento para recién

bautizados ....................... 73

Misión y visión estratégica $\ldots \ldots \ldots \ldots \ldots$. . . . . . . 74

Primera columna - CREO . . . . . . . . . . . . . . . 75

Segunda columna-CONOZCO $\ldots \ldots \ldots \ldots \ldots$

Tercera columna-CELEBRO $\ldots \ldots \ldots \ldots$. . . . . . 82

Cuarta columna - COMPARTO . . . . . . . . . . . . 83

Resultados del programa de entrenamiento $\ldots \ldots \ldots \ldots \ldots$. 
V. RESUMEN, CONCLUSIONES Y RECOMENDACIONES . . . . . 88

Resumen $\ldots \ldots \ldots \ldots \ldots \ldots \ldots$

Conclusiones $\ldots \ldots \ldots \ldots \ldots \ldots \ldots \ldots \ldots$

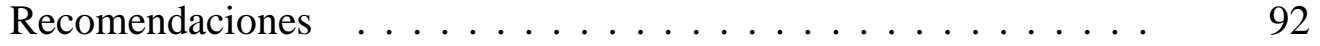

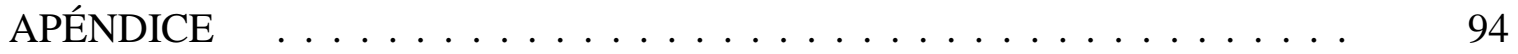

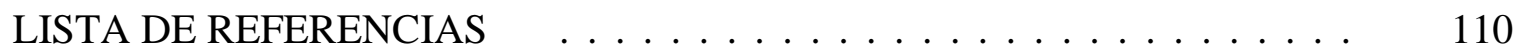

CURRICULUM VITAE $\ldots \ldots \ldots \ldots \ldots \ldots \ldots \ldots$ 


\section{LISTA DE TABLAS}

Tabla 1: Círculo personal de influencia $\ldots \ldots \ldots \ldots$. . . . . . . . 51

Tabla 2: Significado de las regiones de Hechos 1:8 según Anderson . . . . . . 57

Tabla 3: Barreras para testificar en las regiones de Hechos 1:8 . . . . . . . 57

Tabla 4: Crecimiento cuantitativo de AWC entre 2009 y 2013 . . . . . . . . . 85

Tabla 5: Participación de los nuevos creyentes en el programa de crecimiento

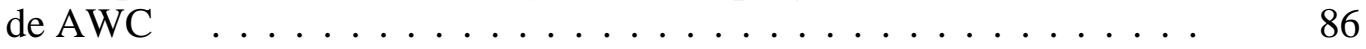




\section{RECONOCIMIENTOS}

Quiero expresar una infinita gratitud a mi esposa Katty por creer, confiar y apoyar cada una de mis iniciativas para terminar este proyecto. Gracias por tu amor expresado en oraciones cada mañana para que pueda terminar. Por ser la mejor amiga, compañera y una ejemplo de servicio a Dios. También a mis hijos Kevin y Keyla porque se conformaron con jugar menos tiempo para que papá pueda terminar.

También agradezco al Pr. Leroy Ramos quién dedicó horas para revisar, corregir y hacer válidas recomendaciones que ayudaron a llegar al documento final.

Deseo reconocer al Dr. Ricardo Norton por ser un excelente asesor pero más aún, un pastor que no se cansa de dar esperanzas para alumnos que se quieren rendir. Finalmente quiero agradecer a mis padres, por ser gladiadores de la vida. Gracias por enseñarme a luchar y a confiar en Dios en cualquier lugar y circunstancia. 


\section{CAPÍTULO I}

\section{INTRODUCCIÓN}

Esta investigación intenta analizar los resultados de un programa de capacitación para los nuevos creyentes de la Asociación del Oeste de Allegheny, o como se la conoce en inglés, Allegheny West Conference (AWC).

Siempre me llamó la atención que algunas iglesias se inclinan por entrenar, discipular y utilizar solamente los dones y talentos de creyentes que ya tienen experiencia como cristianos, o son líderes que aparentemente tienen un grado superior de madurez cristiana por tener mucho tiempo dentro de una iglesia. Por otra parte, la tendencia que he notado es que aquellos que son nuevos en la fe son dejados a un lado y catalogados como gente que necesita mucho tiempo hasta que puedan estar listos para servir, liderar en la iglesia local o testificar a otros de Cristo Jesús.

Tuve que confrontar esta forma de pensar al llegar a la Asociación del Oeste de Allegheny, donde la falta de líderes de experiencia me obligó, como pastor y dirigente, a mirar a cada ser humano que aceptaba a Jesús, cómo un líder y un testigo de Cristo desde el momento que entregaba su vida a Cristo y se convertía en un nuevo creyente.

El presente capítulo mostrará los aspectos en los que esta investigación está fundamentada. En primera instancia se presentará la descripción del problema para luego presentar el propósito por el cual es necesaria una investigación como esta. 
Seguidamente, se especificarán los objetivos principales de la investigación como así tambien la justificación para la misma, describiendo también los capítulos, las limitaciones y delimitaciones correspondientes.

\section{Problema}

El crecimiento de la iglesia depende de seres humanos que se somenten a la voluntad de Dios para que él los utilize en la testificación y el engrandecimiento de su reino.

Cada vez que decidimos que el evangelio penetre en una zona nueva, usualmente nos valemos de gente experimentada y con un alto grado de conocimiento para poder garantizar el éxito. Sin embargo, no siempre contamos con los elementos humanos más dotados o experimentados para tal labor. Es en esta situación que nos preguntamos, ¿cómo se logra que avance el reino de los cielos y la testificación del evangelio si no tenemos gente de experiencia?

Aquellos que van a dar razón de su fe para conquistar a otros deben tener cierto grado de conocimiento y experiencia para poder ser efectivos en la misión.

La Asociación del Oeste de Allegheny fue establecida en 1967, y por más de 30 años no existió presencia hispana a lo largo de su vasto territorio que cubre casi cuatro estados. Cuando finalmente se lograron establecer algunos grupos de hispanos creyentes, no fue por gananacia de almas, ni por un plan de testificación claramente establecido, o por una gran tarea evangelística, o la planificación estratégica para penetrar en una zona. Los registros nos indican que en su mayoría, estos grupos se establecieron con adventistas que simplemente se mudaron de otros lugares. 
Sin embargo, a pesar de que la mayoría de los que establecieron esos centros hispanos de predicación en el territorio de AWC ya eran líderes con experiencia, por más de siete años (2002-2009), el crecimiento fue prácticamente inexistente. De acuerdo a los pocos registros que se pudieron hallar, la ganancia de almas, la testificación sistemática y organizada, y la penetración en otras partes del territorio, no eran parte integral de la realidad semanal de estos centros de adoración.

La siguiente investigación se encuadra dentro de la teología aplicada, entendiendo que la práctica fundamental de todo creyente es la testificación de su fe con otras personas. Aquellos que son nuevos en la fe, deberían ir copiando o imitando de los más experimentados para luego asimilar las prácticas o el estilo de vida de un discípulo comprometido con Cristo y su misión.

Diferentes autores entienden que el crecimiento de una iglesia está directamente relacionado con el crecimiento espiritual de sus miembros, principalmente de aquellos que son nuevos en la fe. Estos, por el simple hecho de tener poco tiempo dentro de la iglesia, tienen un gran potencial para traer a sus amigos y familiares no creyentes a la iglesia.

Por varios años, la AWC no había podido desarrollar su potencial de crecimiento. Aparentemente, aquellos pocos que se unieron a la iglesia tampoco fueron entrenados correctamente como para aprovechar todo su potencial para la testificación.

En consecuencia, esta investigación tratará de observar los efectos en el crecimiento de la Asociación del Oeste de Allegheny, como resultado de un programa de entrenamiento y capacitación para los nuevos creyentes para aprovechar todo el potencial que tienen para la testificación y su desarrollo como líderes dentro de la iglesia local. 


\section{Objetivo}

El propósito del programa fue desarrollar un programa teórico y práctico de varias etapas para capacitar, movilizar e involucrar a los nuevos creyentes de la AWC en la testificación. Así, se planificó un proyecto anual de cuatro etapas junto con los pastores y líderes de las iglesias locales. Este programa se integró al calendario local de las iglesias, y se lo utilizó intencionalmente como parte del plan de crecimiento de la iglesia.

\section{Justificación}

Todo hijo de Dios que ha nacido de nuevo debería ser parte de un proceso de crecimiento y madurez de su fe en Cristo Jesús. Todos los creyentes en Cristo son sus seguidores y sus discípulos. Un discípulo es un aprendiz, uno que es entrenado para seguir las enseñanzas y el ejemplo de su Maestro.

Jesús escogió a sus discípulos para estar con él y para evangelizar (Mr. 1:17). Les encomendó: “Por tanto, id, y haced discípulos a todas las naciones, bautizándolos en el nombre del Padre, y del Hijo, y del Espíritu Santo, enseñándoles que guarden todas las cosas que os he mandado; y he aquí yo estoy con vosotros todos los días, hasta el fin del mundo” (Mt. 28:19-20). Por lo tanto, la iglesia tiene la función de evangelizar y de hacer discípulos a los creyentes.

Las Escrituras nos enseñan que aquellos que se convirtien en discípulos de Cristo comienzan un proceso de crecimiento espiritual en el que necesitan ser enseñados para saber cómo y cuándo dar razón de su fe, y de esa manera continuar la cadena de discípulos que inició Cristo con sus doce aprendices. 
Jesús dijo que nosotros “tenemos que ser perfectos” (Mt. 5:48). Perfecto no significa “sin pecado.” Perfecto significa maduro, pleno, completo, que alcanza la meta (Weber, 2000). Él también nos llamó a tomar su yugo sobre nosotros, y aprender de él (Mt.11:29). Las Escrituras nos indican que Dios está trabajando en la vida de todo creyente para moldearlo y conformarlo a la imagen de Cristo (Ro. 8:29). Todo esto se encuadra dentro de un proceso de crecimiento en el cual todo creyente, especialmente aquellos que son nuevos, deben participar, porque es el deseo de Dios que crezcamos "en la gracia y el conocimeinto de nuestro Señor y Salvador Jesucristo” (2 P. 3:18). El objetivo final es preparar un corazón receptivo al poder del Espíritu de Dios para ser testigos (Hch. 1:8).

La mayoría de los autores revisados entiende que este proceso de crecimiento debe empezar el día en que la persona declara a Cristo como su Salvador, y durar toda la vida. Todo discípulo de Cristo debe estar creciendo diariamente en su conocimiento personal del Señor, el entendimiento de su palabra y su participación en el servicio de su Reino.

Sin embargo, existe un problema en algunas iglesias, que se detectó también en la Asociación del Oeste de Allegheny. Algunos creyentes que tienen muchos años profesando a Cristo aparentemente se han detenido en su crecimiento espiritual, y los nuevos creyentes no están siendo entrenados (discipulados) adecuadamente por estos últimos para la testificación.

\section{Metodología}

La siguiente investigación realizó un estudio de los fundamentos bíblicos que apoyan el entrenamiento de creyentes para la testificación. Se analizaron los principios y 
consejos de Elena de White con referencia al involucramiento de cada creyente en el arte de testificar por Cristo. Además, se realizó un estudio en la literatura contemporánea que recomienda cómo un nuevo creyente puede y debe involucrarse rápidamente en la testificación como parte de su nueva vida en Cristo. Además, se preparó una estrategia de entrenamiento teórica y práctica para los nuevos creyentes de la Asociación del Oeste de Allegheny (Allegheny West Conference, AWC). Este programa se implementó en todos los centros de predicación de esta asociación por un período de cuatro años.

Luego, fue analizado y evaluado para llegar a conclusiones que nos ayudarían a comprender mejor los resultados al implementar un programa intencional de crecimiento espiritual y participativo en la testificación para nuevos creyentes.

\section{Expectativas}

Este trabajo de investigación se limitará a las áreas más relevantes que ayuden a la creación de un programa de entrenamiento solamente para la Asociación del Oeste de Allegheny.

La investigación está limitada a un estudio de los principios y recomendaciones acerca de la testificación en la Biblia, los escritos de Elena G. White y la literatura contemporánea. Además, el entrenamiento se delimitará a aquellas personas que tengan no más de tres años de haber sido bautizados en algunos de los centros de predicación de la AWC.

Una limitación de este autor es la autoridad restringida que tiene como dirigente o coordinador hispano de la asociación y su influencia con los pastores y las iglesias locales. Esta realidad podría impedir en cierta manera la implementación y el 
seguimiento de este programa de entrenamiento para nuevos creyentes de toda la Asociación.

\section{Descripción del proyecto}

Este proyecto está compuesto por cinco capítulos. En la Introducción se describe el propósito y la justificación del proyecto, así como la metodología y las expectativas. En el capítulo dos se presenta la fundamentación teológica de la capacitación de los miembros para la testificación. Destacan los conceptos bíblicos del entrenamiento y la capacitación como parte del crecimiento espiritual de todo creyente. El capítulo tres explora la capacitación del recién bautizado para la testificación a la luz de la literatura contemporánea. Se analizan asuntos como la forma en la cual las iglesias en crecimiento entrenan a sus nuevos creyentes y, por sobre todo, lo que los autores contemporáneos dicen acerca del método de Cristo para entrenar a sus discípulos. En el capítulo cuatro se presenta el programa de entrenamiento para nuevos creyentes en la Asociación de Allegheny West. Se hace una descripción del perfil de la Asociación de Allegheny y su contexto comunitario. Se analizan las estadísticas internas y el perfil demográfico de la iglesia. Finalmente, en el capítulo cinco se presentan el resumen, las recomendaciones y la conclusión, seguidos de la bibliografía. 


\section{CAPÍTULO II}

\section{FUNDAMENTOS TEOLÓGICOS PARA LA CAPACITACIÓN DEL CREYENTE EN LA TESTIFICACIÓN}

Este capítulo expone los fundamentos bíblicos y teológicos relacionados con la capacitación de nuevos creyentes para la testificación. No pretende agotar el tema. Tiene como objetivo exponer los elementos fundamentales que presenta la Biblia sobre la testificación y el involucramiento de los nuevos creyentes en esta práctica. Creemos que contribuirá a la práctica y a la aplicación de los fundamentos de la testificación entre los nuevos creyentes de la Asociación Adventista de Oeste de Allegheny.

\section{Conceptos bíblicos}

Esta sección tiene como objetivo comprender conceptualmente algunos términos que se encuentran en las Sagradas Escrituras tales como testificación, capacitación y evangelización. Entenderlos nos ayudará a tener una mejor comprensión de lo que significa testificar y la importancia de capacitar a los nuevos creyentes.

\section{La testificación}

La aclaración del término es de crucial importancia. El nuevo creyente debe saber lo que la comunidad de creyentes espera de él. Además, le ayudará a comprender lo que Dios desea que practiquen aquellos que en el futuro abrazarán la fe en Cristo Jesús. 
Horn (1960) indica que la palabra testificación proviene del griego martus- que significa “testigo” (p. 1151). Bogaert (1993) asevera que esta palabra aparece aproximadamente 35 veces en el Nuevo Testamento.

La mayoría de los autores estudiados concuerdan que la testificación es el acto de contar a otros lo que se sabe y se ha experimentado. Es mucho más que defender una fe, definir una doctrina o denunciar los pecados del mundo. Barna (2000) afirma que la testificación es la orden de marcha de parte de Dios para el creyente.

\section{Una mejor comprensión del término testificación}

Varios autores consultados creen que la declaración de Lucas en Hechos 1:8: "Y me seréis testigos en Jerusalén, en toda Judea, en Samaria y hasta lo último de la tierra”, suele causar preocupación e incomodidad en la comunidad de creyentes por no comprenderse correctamente el sentido del mismo.

Testificar es afirmar, declarar, explicar y denotar con seguridad algo (Real Academia Española, n.d.). La palabra testigo es usada en varias ocasiones en referencia a todo el grupo de creyentes. En Hechos 1:8 el Señor Jesucristo se dirige a todos los creyentes cuando les dice: “y me seréis testigos”. Rand (1988) afirma que sólo algunos cristianos son evangelistas, pero todos son testigos. Se puede ser testigo sin ser evangelista, pero no se puede ser evangelista sin antes ser un testigo. Según Ausejo (1981) el testigo da testimonio de lo que vio u escuchó en referencia a Cristo y su resurrección, ya que sin la resurrección de Cristo, la predicación de los apóstoles sería vana (1Co. 15:17). Hall (2008) entiende que los discípulos conocían la verdad y tenían pruebas, habían sido testigos de la más gloriosa realidad en la historia de la humanidad, y 
no permitirían que la muerte y la resurrección de Jesús pasara al olvido; ellos se habían comprometido a ser testigos.

\section{Jesús y la testificación}

Las últimas instrucciones de Jesús a sus discípulos, antes de ascender a su Padre estuvieron relacionadas con la testificación. Jesús les prometió que cuando recibieran el Espíritu Santo serían poderosos testigos (Mt. 28:18-20; Mr. 16:15-18; Lc. 24:48-49).

Así, se entiende que la testificación es la praxis de la nueva vida en Cristo. “No se puede ser un cristiano sin ser un testigo” (Rand, 1988, p. 31). Rand (1988) aclara que para poder testificar con veracidad se debe haber experimentado algún hecho y estar seguro de ello. En el caso del testigo cristiano, como lo explica Lucas, "vosotros sois testigos de estas cosas” (Lc. 24:48). El testigo cristiano ha visto u oído en relación a Cristo Jesús y sus hechos.

Richardson (2006) entiende que la testificación cristiana está directamente relacionada con el autor de los hechos, Cristo Jesús. El autor continúa diciendo que “al final del día, la testificación cristiana tiene que ver con Jesús, su historia y los resultados de su historia en el mundo y la vida del creyente. Tarde o temprano, el testigo hablará a otros acerca de Jesús” (p. 112).

Se puede inferir, entonces, que la testificación es simplemente la práctica de decir a otro lo que uno mismo sabe, escuchó o experimentó. El ciego de Juan 9, ahora curado, no era abogado ni sabía mucho de la teología de Jesús, pero fue testigo de algo que le sucedió y lo pudo expresar de esta manera: “Una cosa sé, que habiendo yo sido ciego, ahora veo” (Jn. 9:25). Podemos declarar, entonces, que la testificación es simplemente contar a otro lo que le sucedió a uno cuando se encontró con Jesús. 


\section{La capacitación para testificar}

Esta sección explicará que es la capacitación para testificar de Cristo, además se presentará el ejemplo de Cristo como capacitador y los elementos que El utilizó para entrenar a sus discípulos.

Capacitar es hacer a alguien apto o habilitarlo para algo (Real Academia Española, n.d.). Jesús escogió doce hombres sin capacitación, y dedicó el tiempo necesario para que ellos aprendieran a testificar de lo que habían visto y oído durante tres años.

MacArthur (2002) explica que Jesús tuvo un plan maestro para poder alcanzar y transformar el mundo. Eligió doce seguidores sin capacidad y con grandes deficiencias de carácter. Sin embargo, los invitó desde el primer encuentro a iniciar un proceso de capacitación y aprendizaje junto a él. Esto los habilitaría más tarde para continuar con el plan del Maestro.

Manson (1959) indica que el término discípulo que usó Jesús, podría ser mejor traducido como aprendiz. En Lucas 10, podemos ver cómo Jesús invierte más de dos años entrenando y capacitando a sus aprendices-discípulos. Luego, prepara un equipo de 36 parejas para poder testificar a las multitudes. De esta manera, se puede ver que las instrucciones son similares a las previamente dadas a los discípulos en Mateo 10:5-14.

\section{Jesús como capacitador ejemplar}

Durante su ministerio terrenal, el Maestro asistió las necesidades de grupos y multitudes al menos unas 17 veces. En todas las ocasiones lo hizo a la vista de los discípulos, quienes observaban para luego imitarlo. Manson (1959) advierte que Jesús no llamó meramente estudiantes teóricos, sino aprendices con una tarea práctica. Su trabajo 
no era estudiar, sino pacticar. Estos pescadores serían ahora pescadores de hombres, obreros en la viña y en el campo de Dios (Mt. 4:19).

MacArthur (2002) observa cómo Jesús se convirtió en el Maestro, no tanto como profesor de una doctrina, sino más bien como el maestro-artesano de quien tenían que aprender, a quien tenían que seguir e imitar.

A través de las Escrituras se puede observar cómo Jesús desarrolló y practicó un ministerio capacitador al proveer entrenamiento a los 70; también pasó tiempo entrenando a los 120 y también influyó en el entrenamiento de los 500 en Galilea. Sin embargo, hay aproximadamente 46 menciones en el Nuevo Testamento de tiempo debidamente separado que Jesús pasó con sus aprendices-discípulos. Durante ese tiempo los entrenó y además los encomendó a un ministerio de testificación personal y grupal.

Barna (2001) afirma que Jesús fue un capacitador personal. Jesús realizó un entrenamiento intencional y personalizado; uno a uno, uno a dos, uno a tres; de tal manera que pudieran escuchar, ver, aprender, ser supervisados y corregidos por él mismo como capacitador. (Mt. 5-7; 9:1-17, 35-38; 10:1-26; 24; Mr. 10:1-26; 13; Lc. 7:36-50; 10:1-20; Jn. 8:1-12; 13:1-17; 14-16).

Hendrix \& Householder (1977) entienden que el aprendizaje y la capacitación deberían ser usados hoy de la misma manera dentro de cada congregación. Jesús les comunicó a los discípulos que la mies era mucha y los obreros pocos (Mt. 9:37).

Knowles (1981) asevera que la necesidad de la capacitación surge de la demanda en el campo o en el área de necesidad. Hay un reconocimiento de parte de Jesús en cuanto a la necesidad de obreros. En el ministerio de Jesús descubrimos que no solamente dedicó tiempo trabajando por la salvación de las almas, “sino que buscó constantemente a 
otros que pudieran realizar el ministerio. Pasó mucho de su tiempo capacitándolos para realizar un ministerio efectivo” (p. 50).

\section{Elementos básicos en la capacitación de Jesús}

Mhano (2000) resume algunos elementos básicos de capacitación que Jesús utilizó durante su ministerio. La elección es el primer elemento. Jesús eligió a 12 hombres “a los cuales también llamó apóstoles” (Lc. 6:13). Los invitó para que sean sus estudiantes cuando les dijo: "Venid en pos de mí, y os haré pescadores de hombres” (Mt. 4:19). Hendrix \& Householder (1977) observan que Jesús buscó gente con potencial para realizar el trabajo, humilde y enseñable.

El segundo elemento es el de asociación. Jesús eligió seguidores que pudieran pasar tiempo con él. “Designó entonces a doce para que estuvieran con él” (Mr. 3:14). Stout (1983) resalta esta relación de aprendizaje que tuvo resultados aún después de la resurrección. La gente descubrió estos efectos de asociación y comenzaron a reconocerlos porque habían estado con Jesús (Hch. 4:13).

El tercer elemento es la comunicación. Esta es la fase donde el contenido es transmitido. Esto fue un proceso continuo y constante. Youssef (1986) asevera que en esta etapa se brindaron los principios y el conocimiento.

El cuarto elemento es la demostración. El método de Jesús no fue solamente un entrenamiento teórico. Su ejemplo fue la técnica de capacitación que más utilizó. Jesús compartió sus principios y luego los modeló con su ejemplo. En la última cena lo verbalizó claramente al decir: "Porque ejemplo os he dado para que como yo os he hecho, vosotros también hagáis” (Jn. 13:15). 
El quinto elemento destacado por Stout (1983) es la delegación. Collinson (2004) reconoce que en el futuro "Jesús no sería el maestro inmediato. Los apóstoles y otros que escucharon sus enseñanzas ahora son los que las transmiten a la comunidad” (p. 110). En su momento, Jesús compartió sus responsabilidades con aquellos que estaba entrenando y cuando llegó el momento los envió (Lc. 9:21). Este principio de delegación por parte de Jesús fue claramente estipulado y practicado por El. Coleman (1996) indica que Jesús no dejó la tarea del evangelismo sujeto a una impresión humana o a la conveniencia. El traspaso del ministerio fue expuesto de antemano, “y haré que seáis pescadores de hombres” (Mr. 1:16). Luego, fue progresivamente clarificado a medida que lo seguían y veían lo que ello implicaba. Stout (1983) observó claramente que ellos recibieron responsabilidades. Coleman (1996) lo ratifica diciendo: "Nadie que sigue a Jesús puede escapar de esta conclusión. Así fue antes, así es hoy” (p. 87).

Finalmente, en sexto lugar, se encuentra la supervisión. Coleman (1996) se refiere a la supervisión como la actitud constante de un capataz hacia sus aprendices. Era crucial, como lo aclara Stout (1983) la necesidad de orientación continua, de organización y de liderazgo. Existía una constante observación del trabajo de los discípulos y cuando era necesario hasta una corrección de cómo debían hacer o rehacer las cosas, “Jesús les dijo: Por vuestra poca fe. De cierto os digo que si tenéis fe como un grano de mostaza, diréis a este monte: "Pásate de aquí allá, y se pasará; y nada os será imposible. Pero este género no sale sino con oración y ayuno” (Mt. 17:20-21).

Como parte de la supervisión ellos compartían alegrías y frustraciones en una especie de sesión de revisión y evaluación. “Al regresar los apóstoles, le contaron todo lo que habían hecho” (Lc. 9:10). White (1911) nos resume uno de los encuentros de 
supervisión advirtiendo que los discípulos habían cometido errores en una de sus primeras asignaciones como evangelistas y que necesitaban más instrucción. En otra ocasión, como Coleman (1994) lo resume, los discípulos se encontraron con algo de resistencia al trabajo asignado por el Señor en Samaria. Al ver ellos la situación, quisieron solucionar el problema pidiendo fuego del cielo para que consumiera a los que se oponían (Lc. 9:54). Sin embargo, Jesús los corrige con una reprensión y los envía a otra aldea (Lc. 9:56).

Bartle (2007) entiende que la supervisión garantiza que no se reincida en el mismo error. Es por eso que se implementa en todas las áreas de liderazgo. La supervisión y la corrección fueron cruciales durante el ministerio de Cristo y es crucial para la iglesia de Cristo hoy. La supervisión debe ser constante hasta que se vea madurez en el aprendiz, y que éste puede llevar a cabo la labor por sí mismo.

De esta manera, podemos declarar con certeza que la capacitación es vital para la testificación efectiva. Mc Gavran \& Hunter (1980) nos advierten que no se puede ser un buen administrador de la gracia de Dios sin reacomodar la capacitación dentro de nuestras prioridades.

\section{El evangelismo}

En esta parte se estudiará la terminología de la palabra evangelismo y qué significa para el creyente el involucramiento en la práctica del mismo.

El concepto de evangelismo o evangelización de acuerdo a Webster (1959) se define simplemente como la proclamación de las buenas nuevas del evangelio. Coleman (1973) la presenta como la mano que alcanza al perdido con una oferta de vida. Richardson (2006) intenta redescubrir la evangelización presentándola como un estilo de 
vida menos confrontacional y altamente relacional, donde el Espíritu Santo es quien indica cómo, cuándo y dónde es el momento de impartir la verdad de Jesucristo.

Chronic (2011) resumió el evangelismo y la evangelización de una manera más amplia, donde se incluyen aspectos como la proclamación, la presencia o simplemente la persuasión.

Aunque diferentes estudiosos buscan definir con originalidad la evangelización, el origen sigue siendo las Escrituras. El profeta Isaías adelantó el concepto del evangelio y la evangelización. “El Espíritu de Jehová el Señor está sobre mí, porque me ungió Jehová; me ha enviado a predicar buenas nuevas a los abatidos...” (Isa. 61:1). Estas palabras se convertirían luego en el evangelio viviente en la vida de Cristo. "Pero él les dijo: Es necesario que también a otras ciudades anuncie el evangelio del reino de Dios, porque para esto he sido enviado” (Lc. 4:43). "Yo he venido para que tengan vida, y para que la tengan en abundancia” (Jn. 10:10).

\section{El evangelio como las buenas nuevas de Jesús}

Arndt \& Gingrich (1964) entienden que este concepto de evangelismo impregna todo el Nuevo Testamento. La noción de buenas nuevas aparece más de 72 veces en el Nuevo Testamento, siendo Pablo, con 54 veces, quien más profusamente la usó, y por consiguiente, quien más aportó a la comprensión de su significado.

Ola (1989) afirma que el evangelismo es un mensaje de esperanza que llena el corazón del que lo recibe. Viene de Dios y debe ser depositado en el corazón del hombre. La evangelización es la proclamación del mensaje de esperanza y buenas nuevas de salvación del pecado, para todos los hombres. Esto se logra gracias al sacrificio de Jesús en la cruz del calvario (Ro. 1:16-117; Mr. 13:10, 16:15; Hch. 15:7). 
Little (2006) advierte que aquellos que no conocen a Cristo necesitan darse cuenta de nuestra experiencia cristiana. Para ello, necesitan escuchar nuestras palabras y lo que tenemos que decir acerca de Jesús. De la misma manera, Jesús comunicaba a sus oyentes lo que él tenía para decir acerca del Padre y de él mismo, (Jn. 5:36; Mt. 11:37). Campbell (1987) afirma que "La tarea del evangelismo es comunicar el amor de Dios a otras personas, permitiéndoles que encuentren fe personal en Cristo” (p.12).

\section{El evangelio debe ser compartido}

De esta manera, cada creyente ha sido llamado y comisionado por Jesús a contribuir en la construcción de su reino, compartiendo las buenas nuevas del Padre y lo obtenido en nuestro favor por Cristo en la cruz del calvario. La comisión es la de practicar la evangelización en el mundo que nos rodea y aún más allá (Hech. 1:8).

Early \& Wheeler (2010) advierten que las palabras evangelio y buenas nuevas son usadas unas 130 veces en la Biblia, 109 sólo en el Nuevo Testamento. De este número de referencias se infiere con claridad que la evangelización o el compartir las buenas nuevas es algo que todo creyente y seguidor de Jesús debe tomar con mucha seriedad. Abraham (1994) afirma que en la Biblia la proclamación de las buenas nuevas a los no creyentes es una de las visiones esenciales para la iglesia. Se comprende, de esta manera, que evangelización es la continuación del trabajo de compartir las buenas nuevas que Cristo inició en esta tierra.

\section{El llamado a la testificación}

Todos los discípulos sabían que Jesús les había entregado una gran comisión, la de ir y hacer discípulos (Mt. 28:18-20). Sabían que debían tener éxito. Coleman (1986) 
señala que "si cada criatura humana va a escuchar el evangelio, entonces cada creyente debe predicar el evangelio” (p. 136). Como lo indica Ola (1989), para los discípulos, no existía distinción entre apóstol y no apóstol, entre clero y laico. Cada uno de los creyentes aceptó el desafío y proclamó el evangelio.

Dunbar (1992) afirma que el llamado a la testificación personal se ve primeramente reflejado con total claridad en la vida de Cristo. Los discípulos pudieron observar a Jesús y nosotros podemos interpretar lo que ellos vieron. La testificación personal en la vida de Cristo es vasta.

Miles (1982) observó que Jesús tuvo contacto personal con al menos 35 personas en los cuatro evangelios. La historia bíblica revela que no solamente satisfizo necesidades básicas, sino que también hubo enseñanza sobre algún aspecto del reino de los cielos (Mt. 21:23; 22:16, Mr. 6:6; Lc. 13:22; 23:5). Aun más, se puede ver cómo Jesús, intencional y personalmente enseñó, de acuerdo a Mateo 4:23 y a Marcos 14:49, dentro y fuera de la sinagoga.

En Juan 15:5, Cristo aclara que los verdaderos discípulos deben inequívocamente permanecer en él y producir frutos como él. Phillips (2008) destaca que no existe un llamamiento más alto ni una comisión más clara en el Nuevo Testamento que reproducirnos en otros.

Hall (2008) explica que al proclamar el evangelio hay que entender que Dios no ha delegado esta tarea a los ángeles o algún otro ser celestial; desde el comienzo intentó que el evangelio sea anunciado combinando los esfuerzos personales del hombre con lo divino. De esta manera, Rand (1988) asegura que cada cristiano debiera permanecer constantemente listo para testificar. 
Así, se comprende que existe un llamado a testificar continuamente sobre la realidad de Cristo en nuestra vida. La buena reputación no es suficiente. El llamado conciso es a hablar a otros de Cristo y de éste resucitado (2 Ti. 3:7; Rm. 1:1; 1 Co. 9:16).

\section{Adaptaciones necesarias para testificar}

Para poder testificar, el creyente debe poseer la actitud correcta. En el siguiente segmento identificaremos algunas actitudes que deben estar presente en todo testigo de Cristo.

Para testificar de Cristo y las buenas nuevas de salvación, primero debemos entender y adoptar un nuevo estilo de vida inspirados en él. En 1 Juan 2:6 se lee: "El que dice que permanece en él, debe andar como él anduvo”.

Actitud de servicio

El seguidor de Cristo debe adoptar una actitud de servicio. Stott (2010) sugiere adoptar la actitud de servicio de Jesús. Jesús ratifica su constante actitud de servicio y toma momentum durante la última cena cuando se quita el manto, toma la toalla y lava los pies de los discípulos (Jn.13:1-15). "Porque ejemplo os he dado, para que, como yo os he hecho, vosotros también hagáis” (v.15). Esta actitud de servicio durante la última cena fue el sello del ministerio terrenal de Jesús. Stott (2010) se refiere a esto diciendo: “Así cómo Jesús realizó lo que para su cultura era el trabajo servil de un esclavo, de la misma manera nosotros en nuestra cultura no debiéramos considerar ninguna tarea demasiada servil o degradante como para ser llevada a cabo” (p. 33).

McClung (1990) asegura que "la gran paradoja en el cristianismo hoy es entender que ser grandes en el reino de los cielos significa ser siervo de todos” (p. 146). Así lo 
hizo Jesús, “que se despojó a sí mismo, tomó la forma de siervo y se hizo semejante a los hombres" (Fil. 2:7).

McClung (1990) explica que la primera motivación en la vida de un cristiano es la de servir como Jesús sirvió. “Nada revela los motivos del corazón con mayor claridad que la reacción que se tiene cuando se nos pide servir a los demás” (p. 146).

Actitud de humildad

Otra de las actitudes es la de encarnar su humildad. "La encarnación de Cristo fue un evento único y no puede ser imitado” (Stott, 2010, p. 32). Nuestra función es la de adoptar una actitud de humildad tal como la del Maestro y que se adapte a nuestra realidad. De esta manera, podrá haber en cada uno de sus seguidores, la misma actitud que hubo en Cristo Jesús (Fil. 2:5-8). Esto significa deposición absoluta de la voluntad propia y adopción humilde de la voluntad de Jesús.

Hunter (2009) indica, citando a Tom Wright, que el "levantar a Jesús en nuestra vida nos permite convertirnos para el mundo lo que él mismo fue para el mundo” (p. 111). De esta manera, se entiende que Jesús fue un modelo de humildad y de absoluto sacrificio, “eje fundamental en la vida de Jesús” (Hunter, 2009, p. 112).

\section{Actitud misional}

La última actitud es la misional. Cristo pidió al Padre: “Como tú me enviaste al mundo, así yo los he enviado al mundo” (Jn. 17:18). Luego comisiona: “Como me envió el Padre, así también yo os envío” (Jn. 20:21). Estas palabras cobran un significado único cuando se comprende que lo escrito por Juan no es simplemente un recordatorio de la Gran Comisión de Mateo 28. Stott (2010) afirma que en Juan hay instrucciones claras 
que ayudan a entender que la misión de los apóstoles en el mundo se asemeja a la del ministerio terrenal de Cristo. Según este último autor, cuando Juan dice: “así los he enviado al mundo” (Jn. 17:18), “significa que, como Cristo tuvo que entrar a nuestro mundo, así tenemos nosotros que entrar al mundo de las personas” (Stott, 2010, p. 34).

Crandall (1999) apoya este concepto al reconocer que los discípulos adoptaron un carácter misional al entender “que el evangelio efectivo y la testificación cristiana eran mayormente actuar como Cristo Jesús” (p. 138). Podemos notar que los discípulos asumieron la responsabilidad y aceptaron que las buenas nuevas no eran solamente para ellos, sino de ellos para otros.

\section{Principios de testificación en el ministerio de Jesús}

En esta sección se analizará cómo durante su ministerio terrenal, Jesús utilizó principios de testificación que lo identificaron constantemente con su misión. Esas directrices, claramente expuestas en los evangelios, siguen vigentes aún en la actualidad.

Ola (1989) entiende que a través de la historia “cada generación ha encontrado métodos que son más productivos que otros para alcanzar nuevos creyentes con el mensaje de salvación” (p. 41). Sin embargo, algunas veces se ha insistido demasiado con metodologías que han dado pocos resultados. Cuando esto sucede, la iglesia pierde efectividad y disminuye su crecimiento. Por ende, es crucial que la iglesia regrese siempre a sus raíces y se enfoque nuevamente en aquellos principios universales y eternos que Jesús utilizó tan efectivamente durante su ministerio terrenal.

Hay que señalar el sentido de educación continua que Jesús manifestaba hacia sus discípulos. Mientras ellos lo acompañaban (Jn. 1:35-42), él les mostraba los principios básicos de testificación personal. Stott (2010) afirma que "la voluntad final de Dios es 
que lleguemos a ser como Cristo Jesús” (p. 29). Imitar a Jesús es el primer resultado de la entrega. Al entregarse a él, el ser humano se somete a una transformación. Coleman (1996) lo expresa de la siguiente manera: "Uno no puede transformar al mundo a menos que los individuos del mundo sean transformados, y los individuos no pueden ser cambiados a menos que sean moldeados en las manos del Maestro” (p. 24).

El principio de la iniciativa

Early \& Wheeler (2010) resumen algunos principios que surgen del ejemplo de Cristo Jesús y el encuentro con la mujer Samaritana de Sicar. Varios eruditos han visto en este encuentro significativo, pautas claras de cómo llevar a cabo la práctica de la testificación. Borchert (1976) admite que la historia “ofrece un hermoso paradigma sobre el evangelismo que se debe considerar” (p. 140). Sin embargo, es importante comprender la separación física, social y religiosa que existía entre judíos y samaritanos para poder apreciar lo que sucedió en el encuentro. Horn (1960) explica que el descontento entre samaritanos y judíos inició más de 700 años antes de que Jesús y la Samaritana conversaran junto al pozo de Jacob. La historia cobra más fuerza y significado cuando se sabe que "el odio entre judíos y samaritanos no había declinado durante el tiempo del ministerio de Jesús en la tierra” (p. 949). Varios pasajes en el Nuevo Testamento puntualizan claramente este aspecto (Lc. 9:51-54; Jn. 4:9, 8:48). Esta era la razón principal por la cual los que viajaban de Galilea a Jerusalén evitaban pasar por Samaria. Sin embargo, contra la costumbre de su tiempo, Jesús intencionalmente decide pasar por allí y hablarle a la mujer (Jn. 4:7).

Early \& Wheeler (2010) descubren en Jesús un principio que rige su vida más allá de las condiciones físicas en las cuales se encuentra en ese momento, pues aún "cansado 
del viaje” (Jn. 4:6) se dirigió a la mujer y le dijo: “Dame de beber” (Jn. 4:7). Early \& Wheeler (2010) explican que "iniciar conversaciones con gente perdida no es siempre cómodo o conveniente, pero lo tenemos que hacer de todas maneras” (p.122).

Necesitamos comprender que si algunas personas extraviadas llegarán alguna vez a escuchar el evangelio, será porque nosotros se lo digamos. De esta manera vemos como este principio de tomar primero la iniciativa se manifiesta claramente en este encuentro tan significativo por su naturaleza.

\section{El principio de cruzar barreras}

El divisionismo entre judíos y samaritanos era evidente en los días de Jesús. De acuerdo a Borchert (1996), el territorio de Samaria se encontraba en el centro de la ruta entre Judea y Galilea, “conocida como la ruta de los patriarcas” (p. 199) y tomaba unos tres días atravesando por Samaria.

En los días de Jesús, la tensión entre las regiones de Judea y Samaria continuaba vigente. Burge (2000) reconoce que esta división, “parcialmente basada en la raza y en la religión, resonaba en siglos de peleas políticas” (p. 141). Borchert (1996) asegura que esta es la razón primordial por la cual “algunos judíos de este tiempo probablemente preferían evitar esa ruta y viajar el camino más largo que va desde Jerusalén bajando hacia el Valle del Jordán, siguiendo por el río para entrar así a Galilea” (p. 199).

Burge (2000) resalta otro aspecto que hace aún más significativo el encuentro iniciado por Jesús. Era costumbre de los judíos no hablarle a las mujeres en público, incluyendo a la propia esposa. Esta mujer, a quien Jesús se dirige en público y en primera instancia, es una mujer que "lleva la historia, el lenguaje, la religión y las actitudes de gente que se encuentra en el borde más lejano del Judaísmo. Un lector del primer siglo 
apenas esperaría que Jesús y la mujer se prestaran mutuamente atención, mucho menos que hablaran entre sí” (Burge, 2000, p.141). Si a este contexto se le agrega que la mujer era de reputación cuestionable (Jn. 4:8), se entiende la razón de la sorpresa de los discípulos (Jn. 4:27) y de la propia mujer (Jn. 4:9).

En este contexto es que Early \& Wheeler (2010) ven a Jesús como "el primer misionero cros-cultural” (p. 122). "El evangelismo efectivo es aquel que está listo y dispuesto a cruzar barreras con las buenas nuevas de Cristo Jesús” (p. 122). Esto demuestra cómo Jesús implementó el principio de cruzar barreras sociales, culturales, étnicas, y hasta de reputación.

\section{El principio de escuchar}

Burge (2000) reconoce que aunque la conversación se inicia hablando de “cosas comunes y corrientes como fuentes, agua, esposos” (p. 143), hay un interés de parte de Jesús, no de tener una clase del tipo maestro-alumno, sino una inusual conversación.

Cuando Jesús le habla por primera vez, y le dice “dame de beber” (Jn. 4:7), él entiende que existirá una respuesta; en este caso la respuesta surgirá de la sorpresa de que Jesús, como judío, se haya rebajado a hablarle a una mujer samaritana (Jn. 4:9).

No obstante, Early \& Wheeler (2010) entienden que Jesús la invita a conversar cuando mencionó las palabras, “Si conocieras el don de Dios, y quién es el que te dice: ‘Dame de beber’, tú le pedirías a él, y él te daría agua viva” (Jn. 4: 10). Recién aquí “la mujer inmediatamente hace un comentario acerca de la falta de material y recursos que supla sus necesidades” (p.123). Así vemos como Jesús escucha cuidadosamente sus palabras y planifica una respuesta; de esta manera se afirma la importancia de no 
subestimar jamás el principio de escuchar cuando se está construyendo una relación para testificar.

El principio de ofrecer asistencia espiritual

Cuando la samaritana mencionó a Jacob (Jn. 4:12), se estaba refiriendo al patriarca hebreo "reverenciado por los judíos como también por los samaritanos" (Borchert, 1996, p. 204). Early \& Wheeler (2010) reconocen que si bien Jesús y la mujer podrían haberse envuelto en la vieja discusión entre judíos y samaritanos, “Jesús se enfocó en el punto principal, su necesidad de vida eterna” (p. 124).

Jesús fue intencional al permitirle que ella se exprese. El Maestro estaba interesado en escucharla para ofrecerle la asistencia espiritual que ella necesitaba y queda ilustrado en la expresión que usó cuando le dijo: “tu le pedirías y él te daría agua de vida” (Jn. 4:10).

El principio de no apresurar la cosecha

La mayoría de los comentaristas bíblicos consultados, aceptan que la mujer reconoce que puede obtener un beneficio de la conversación. Así, la mujer le pide al Señor: "Dame esa agua, para que no tenga yo sed ni venga aquí a sacarla” (Jn. 4:15).

Early \& Wheeler (2010) ven que esta expresión pudo tener dos significados. El primero es que "la mujer estaba lista para responder a Cristo" (p. 124). El segundo significado es que "ella estaba siendo sarcástica y continuaba dudando" (p. 124). Burge (2000) observa un tercer significado, y es que "ella continúa buscando agua en el sentido literal” (p. 144). 
Aquí es interesante destacar el comentario de Botha (1991) quien ve un cambio de actitud en la mujer, al aceptar que Jesús tiene algo que ella no tiene pero le gustaría obtener: “Agua, para que no tenga yo sed” (Jn. 4:15). Burge (2000) argumenta que la mujer acepta que Cristo tiene acceso a un tipo de agua especial y él la puede conseguir. Esa aceptación de parte de la mujer, es el cambio de actitud y disposición. Sin embargo, a diferencia de la común manera de actuar, Jesús no cosechó los frutos espirituales en ese momento. Early \& Wheeler (2010) puntualizan el hecho de que Jesús fue intencionalmente paciente en sus acciones para lograr que la mujer, “continúe el diálogo que finalmente la llevaría a la verdad” (p.124). Reconocer que ese hombre podría ser el Cristo (Jn. 4:29).

\section{La testificación en el libro de Hechos}

Una mirada rápida al libro de Hechos ayuda a verificar el compromiso de los nuevos creyentes del Nuevo Testamento hacia una vida de testificación. Además, en esta parte observaremos cómo el principio del amor, se convierte en el motor de los primeros creyentes para entregarse por completo a la testificación en Jerusalén y por el mundo. Los primeros capítulos del libro de Hechos indican que miles de personas le dieron la bienvenida al mensaje de salvación de los apóstoles (2:41; 4:4; 5:14). La cantidad de veces que se hace mención a reuniones de cristianos indican que los nuevos creyentes se reunían en casas (2:46; 5:42; 12:12). Luego las casas comenzaron a ser vendidas (4:34) como un esfuerzo para generar fondos para otras necesidades dentro de la comunidad de creyentes y continuar así con la testificación.

Marshall \& Peterson (1998) comentan que el templo, las sinagogas, los pasillos de lecturas y otros lugares públicos servían de plataforma para predicar el evangelio. Pero, 
por otro lado, lo nuevos creyentes estaban comprometidos en la formación de comunidades centralizadas en las propias casas de los ya convertidos. "El evangelio fue primero proclamado en lugares públicos aceptables. Seguidamente, aquellos que respondían eran traídos a la confraternización en lugares privados” (p. 486).

El compromiso con la testificación en los Apóstoles

Los apóstoles comprendieron que la gran comisión de Jesús era la de ir y hacer a otros discípulos (Mt. 28:18-20). Collinson (2004) entiende que hay un punto culminante en el ministerio discipular de Jesús, es como una especie de puente entre Jesús y los discípulos. De haber sido discipulados, ahora son encomendados y comprometidos a la tarea de testificar y discipular.

Ola (1998) advierte que no había distinción entre el clero y el laico. Sin ayuda, equipos modernos, ni transportación, sacudieron al imperio Romano hasta que lograron testificar y convertir a nuevos creyentes a metros del César.

Collison (2004) asegura que los discípulos entendieron con claridad el verbo imperativo matheteusate (hacer discípulos) y se entregaron a la tarea de hacer de otros lo que ellos mismos eran. De esta manera confirmamos la importancia de continuar con este legado de discípulos que testifican siendo así obedientes como los primeros discípulos.

Earley \& Wheeler (2010) ven con mucha más claridad este cambio de actitud hacia la testificación de parte de los discípulos, después de la resurrección de Cristo. Los discípulos cambiaron radicalmente, sus ojos espirituales fueron abiertos y ahora lo entendieron. Comenzaron a seguir el ejemplo de Jesús deteniéndose para ministrar las necesidades, empezando con los más ignorados por la sociedad (Hch. 3:1-10; 5:12-16). 


\section{Estrategias de testificación}

Stedman (1976) advierte que la iglesia primitiva utilizaba dos estrategias de testificación hacia el mundo: proclamación (kerygma) de las buenas nuevas y camaradería (koinonia) con los creyentes. Los paganos podían rechazar la predicación de las buenas nuevas de Jesús, “pero no sería fácil ignorar los resultados de la camaradería cristiana en los hogares, del amor genuino y la simpatía que allí se demostraba” (pp. 108109).

Esto evidencia un compromiso práctico con la testificación constante de parte de la iglesia en Hechos. Mhando (2000) asegura que hay evidencias para creer que la iglesia primitiva “atraía a muchos por medio de las poderosas reuniones de servicio y camaradería” (p. 51).

Green (2002) entiende que estas técnicas de atracción las habían aprendido de Jesús. Él dice: “En obediencia a Jesús comenzaron a actuar como testigos” (p. 47), primero en Jerusalén, luego en Judea, luego en Samaria, y luego hasta los confines más remotos de la tierra.

Aparentemente existía una técnica que no era común o demasiado habitual, y eso producía un efecto de atracción que no se había visto hasta el momento. White (1957) alude al hecho explicando que cada cristiano convertido veía en su hermano una revelación del amor y la benevolencia divinos. “La ambición de los creyentes era revelar la semejanza del carácter de Cristo, y trabajar para el engrandecimiento de su reino” (p. 40). De esta manera, la proclamación y la camaradería como estilo de vida se había impregnado en la vida diaria de cada creyente. 
El amor como base de la testificación

Jesús explicó a sus discípulos y a los líderes religiosos de su época que el amor era la base de su misión terrenal. Lo expuso claramente cuando resumió y contextualizó la ley diciendo: “Ama a Dios de todo corazón y a tu prójimo como a ti mismo” (Mt. 22:37-40). Aunque esta idea no era difícil de aceptar, especialmente la que se refería al Padre, la discrepancia surge en cuanto a la forma práctica de cumplir con la segunda parte del mandato: “Amarás a tu prójimo como a ti mismo” (Mt. 22:39).

\section{El amor como resumen de la ley}

En los encuentros que Jesús tuvo con algunos fariseos y saduceos, era de esperarse que el tema de la ley y el amor surgieran a menudo (Mt. 22:34-40). Knight (1994) explica que para los rabinos era obvio que algunos mandamientos eran más importantes que otros. "Ellos dividían los mandamientos en los más livianos y los de más peso, y especulaban acerca de cuál de los 613 mandamientos de las Escrituras era el mayor" (p. 225).

McCumber (1975) entiende que cuando los fariseos cuestionaban a Jesús, el interés no era buscar una respuesta singular. Los rabinos venían buscando desde hacía un largo tiempo un mandamiento que resumiera los 613 mandamientos, pero hasta ese momento no lo habían hallado. Él considera que en el caso de la pregunta acerca del mandamiento más importante (Mt. 22:34), aunque era más sincera que las anteriores, la intención final era “probar a Jesús” (p. 173).

Knight (1994) puntualiza la actitud de Cristo ante la expectativa de los oyentes, quienes esperaban una respuesta que surgiera directamente del decálogo. Pero Jesús elude el decálogo y va directamente al texto más conocido en la cultura judía, Deuteronomio 
6:5, que era parte de la Shema (la confesión judía de fe). Este versículo era usado en la apertura de cada servicio judío y formaba parte de la oración de la mañana.

Prácticamente, “Jesús define el corazón de la religión como amar a Dios con todo nuestro ser (v. 37)” (p. 226).

La respuesta de Jesús pudiera haber sido suficiente, sin embargo él fue un poco más allá. En este caso, citó Levítico 19:18, con la orden de amar al vecino. Así dejó en los oyentes la clara enseñanza de que "es verdaderamente imposible amar a Dios sin amar a otros” (Knight, 1994, p. 226).

\section{El amor al prójimo}

Allen (1969) observa que no fue la primera parte de la respuesta de Jesús lo que impacientó a los oyentes judíos ortodoxos, más bien fue la segunda parte, la que tiene que ver con el “amar al prójimo” (Mt. 22:39). Se entiende que para el fariseo la palabra “prójimo” significaba otro fariseo como ellos. La palabra “fariseo” significaba “separado”, y aludía al objetivo primario de separarse de personas o cosas ritualmente inmundas. "Inmundo, era un apodo dado por ellos a otros” (p. 209). Allen (1969) afirma que el término por el cual se conocían entre los fariseos era el de haberim, prójimos o asociados, “pero del mismo estrato social y religioso” (p. 209).

Jesús amplía el concepto de prójimo. Knight (1994) hace notar cómo Jesús amplió enormemente el concepto de prójimo en los oyentes judíos al mencionar la segunda parte del gran mandamiento. "Para Jesús, el prójimo de una persona no era solamente otro judío de la misma ortodoxia, sino que el término incluía también a los enemigos y aún a aquellos en rebeldía contra Dios. Amar al vecino entonces incluía también a los gentiles”. (p. 226). 
La compatibilidad del amor

McCumber (1975) va aún más allá al explicar que la ley y el amor no son incompatibles y que todas las leyes eran expresiones de amor de Dios hacia el hombre. "No se puede amar a Dios sin amar a los hombres. La vida es triangular (Dios-otros-yo), no es horizontal (yo-otros), no es vertical (yo-Dios)” (p. 173).

El crecimiento de la iglesia primitiva fue impulsado por el amor. Dupont (1979) describe el efecto de estas enseñanzas las cuales los discípulos habían recibido con anterioridad. Especialmente la que hace referencia a "amar al prójimo como a uno mismo” (Mt. 22:39). Después del Pentecostés, la historia de la iglesia apostólica es una historia de crecimiento continuo. Hechos 2:41 indica que cerca de "tres mil personas fueron añadidas” a la comunidad cristiana. Luego de la curación del cojo, cerca de 5000 personas aceptaron la fe (Hch. 4:4). Hechos 5:15 indica que, “los que creían en el Señor aumentaban más, gran número de hombres y de mujeres”.

Dupont (1979) observa que antes de que el movimiento se expandiera más allá de Jerusalén, la iglesia primitiva, “ya incluía vibrantes comunidades por todo Judea, Samaria, Galilea, en Fenicia, en la Isla de Chipre, en Asia Menor, en Grecia, en Puteoli, y en Roma” (p. 61). Martin (2006) encuentra que el verdadero amor de Dios impregnaba el corazón de los nuevos discípulos.

Podemos concluir diciendo que los primeros creyentes poseyeron una clara determinación en la testificación. Habían aceptado el desafío del maestro, estuvieron dispuestos a ser capacitados y también a capacitar a otros para ser fieles al pedido de su Señor. Esta actitud estaba basada en el amor que habían experimentado de parte de otros 
creyentes, y que ahora se reflejaba en el deseo de predicar a Jesús, y sólo a Jesús resucitado, a toda raza, nación, tribu, lengua y pueblo. 


\section{CAPÍTULO III}

\section{LA CAPACITACIÓN DEL RECIÉN BAUTIZADO PARA LA TESTIFICACIÓN EN LA LITERATURA CONTEMPORÁNEA}

En este capítulo se estudiará el concepto de la capacitación a creyentes en los autores contemporaneos. La investigación no es exhaustiva, pero logra presentar un cuadro general de lo que escritores, pastores y líderes en crecimiento de iglesia indican sobre la importancia de entrenar o capacitar a todos los creyentes, pero especialmente a aquellos que son nuevos en la fe. Se examinarán las razones principales que ameritan un

programa de entrenamiento para aquellos que son nuevos. Se estudiarán algunas técnicas modernas que ayudarán al recién bautizado a practicar el cómo compartir su nueva fe. Finalmente se estudiará la importancia del Espíritu Santo y cómo El se compromete en capacitar a todo aquel que dará testimonio de Cristo Jesús.

Se entiende que la misión de la iglesia es la de testificar las buenas nuevas de salvación y bautizar a los nuevos creyentes que han confesado a Cristo Jesús como Señor y Salvador. Colson y Rigdon (1969) aseveran que por el poder del Espíritu Santo estos deben crecer en la madurez cristiana por medio de la adoración, la proclamación, la testificación, la nutrición y la educación.

Uno de los métodos más efectivos de la misión evangelística de la iglesia fue el de la testificación personal. Desde los tiempos de Jesús, el método de evangelización por medio del testimonio personal, fue el predilecto para salvar a otros. 
La mayoría de los autores revisados, señalan que los misioneros de diferentes épocas utilizaron varias estrategias efectivas para ganar nuevos discípulos. Sin embargo, el método de testificación de persona a persona era irremplazable por los resultados que generaba. Cooter (2013) advierte que la gente hoy es confrontada con cerca de 5,000 proposiciones, incentivos y propagandas diferentes, que intentan a diario comprometer a una persona con algo. De esta manera, pereciera que hoy más que en otras épocas, las buenas nuevas de perdón, gracia y reconciliación con Cristo Jesús, se diluyen o se pierden entre tanta oferta publicitaria. Por eso, como lo señala Cooter (2013) “compartir hoy las buenas nuevas requiere una vez mas, el desarrollo de relaciones de confianza por medio de la conversación y el escuchar respetuosamente” (para, 19).

En este sentido, para que la testificación sea efectiva como lo fue antes, la capacitación es y será de vital importancia.

\section{La capacitación del nuevo creyente}

En esta parte se analizará la importancia de la capacitación al nuevo creyente. Capacitar tiene que ver con la adquisición de conocimientos, habilidades y aptitudes como resultado de un proceso de enseñanza y aprendizaje basado en algunas disciplinas particulares. Pfeiffer y Harrison (1962) explican que en la capacitación, un entrenador o instructor experimentado guía a los nuevos creyentes para que aprendan las disciplinas de la testificación, por medio de la teoría y la práctica de las nuevas habilidades.

Capacitar significa hacer a alguien apto, habilitarlo para algo, (Espasa-Calpe, 2005). En la mayoría de los casos la capacitación es brindada por instrucción y práctica. En el entrenamiento, el maestro experimentado guía al alumno inexperto, quien deberá aprender las técnicas y obtener la práctica de la nueva disciplina. La capacitación 
religiosa está directamente relacionada con la purificación de la mente, el corazón, el entendimiento y las acciones para poder obtener una variedad de objetivos religiosos.

En el proceso del discipulado, Jesús comienza pasando tiempo con sus discípulos. Luego los entrena y los envía a testificar (Mr. 3:14). Más adelante, sus seguidores continuaron con el modelo de pasar tiempo con los conversos al volver a las iglesias que habían fundado, para confirmar su fe y exhortarlos (Hch. 14:21-22). En referencia al pasaje de Hechos 14: 21-22, Marshall (1998) agrega que la iglesia estaría siempre bajo un ambiente hostil, por lo tanto debía auto capacitarse continuamente de acuerdo a la situación. Zuck (1998) indica que en el proceso del discipulado, la capacitación era continua y recíproca, de unos a otros.

\section{Los beneficios de la capacitación}

La capacitación de los que sirven dentro de la iglesia local ha sido siempre una parte importante de la dinámica eclesial. Benner (1999) entiende que para poder transmitir las enseñanzas de Cristo, los discípulos tuvieron que ser capacitados y desarrollados en la habilidad de comunicar las enseñanzas de su maestro.

La Biblia contiene historias de discípulos como Timoteo, Priscila, Aquila y Felipe, quienes fueron entrenados y capacitados para trabajar para Cristo (1 Ti. 4:12-16; Hch.18:24-25; Hch.16:3). Tanto la iglesia naciente como ellos mismos se vieron altamente beneficiados de la capacitación que alguien les brindó en su momento.

De la misma manera, la iglesia hoy se ve beneficiada al tener discípulos capacitados, competentes y exitosos. Esto es vital para que la misión de la iglesia continúe y además, desarrolla al individuo durante el proceso del entrenamiento (Benner, 1999). 
La capacitación tiene un beneficio doble. La iglesia se beneficia a través del creyente porque este cumple con su misión. A su vez, el creyente se beneficia al descubrir que no está solo, tiene una nueva familia que es la iglesia.

Robinson (2004) entiende que si una persona se capacita, será mas ferviente y espiritual. Además, está invirtiendo en algo que promete bendiciones para esta vida y la venidera.

Byun-Yang (1995) enumera los siguientes beneficios que resultan de la capacitación a los nuevos conversos. Primero, establece en el individuo una sólida perspectiva de la fe. Segundo, establece la correcta perspectiva de lo que es la iglesia. Tercero, asienta los principios cristianos. Cuarto, establece valores cristianos. Quinto, familiariza al individuo con la historia cristiana. Sexto, establece la nueva cultura de vida del creyente.

La meta del nuevo creyente es capacitarse y crecer así como se describe en Efesios 4:13, "hasta que todos lleguemos a la unidad de la fe y del conocimiento del Hijo de Dios, a un varón perfecto, a la medida de la estatura de la plenitud de Cristo”.

Así, la capacitación es la manera más beneficiosa de ayudar al nuevo creyente en su madurez cristiana (Col. 1:28-29).

Consecuencias de la falta de capacitación

La falta de capacitación trae consecuencias negativas en cualquier disciplina nueva o emprendimiento con el cual no se está familiarizado.

Trueblood (1979) entiende que esta falta es la debilidad más grande de la iglesia contemporánea. "No hay oportunidad de victoria en un ejército donde el 90\% está sin 
entrenar. Es aquí donde nos encontramos hoy. La mayoría de los cristianos no entienden lo que significa ser leal a Cristo y compartir personalmente su ministerio” (p. 34).

Hull (2007) indicó que sin capacitación no tenemos discípulos y sin discípulos no podremos alcanzar el mundo. Esta falta de entrenamiento ha causado una profunda crisis en la iglesia actual. Gallup (citado por Hull, 2007) demostró que de los 22 millones de evangélicos que asisten a la iglesia, sólo el 7 \% había tomado algún entrenamiento y solamente el 2 \% había compartido su testimonio de fe con otra persona.

Cuando la capacitación falla (Odgen, 2003), el desarrollo de nuevos discípulos se ve afectado. El ministro pierde la visión de su rol como capacitador, y la iglesia cae en la tentación de creer que los programas regulares darán los mismos resultados que la capacitación. Poco a poco, el camino hacia la madurez cristiana se hace difuso y afecta la claridad en cuanto a la misión que debiera tener la iglesia hacia la comunidad, y su rol de testificar y discipular.

Noland (2013, para, 7) explica que la falta de capacitación produce apatía en la iglesia. Cuando la apatía espiritual se manifiesta en la iglesia, el deseo de hacer discípulos a otros fracasa rotundamente. Así, algunos ministerios de la iglesia que antes estaban llenos de vigor espiritual, ahora carecen de poder y frutos debido a la apatía de los creyentes. Esto produce pereza espiritual. La iglesia pierde el fuego y la voluntad de servir; se torna fría, desinteresada y sin deseo de testificar para a hacer discípulos.

\section{La capacitación del nuevo creyente para la testificación}

La capacitación es indispensable para el desarrollo correcto de cualquier habilidad aprendida. La testificación es una de varias habilidades que el nuevo creyente adopatará 
en su nueva vida cristiana. En esta sección se presentarán algunos elementos indispensables para desarrollar en el nuevo creyente la habilidad de testificar.

De acuerdo a la Biblia, el nuevo creyente es un bebé espiritual y necesita crecer para salvación (1 P. 2:2). Como parte del crecimiento, el nuevo creyente necesita convertirse en un discípulo que testifica de Cristo y para ello tiene que aprender el proceso. Chang (2011) observa que el desafío principal en las iglesias es cómo convertir en testigos a los nuevos creyentes. No lo pueden hacer por sí mismos. Los discípulos son descriptos en la Biblia como cristianos maduros que usan sus dones personales para testificar y así edificar la iglesia de Cristo. Para poder parecerse más a los discípulos de Jesús de los cuales habla la Biblia, los nuevos creyentes deben recibir capacitación de la manera como lo hizo Jesús con ellos. Por eso, deben ser moldeados y entrenados para compartir la fe.

La indispensabilidad de la capacitación para la testificación El nuevo creyente necesita entender que la testificación es parte del compromiso de seguir a Cristo y no algo opcional en la vida de un discípulo (Willis, 1998). Se entiende que la nueva vida en Cristo (Ef. 4:22-24) es transformada, dando frutos por el Espíritu Santo. Esta es la marca o característica distintiva del nuevo discípulo (Jn. 15:8).

La testificación personal es indispensable por las siguientes razones: Primero, el amor por Cristo es el primer fruto de la conversión. El apóstol Pablo lo expresa de esta manera. "Porque el amor de Cristo nos constriñe” (2 Co. 5:14). Willis (1998) entiende que la demostración del amor a Cristo es el compartir la fe. El amor que tenemos por Jesús nos impele a plantar la semilla en otros para que se transformen en discípulos. 
Segundo, la testificación personal es uno de los frutos que da gloria a Dios. Jesús dijo: "Y me seréis testigos en Jerusalén, en toda Judea, en Samaria, y hasta lo último de la tierra” (Hch. 1:8).

Tercero, testificar es una orden directa de Cristo Jesús. "Y les dijo: Venid en pos de mí, y os haré pescadores de hombres” (Mt. 4:19). Hybels y Mittelberg (1994) explican que los creyentes, luego de que ellos mismos fueran atrapados por el amor de Cristo, entendieron que él los enviaba a atrapar con urgencia a otros, buscándolos y contagiándolos uno por uno, hasta que en el mundo existió una epidemia de contagio de amor por aquel que los envió, Cristo Jesús.

Cuarto, la gente sin Cristo está perdida. El apóstol Pablo pregunta: “ ¿Cómo, pues, invocarán a aquel en el cual no han creído? ¿Y cómo creerán en aquel de quien no han oído? ¿Y cómo oirán sin haber quien les predique?” (Ro. 10:14). En un estudio, (Barna, 2013), se descubrió que el 74\% de las personas que no asisten a una iglesia nunca habían sido invitados. En el mismo estudio, (Mary Schaller, 2013., para. 5) advierte que no todos los creyentes tienen algún tipo de relación con los no-creyentes. Muchos en la iglesia se acostumbran a relacionarse con otros creyentes y van perdiendo el contacto e influencia sobre otros no creyentes. De esta manera se va perdiendo la habilidad para hablar de Cristo a aquellos que no lo conocen aún.

Quinto, la testificación produce gozo, o como lo dice Lucas en Hechos 8:8, "gran gozo”. El mensaje de gracia y salvación produce alegría en el corazón del que lo escucha, como en el caso de la gente de Samaria (Hch. 8:5). También emociona la vida del testigo (Jn. 4:28-29). Hybels y Mittelberg (1994) comentan que el que testifica se conecta indiscutiblemente al "gozo en el cielo por un pecador que se arrepiente" (Lc. 15:7). Se 
entiende que no siempre la testificación terminará con un pecador arrepentido, pero “produce gozo el saber que se participó como jugador principal en el proceso de intentar llevar un amigo a Jesús” (p. 24).

Sexto, la testificación brinda sentido de propósito. En Hechos 26, encontramos al apóstol Pablo testificando ante el gobernador Festo y ante el rey Agripa. No podían hacerle nada, pues era un ciudadano romano y había apelado a César. El propósito era testificar sobre el rotundo cambio de estilo de vida que el mismo, Saulo, había experimentado, y ahora “da testimonio a pequeños y a grandes” (Hch. 26:22). Hybels y Mittelberg (1994) advierten que en todos los creyentes sinceros se producirá un nuevo sentido de propósito como sucedió en la vida de Saulo. Así como Dios alteró el presente y el futuro de Saulo, la vida de todo creyente cobra un nuevo significado porque ahora es parte del gran cuadro en el plan de Dios.

La falta de testificación personal hará que el nuevo creyente pierda beneficios y le sea menos efectivo fungir en su nuevo rol de discípulo de Cristo. La capacitación permitirá que todas estas oportunidades de bendición se vean manifestadas en la praxis diaria de todo nuevo creyente.

El primer amor y la habilidad para testificar

Todo nuevo creyente que ha recibido la gracia, el perdón y la nueva vida en Cristo experimenta un amor singular por Dios conocido en la Biblia como el primer amor (Ap. 2:1-7). Greg (2013) reconoce que esta experiencia produce cambios en la vida del nuevo creyente. La experiencia de la salvación predispone a la persona a hacer lo que sea necesario mientras complazca a Dios. Cuando Dios opera un cambio, lo hace a nivel de la 
mente y de las emociones. Por esta razón, el nuevo creyente observa cambios en su conducta y emociones nunca antes experimentadas.

Bajo estas condiciones, un nuevo creyente está dispuesto a ser instruido para llevar a cabo la misión del creyente. Dice Greg (2013), “No necesita un título en teología o en oratoria pública para poder compartir su fe. Sólo necesita un corazón cambiado, un corazón que ha sido libertado y ahora siente pesar por aquellos que todavía no han encontrado cura para su pecado” (p. 1547).

Sin lugar a duda, el nuevo creyente tiene una motivación superior, fresca, reciente y esto lo condiciona positivamente para testificar de lo que está experimentando como una nueva creación en Cristo Jesús. Aldrich (1993) explica que muchos de los nuevos creyentes experimentan alguna clase de temor y evitan por ello la testificación. Sin embargo, él reconoce que la razón principal de esto es que la mayoría sencillamente no saben cómo compartir su fe y nunca fueron disciplinados en aprender cómo hacer una presentación lógica y bíblica.

Aprovechar el primer amor del nuevo creyente es indispensable, no sólo para afianzarlo en la fe, sino también para instalar el ADN correcto de su nueva vida en Cristo. Por medio de la instrucción y la práctica, desarrollará la habilidad de la testificación.

Strobel (2009) admite que nunca se sabe lo que puede resultar de un testimonio poderoso, pero cuando una persona testifica de Cristo a su amigo, a su padre, a su tío o quizás a alguien que parece insignificante, el esfuerzo limitado puede tener un efecto en cadena a través de la historia. De esta manera vemos como el testimonio de una persona apasionada por Jesús resultará en un número ilimitado de vidas transformadas a lo largo de las generaciones futuras. 
El desarrollo de relaciones para testificar

La capacitación para la testificación no es solamente un curso bíblico. No se trata de implantar mera información cognitiva en la vida un nuevo creyente. George (1994) estudió que la capacitación para la testificación se hace efectiva por medio del desarrollo de las habilidades para relacionarse personalmente y no de un proceso educativo mecánico.

Muchas iglesias han fracasado tratando de producir discípulos que testifiquen por medio de los programas de las iglesias. Chang (2011) observa que los creyentes que testifican no son el resultado de programas de entrenamiento teóricos y que remueven el aspecto práctico-relacional de la capacitación. Mas bien, como lo estudió Ogden (1998), la capacitación con sentido relacional es más efectiva que un simple programa de entrenamiento informativo.

En este artículo, Lorch (2013) propone tres elementos relacionales que capacitarán al nuevo creyente para ser efectivo en la testificación.

Primero, los nuevos creyentes necesitan aprender cómo desarrollar una comunicación diaria con Dios. Esto los ayudará a mantenerse firmes y actuar en el momento preciso (Dn. 11:32). Para esto, es necesario que el creyente desarrolle una relación con Dios sólida, esto lo ayudará a estar seguro de su salvación (1 Jn. 5:11-13), y de que han sido perdonados y aceptados por Dios. También necesita conocer a Dios personalmente estudiando la Biblia por sí solo. De esa manera, descubrirá las promesas y las bendiciones de la relación diaria con Dios. Segundo, se destaca la importancia de desarrollar relaciones con otros creyentes. El nuevo creyente tiene que aprender a servir y a compartir con un nuevo grupo de personas que antes no conocía. Tercero, el nuevo 
creyente necesita aprender a mantener las relaciones de amistad con aquellos que no son creyentes, incluyendo aquellos que conformaban su círculo de amigos y familiares antes de cambiar de vida.

El estudio de la biblia para testificar

El conocimiento de las Escrituras es básico para desarrollar confianza en el testimonio de Cristo Jesús. Jesús extendió una clara invitación a la capacitación cuando dijo: "Escudriñad las Escrituras, porque a vosotros os parece que en ellas tenéis la vida eterna; y ellas son las que dan testimonio de mí” (Jn. 5:39). Laurie (2002) entiende que el estudio de la Biblia desarrolla conocimiento, pero por sobre todo, amistad con la persona de la cual tenemos que dar testimonio, Cristo Jesús.

Es común utilizar Apocalipsis 3:20, que dice: “He aquí, yo estoy a la puerta y llamo; si alguno oye mi voz y abre la puerta, entraré a él, y cenaré con él, y él conmigo”, como uno de los versículos principales para ayudar a los nuevos creyentes a establecer una relación viva y real con Cristo Jesús. Redford (2007) explica que esta es una de las imágenes bíblicas mas sobresalientes en la relación que Jesús quiere establecer con nuevos creyentes. Aquí, Jesús espera pacientemente para iniciar una relación íntima de amistad con aquellos que quieran y acepten su invitación. Laurie (2002) resalta el concepto de “cenar con él” como el elemento central. En tiempos bíblicos, la comida de la cena era el evento más importante del día. Este era el momento de depositar las cargas del día, relajarse, discutir y escuchar. De esta manera, se entiende que al estudiar las Escrituras, el nuevo creyente abre la puerta para establecer una conexión sólida con Cristo basada en la amistad. 
La Biblia también nos indica que Jesús considera amigos a aquellos que hacen lo que él les pide. "Vosotros sois mis amigos, si hacéis lo que yo os mando” (Jn. 15:14). El estudio de la Biblia tiene como objetivo desarrollar amistad con el autor de nuestra salvación y familiarizar al creyente con el mandato de ir y hacer discípulos a todas la naciones (Mt. 28:19).

Laurie (2002) asevera que toda persona entiende que tiene que obedecer, pero la única manera de saber qué obedecer es conociendo las Escrituras. Por medio del estudio diario se establece una relación perdurable con Cristo que guía al creyente a la obediencia, a un cambio de actitud y a un cambio de vida. Ese cambio de actitud se vio claramente ejecutado en la iglesia primitiva cuando aceptaron las palabras de Cristo: "Y me seréis testigos en Jerusalén, en toda Judea, en Samaria, y hasta lo último de la tierra” (Hch. 1:8).

La oración personal para poder testificar

La oración es comunicación con Dios de manera personal. Wilkinson (2000) enfatiza la importancia de la oración en la vida del creyente. Todo cristiano debe estar en comunicación con el Señor por medio de la oración. Jesús, por ejemplo, dio a sus discípulos un bosquejo para seguir en la oración (Mt. 6:9-13), y dio una parábola para animarlos a ser persistentes en la oración (Lc. 18:1-7). La oración debe llegar a ser indispensable para el cristiano. El creyente es, por definición, el hombre (o la mujer) que ora.

Finley (2010) advierte que los creyentes del Nuevo Testamento que aceptaron la admonición de Jesús de salir a testificar, lo hicieron en oración y buscando con fervor al 
Espíritu de Dios. Ellos entendieron que: “recibirían poder cuando el Espíritu Santo descendiera sobre ellos desde el cielo el cielo” (p. 7), para testificar.

Laurie (2002) entiende que la oración es una de las formas de crecer y madurar en la vida cristiana. De esta manera, mientras más nos comunicamos con Dios, más comenzamos a ver a Dios trabajando en nosotros.

Las Escrituras indican que la oración que realiza el creyente tiene poder (Sant. 5:16). Escritores como Strobel and Mittelberg (2009) admiten que es imposible entender de qué manera la oración funciona en su totalidad. Sin embargo, cuando se ora, coincidencias suceden; mientras que cuando el creyente no lo hace, no suceden.

La oración personal desarrolla madurez en el nuevo creyente, lo conecta con Dios y lo hace sensible a la búsqueda de otros que puedan llegar a creer. Coleman (1996) resalta el hecho de que Jesús hizo a propósito que los discípulos observaran la relación que él tenía con su padre por medio de la oración. Los discípulos podían ver su fortaleza espiritual y esto los animó a pedirle que les enseñara a orar. (Lc. 11:1). Durante su ministerio terrenal Cristo se encargó de capacitarlos en la oración. Stein (1992) reconoce que este momento (Lucas 11) y esta oración que Jesús les enseña, es la marca distintiva del nuevo discípulo. Esta es la oración del que comienza a creer y “fue practicada por los primeros cristianos inmediatamente después de su bautismo” (p. 324).

Bright (1998) resalta la oración de Cristo en Juan 17:20: “Mas no ruego solamente por éstos, sino también por los que han de creer en mí por la palabra de ellos”. Dice que este fue el modelo de oración que Jesús enseñó antes de su muerte en la cruz. El autor entiende que es menester orar en privado por aquellos que luego intentaremos alcanzar por medio de la testificación. 
Observamos, que de la misma manera cómo Jesús oró para que el Espíritu Santo trabaje en la vida de sus discípulos, los nuevos creyentes deben aprender a orar para que el Espíritu de Dios obre y convenza a los no creyentes en el testimonio que se les impartirá.

\section{La actitud de servicio para testificar}

Las Escrituras enseñan que un creyente debe tener una actitud de servicio similar a la de Cristo para poder ser efectivos en la testificación (Fil. 2:5).

Sjogren (2007) compara la actitud de servicio de Jesús, quien vino a servir y no ha ser servido (Mr. 10:45); con la actitud que debe tener todo nuevo creyente. Este concepto se puede encontrar con claridad en algunos pasajes como el de Juan 13:35, "En esto conocerán todos que sois mis discípulos, si tuviereis amor los unos con los otros”. Esta idea de amor cobra un sentido más pragmático en Gálatas 5:13, donde el apóstol insta a hacer buen uso de la libertad que hemos recibido como creyentes en Cristo Jesús. Esa libertad se ve plasmada en la expresión "servíos por amor los unos a los otros."

Fontaine (2014) explica que para un creyente es muy fácil tener una actitud de servicio hacia Dios, pero se hace más incómodo tener una actitud y accionar de siervo con sus pares. De aquí la importancia de recordar, como dice Sjogren (2007), el verdadero amor a Dios que ha nacido en el corazón, se debe demostrar con amabilidad, ofreciendo humildes actos de servicio, sin compromiso, a quienes podamos.

Es interesante la manera como Warren (2013) destaca aún más esta nueva actitud del creyente explicando que todos hemos sido llamados al servicio más allá de lo que nos podemos imaginar. Hemos sido colocados en esta tierra para hacer una contribución. Warren continúa explicando que todo creyente ha sido llamado a ser un ministro. "En la 
Biblia, la palabra siervo o ministro son sinónimos, de la misma manera que lo son ministerio y servicio” (Warren, 2013, para. 3).

Kaung (2014) afirma que si eres creyente, entonces eres un ministro y si eres un ministro, entonces estás al servicio de Dios con una actitud de servicio hacia los demás.

Chang (2012) entiende que el objetivo de toda iglesia es lograr que sus miembros crezcan y se parezcan más a Jesús. La mayoría de los autores consultados ven en Jesús una clara actitud de servicio hacia otros. Bechtle (2006) identifica la actitud de servicio del Señor, en los siguientes modelos de los primeros tres capítulos del libro de Marcos: 1) Cuando el hombre con espíritu impuro vino a Jesús (Mr. 1:23). 2) Cuando Jesús se dirigió a la casa de Simón y Andrés para sanar a su madre (Mr. 1:29:31). 3) Cuando la gente se agolpó en la puerta trayendo a los enfermos y endemoniados (Mr. 1:32-33). 4) Cuando un leproso se le acercó por sanidad (Mr. 1:40-42). 5) Cuando un grupo de amigos trajeron un paralítico a sus pies (Mr. 2:3). 6) Cuando se encontró con el hombre de la mano seca (Mr. 3:1).

De esta manera, como lo explica Malphurs (2009), el nuevo creyente o nuevo discípulo es un siervo que testifica como Jesús, del Padre, de su gloria y de su pronto reinado.

En consonancia con esto, Sjogren (2007) afirma que el objetivo de la testificación por medio del servicio es "hacer brillar el reino de Dios para otros” (p.19). Así entendemos que practicando actos humildes de servicio testificamos al mundo y hacemos que ellos escuchen nuestro mensaje. 
El testimonio personal

La expectación del testimonio personal fue la herramienta que Jesús recomendó que utilizaran desde los comienzos de su ministerio. Fue Cristo mismo quien dijo: “Id y contad a Juan lo que habéis visto y oído” (Lc. 7:22). En una ocasión, Jesús sanó a un hombre poseído por demonios (Mr. 5:1-19). Cuando este quiso seguir a Jesús, él le dijo: "Vete a tu casa, a los tuyos, y cuéntales cuán grandes cosas el Señor ha hecho contigo y cómo ha tenido misericordia de ti” (Mr. 5:19).

Bullón (2009) advierte que testificar es compartir la experiencia personal que tuvimos con Cristo para animar a otros a aceptarlo. El libro de Filemón le llama "la participación de tu fe” (v. 6).

La testificación personal fue practicada y promovida por el apóstol Pablo. Este le dijo a Timoteo: “Lo que has oído de mí ante muchos testigos, esto encarga a hombres fieles que sean idóneos para enseñar también a otros” (2 Tim. 2:2). Bisagno (2002) asevera que con esta simple orden, Pablo describe y entrega el plan de evangelización por medio del testimonio y la enseñanza a otros. "Este fue el plan utilizado por muchos creyentes a través de los años” (p. 192). Pablo presenta tres generaciones de creyentes, comenzando con él mismo; reconociendo así, que este es el plan establecido por nuestro Señor (Bisagno, 2002).

Este principio se ve muy bien practicado en la historia de Apolos. Pablo había discipulado a Aquila y a Priscila mientras estaban en Corinto. Estos dos seguidores de Pablo ahora eran discípulos de Apolos. Como resultado, estos evangelistas consagrados siguen su llamamiento celestial a Corinto para discipular a los creyentes que estaban allí, quienes aceptaron formar parte del reino a través del testimonio de Pablo. Apolos estaba construyendo sobre la base del testimonio y ministerio de Pablo. Pablo plantó, Apolos regó, y Dios ha dado el crecimiento (p. 192). 
Fay \& Shepherd (1999) aseveran que el éxito y la realización en la vida de un creyente está directamente relacionado con la práctica de compartir la fe por medio del testimonio personal. Aún, sin poder ver los resultados inmediatos de la testificación, “el creyente tiene que entender que no ha fracasado; el hecho de haber dado un testimonio personal lo hace obediente a Cristo” (p. 4).

Coleman (1996) entiende que el testimonio personal está relacionado con la orden que Cristo le dio a su iglesia cuando dijo: "Por tanto, id, y haced discípulos a todas las naciones,” (Mt. 28:19). De esta manera, el creyente debe ir al mundo para ganar a otros para que se conviertan en discípulos. Practicando la testificación personal "no se fracasará en ver la relación directa que existe entre el testimonio de Cristo y la victoria de la iglesia sobre el mundo” (p.100). Con relación a esto, Fay \& Shepherd (1999) insisten en la importancia de que los creyentes se hagan preguntas tales como: “¿Estoy compartiendo mi fe?” “¿Tengo sólo amigos cristianos?” “¿Paso tiempo con los que están muertos espiritualmente, enfermos o perdidos?” (p. 6). Estas preguntas son importantes ya que existen dos tipos de creyentes; “aquellos que hablan de los perdidos y aquellos que le hablan a los perdidos” (Fay \& Shepherd, 1999, p. 6).

El testimonio personal presupone una gran responsabilidad. Collins (1997) lo resalta diciendo que, esta responsabilidad es personal y directa con Dios. El creyente que testifica no lo hace como una actividad esporádica o cuando tiene tiempo libre. En realidad, la testificación se convierte en una cualidad del tipo de vida que decide tener el creyente. Ahora no da testimonio de Cristo como una acción separada de otras, sino que su vida entera testifica de Cristo Jesús. 
Graham (2009) recomienda pedirle a Dios que toda nuestra vida de testimonio de él, aún sin poder verbalizarlo, se debe pedir ayuda celestial para que otros puedan ver la paz y el gozo del cielo en nuestra vida.

\section{La testificación y el marco social del nuevo creyente}

En este segmento se intentará analizar el cuadro social del nuevo creyente. Se entiende que la persona que ha nacido de nuevo viene de un ambiente no necesariamente conformado por otros creyentes. En otras palabras, el nuevo creyente tiene todavía un gran número de personas no creyentes que conoce, son amigos, familiares, vecinos, compañeros de trabajo, o simplemente personas que se relacionan y algunos confían en él.

El círculo de influencia del nuevo creyente

Se comprende que el nuevo creyente posee un círculo de influencia compuesto por personas que eran como él antes de su nuevo nacimiento. Este marco social sería el círculo inmediato de influencia del nuevo creyente para testificar de su nueva vida en Cristo Jesús. Muchos estudiosos modernos del tema, han denominado a esto el oikos (los de su casa). Son el equivalente de la orden de Cristo a sus discípulos de ser testigos; cuando haya venido el Espíritu Santo, me seréis testigos primeramente en Jerusalén (Hch. $1: 8)$.

Aldrick (1993) observa que mantener las relaciones con este círculo de influencia es importante para el impacto del evangelio. La razón es evidente, porque al pasar el tiempo, "la mayoría de los cristianos dejan de tener un contacto significativo con los no 
creyentes, aún pierden la habilidad de relacionarse con ellos de manera redentora” (p. 16).

Wilson (2014) afirma que fue mediante esta metodología, la de testificar al mundo inmediato que nos rodea, como la fe cristiana se esparció en los primeros días y hasta los confines de la tierra. Si bien es importante que la iglesia como institución busque metodologías para testificar a los no creyentes, es menester insistir, como indica Marsh (1997), que “la testificación de persona a persona es el corazón del evangelio en acción” (p. 69).

Para ser efectivos necesitamos ser intencionales cuando pensamos en testificar. Wilson (2014) propone hacer una lista de nuestro círculo de influencia. Para ello, sugiere intencionalmente identificarlos y anotarlos.

Tabla 1

Círculo Personal de Influencia

\begin{tabular}{cccc}
\hline Categoría & Nombre & Nombre & Nombre \\
\hline Familiares & Andrés & Pedro & Diana \\
$\begin{array}{c}\text { Compañeros de } \\
\text { Trabajo }\end{array}$ & Wally & Sheila & Matthew \\
$\begin{array}{c}\text { Compañeros de } \\
\text { Escuela }\end{array}$ & Nataly & Allan & Mike \\
Vecinos & Robert & Mónica & Carlos \\
$\begin{array}{c}\text { Gente del club o del } \\
\text { equipo deportivo }\end{array}$ & Julio & Luis & Cristy \\
\hline
\end{tabular}


Es importante destacar que no siempre el círculo de influencia está listo para ser evangelizado. Aldrich (1993) advierte que este error común ha causado fracaso en el proceso de ir y hacer a otros discípulos.

Fitch (2007) cree que este cambio de enfoque, de la evangelización directa a la testificación personal como primera instancia en nuestro enfoque misional, es esencial para la iglesia de nuevo milenio.

Es importante aclarar, como lo indica Shrum (2010), que la acción de evangelizar es la proclamación directa del mensaje de buenas nuevas de Cristo Jesús con el objetivo de convencer a la otra persona. Mientras que la testificación, según los indica Fitch (2007), se encarna en toda la vida del testigo. Incluye en algún momento la proclamación; pero desde el comienzo involucra a todo el entorno de la vida del testigo.

De esta manera, Wilson (2014) diferencia dos etapas en el proceso de la evangelización a nuestro círculo íntimo. Primero, mi testimonio personal; o sea, lo que Cristo hizo en mi vida. Segundo, lo que el evangelio de Cristo puede hacer en otros; en otras palabras, lo que Cristo puede hacer por otra persona. Lovett, (citado por Aldrich, 1993), agrega el tercer elemento, la invitación de tomar una decisión por Cristo. A esto se le llama "el proceso de la ganancia de un alma" (p. 18). La persona decide aceptar a Cristo y da su primer paso de fe.

Marsh (1997) también comprende que el evangelismo saludable es sensitivo y paciente. Si bien vivimos en una sociedad que está acostumbrada a lo instantáneo; en la testificación, la paciencia es una virtud esencial dada por Dios “porque estamos lidiando con la salvación eterna de una persona” (p. 82). 


\section{Las barreras sociales y la testificación}

En ocasiones, los creyentes pueden levantar barreras que les dificulten el cumplimiento de la misión con los no creyentes. Es evidente que para la mayoría de los cristianos se hace más fácil relacionarse con los miembros de su comunidad de fe que con su antiguo círculo social. Prácticamente todos los autores analizados promueven la koinonía con la nueva familia de creyentes por medio de grupos pequeños, asistencia a los servicios y otras actividades sociales. Sin embargo, Byungjoon (2010) advierte sobre la importancia de no levantar barreras contra la vieja comunidad que antes los rodeaba. “Es importante dejar la vieja vida atrás, pero no detenernos allí. De hecho, creo que Dios desea que regresemos a nuestro viejo círculo social para testificar de Jesús” (Electronic Loc. 664).

Marsh (1997) reconoce que esta práctica de levantar barreras viene de los tiempos de Jesús. La mujer samaritana fue segregada por razones raciales, culturales, de vida, y por su sexo (Jn. 4). Por esta razón, los discípulos se asombraron de que Jesús hablara con ella (Jn. 4:27). También fue criticado en varias ocasiones por comer y beber con la gente equivocada (Mt. 9:10-13). El apóstol Pedro experimentó algo similar luego de que le predicara el evangelio a Cornelio (Hch. 10:1-48), luego de dar testimonio de lo sucedido hubo reacciones de alegría tales como: "De manera que también a los gentiles ha dado Dios arrepentimiento para vida!” (Hch. 11:18). Sin embargo, al poco tiempo, las barreras naturales de los creyentes se levantaron contra los gentiles y contra los futuros creyentes de entre los gentiles (Marsh, 1997).

Algunas personas que habían venido de Judea levantaron la barrera de la circuncisión diciendo que los gentiles debían hacerse primero judíos y después cristianos 
(Hch. 15:1-5). En esta ocasión le tocó a Pablo, a Bernabé y a Santiago derribar el muro de separación que se estaba levantando (Hch. 15:12). El apóstol Santiago hizo la siguiente moción: "Por lo cual yo juzgo que no se inquiete a los gentiles que se convierten a Dios” (Hch. 15:19).

Norton (2005) advierte que los cristianos levantan barreras para evitar ser contagiados por el mundo. Por esa razón, establecen sus propias escuelas, supermercados, librerías y hasta sus propias actividades deportivas (pp. 20-21).

Si bien a través de los años las barreras han ido variando, Marsh (1997) asegura que los seres humanos tenemos una tendencia natural a segregar y separar.

De ahí la importancia de recordar a la comunidad de creyentes las sabias palabras del apóstol Santiago:

Hermanos míos, que vuestra fe en nuestro glorioso Señor Jesucristo sea sin acepción de personas. Porque si en vuestra congregación entra un hombre con anillo de oro y con ropa espléndida, y también entra un pobre con vestido andrajoso, y miráis con agrado al que trae la ropa espléndida y le decís: Siéntate tú aquí en buen lugar; y decís al pobre: Estate tú allí en pie, o siéntate aquí bajo mi estrado; ¿no hacéis distinciones entre vosotros mismos, y venís a ser jueces con malos pensamientos?” (Sant. 2:1-4).

Walker (2012) observa que en realidad, es el enemigo de Dios quien no quiere que testifiquemos, colocando en nosotros un espíritu de temor. Esto hace que inmediatamente levantemos barreras de auto protección.

Walker (2012) continúa indicando que existe la idea de que los no creyentes son los que han levantado las barreras de rechazo. Pero este pensamiento contradice la estadística realizada por Rainer (citado por Walker, 2012). Él observó que sólo el 5\% de los que no asisten a una iglesia tienen resistencia o antagonismo al evangelio, o agresividad en sus conversaciones con cristianos. Por esta razón, se entiende que hay 
muchas personas dispuestas a escuchar las buenas nuevas, si se las comparten de la manera correcta (Walker, 2002).

La mayoría de los autores consultados entienden que el nuevo creyente no tiene barreras que lo separan de la sociedad de la cual salió; ese era sencillamente su ambiente, probablemente el único que conoció hasta ese momento.

Aún así, pareciera que el nuevo creyente podría aprender a levantar barreras contra su previa comunidad de amigos dentro de la nueva comunidad de creyentes. Por esta razón, dice Marsh (1997), “se debe aprender a romper barreras de separación sin comprometer el mensaje” (p. 64). Romper barreras es uno de los desafíos principales en la práctica de la testificación. De ahí la importancia de conocer cuáles son las barreras y cómo superarlas.

En este sentido, Harney (2009) señala que todo creyente debe recordar que el mundo al que debemos dar testimonio aún no ha experimentado la gracia del perdón en Cristo Jesús. El testigo debe ser como Jesús, quién cruzó la barrera de separación que existía entre judíos y samaritanos para extender la gracia del evangelio (Jn. 4:1-42).

Harney (2009) asevera que para poder ser testigos efectivos de la gracia, debemos “cambiar nuestra perspectiva y recordar que nosotros fuimos pecadores salvados por la gracia.” (p. 36). Así, el creyente se transforma en portador de la gracia de Dios al mundo y por su testimonio “el amor de Cristo atraviesa la historia una y otra vez” (p. 37).

Anderson (n.d. para.1) propone el siguiente esquema para cruzar barreras y practicar efectivamente la orden de Cristo de Hechos 1:8: “Pero recibiréis poder, cuando haya venido sobre vosotros el Espíritu Santo, y me seréis testigos en Jerusalén, en toda Judea, en Samaria, y hasta lo último de la tierra”. Según el mismo autor (n.d. para.2), 
estas regiones tienen un significado aplicable para nuestros días. La tabla que aparece en la próxima página presenta cada región de Hechos 1:8 así como lo que ésta significa, de acuerdo con el autor citado. 
Tabla 2

Significado de las Regiones de Hechos 1:8 Según Anderson

\begin{tabular}{|c|c|}
\hline Región & Significado \\
\hline - Jerusalén & $\begin{array}{l}\text { - La ciudad donde Jesús pronunció las palabras de Hechos } \\
\text { 1:8. Jerusalén significa nuestra familia, nuestros amigos, } \\
\text { nuestros vecinos, compañeros de trabajo o cualquier otra } \\
\text { persona que conocemos en la actualidad. }\end{array}$ \\
\hline - Judea & $\begin{array}{l}\text { - Judea es el área de los alrededores de Jerusalén y puede } \\
\text { ser comparada con nuestro barrio o el resto del área } \\
\text { metropolitana donde vivimos. Son personas que están a } \\
\text { nuestro alrededor, pero aún no conocemos. }\end{array}$ \\
\hline - Samaria & $\begin{array}{l}\text { Samaria es el lugar que está cerca, pero compuesto por } \\
\text { gente de diferente cultura, etnicidad, religión y hasta } \\
\text { costumbres. Nuestra Samaria es lo mismo, gente diferente } \\
\text { a nosotros. Color, religión, nacionalidad y lenguaje. }\end{array}$ \\
\hline $\begin{array}{l}\text { - Lo último de } \\
\text { la tierra }\end{array}$ & $\begin{array}{l}\text { - Lo último de la tierra representa todo ser humano que no } \\
\text { está representado en los otros tres grupos. }\end{array}$ \\
\hline
\end{tabular}

Cada una de esas regiones representa desafíos con barreras de diversos tipos. De acuerdo con el autor, estas son las barreras que tenemos que cruzar para alcanzarlos:

Tabla 3

Barreras Para Testificar en las Regiones de Hechos 1:8

\begin{tabular}{|c|c|}
\hline Región & Tipo de barrera \\
\hline - $\quad$ Jerusalén & - $\quad$ La barrera de nuestros propios temores. \\
\hline - Judea & - La barrera de familiarizarnos con los extraños. \\
\hline - Samaria & $\begin{array}{l}\text { - La barrera de entender otras culturas, personalidades, } \\
\text { religiones y grupos étnicos. }\end{array}$ \\
\hline $\begin{array}{l}\text { - Lo último de la } \\
\text { tierra }\end{array}$ & $\begin{array}{l}\text { - La barrera de aprender otros idiomas y culturas para } \\
\text { testificar por el mundo. }\end{array}$ \\
\hline
\end{tabular}


March (1997) afirma que cruzar las barreras sociales para testificar es una de las funciones del evangelio. Para poder lograr esto es menester que el creyente se conecte con la sociedad estableciendo puentes de conexión por medio de relaciones saludables. Cruzar barreras es “el amor en acción para el evangelismo” (p. 65).

Amigos y familiares como el marco social inmediato

Esta sección habla de la importancia de la testificación en el círculo de influencia del nuevo creyente. Anteriormente se pudo ver con claridad que la testificación en Jerusalén se refiere entre otros, a familiares y amigos cercanos del nuevo creyente.

Lewis (2012) asevera que la familia y los amigos cercanos son la estructura social más extensa y duradera en nuestra sociedad.

Newman (2011) asegura que la testificación a este grupo social debe darse en el contexto apropiado, ya que tiene dos implicaciones críticas. En primer lugar, testificarle a amigos y familiares es difícil porque no queremos ofenderlos. Y en segundo lugar, testificarles tiene una carga emocional mucho más alta que si lo hiciéramos con extraños.

Miano \& Slick (n.d) mencionan ciertas razones por las cuales se dificulta la testificación a familiares y a amigos. Primero, los familiares y amigos son aquellos que mejor nos conocen. Por lo tanto, muchos creyentes se abstienen de la conversación espiritual por miedo a ser catalogados de hipócritas. Segundo, los familiares y amigos se sienten más cómodos en responder con rudeza a cualquier acercamiento espiritual de parte del testigo creyente. Tercero, los creyentes sienten temor de las consecuencias que podrían tener como resultado de compartir el evangelio con ellos. Si la conversación termina en malos términos podría acarrear consecuencias a largo plazo y esto aumentaría la tensión familiar. 
Por esta razón, Newman (2011) considera de vital importancia aprender a testificar entre nuestros amigos y familiares, de lo contrario "se podrían romper las relaciones causando dolor, amargura y alejamiento” (p.42).

En este sentido, Newman (2011) ofrece una metodología que aunque sencilla, puede ser efectiva. Primero, estudiar las Escrituras para tener respuestas concretas en el momento de interactuar. Segundo, desarrollar un modelo de oración constante, presentando en oración las necesidades que caracterizan al familiar o amigo no creyente. Tercero, cuando se de la oportunidad de dialogar, hay que permitir que ellos sean el foco central de la conversación. El permitir que ellos se expresen libremente e interrumpiendo lo menos posible, afianzará la confianza mutua. Cuarto, pedir permiso para conversar sobre un tema espiritual, si es que ve a la persona abierta a la discusión saludable. Quinto, iniciar la conversación sobre un tema espiritual. Hacer preguntas ayudará a conocer la creencia de la persona y ayudará a preparar el camino para contar el testimonio personal.

De esta manera, Newman (2011) sugiere la actitud de escuchar activamente antes de compartir el testimonio. Él dice: "Muchos entrenamientos de evangelismo se enfocan en seminarios que tratan exclusivamente acerca de qué decir, pero por el bien del evangelio, hay que aprender a recuperar el arte perdido de escuchar” (pp. 147-148).

Miano (n.d.) menciona algunos otros elementos importantes. Hay que recordar a quién se le está hablando. “Cuando se está compartiendo el evangelio con amigos o familiares, hay que recordar que no son extraños” (Remember to Whom You are Speaking section, para. 2). Esto ayudará a no cambiar el tono de la voz, la mirada ni la postura física en la conversación. 
Otro elemento es el de la honestidad. Si la relación es buena y está fundada en la honestidad, entonces “se puede ser más directo mientras seamos sensitivos y respetuosos” (Be honest section, para. 2). Por último, recordar el lugar que tenemos en la relación. El autor nos recuerda que este es uno de los errores críticos en muchos cristianos a la hora de testificar. Él explica que, "los padres, los abuelos, los tíos y los tatarabuelos, no desean recibir un discurso moral o religioso de parte de alguien menor que ellos” (Remember Your Place, para. 2). Aquí lo que funciona es contar el testimonio como si fuera una historia, con humildad y respeto.

Testificar a familiares y amigos no es fácil, pero es muy necesario para el avance de la misión de la iglesia. Vencer el temor y mostrar un profundo amor por ellos es la clave para avanzar. Es necesario recordar lo que Jesús le dijo a sus discípulos antes de enviarlos a Jerusalén: “He aquí yo estoy con vosotros todos los días, hasta el fin del mundo. Amén.” (Mt. 28:20).

La testificación a amigos y familiares en las redes sociales Varios sociólogos e institutos de investigación, ven significativos cambios en la estructura de las relaciones inmediatas en la sociedad actual, especialmente en la manera como se conectan entre ellos.

Barnes (2012) menciona que en un estudio realizado en el 2006 por la American Sociological Review, se reveló que en 1985 el promedio de amigos cercanos por persona era de 3. Sin embargo, en el 2004, bajó a 2. El estudio también demostró que la amistad interpersonal había decaído 50\% en los últimos 25 años.

Aunque el número de relaciones de amistad interpersonal ha disminuido, un reporte realizado por eMarketer (2013), reveló que el aumento de amigos interconectados 
por redes sociales ha aumentado de manera significativa. Una de cada cuatro personas en el mundo está conectada por medio de una red social. El número ha aumentado de 1.47 billones en el año 2012, a 1.73 billones en el año 2013. Esto revela un aumento del 18\%. Sin embargo, la proyección para el año 2017 es de 2.55 billones. Esto representa poco menos de un tercio de la población del mundo actual.

Según, Browser Media, Socialnomics, \& MacWorld (2014), Facebook es considerada la red social más usada con el 56\% del total de usuarios de todas redes.

Un estudio realizado por Smith (2014) demostró que el 57\% de los adultos y el 73\% de los adolescente entre 12 y 17 años, usan la red social llamada Facebook para conectarse con amigos y familiares en todo el mundo. Este mismo estudio reveló que el promedio de amigos y familiares conectados a una persona por medio de la red, es de 338.

El 39\% de los que usan Facebook son adultos. La mitad de ellos son aproximadamente 273 millones y tienen un promedio de 200 amigos cada uno en su red. Al sumar las interconexiones entre sí, el número de interconexiones que arroja entre todos ellos es de 54,600,000,000 (cincuenta y cuatro mil seiscientos millones). Strogatz (2009), llamó a esto “un fenómeno social con características colosales” (Friends You Can Count On section, para. 2).

Un estudio (Anderson \& Rainie, 2010), reveló que para el 2020, el 67\% de la así llamada generación del milenio, continuará usando las redes para compartir opiniones personales, religiosas, políticas y sociales. En el estudio, ellos dijeron que las redes sociales serían un hábito para toda su vida. 
En otro estudio reciente por Dakin (2014) indicó que las redes sociales han cambiado en los adolescentes el concepto de amistad e intimidad. Un adolescente promedio tiene unos 300 amigos en Facebook y alrededor de 79 seguidores en la red social llamada Twitter.

Dentro de esta misma investigación, Greenfield (citada por Dakin, 2014), descubrió que los estudiantes de nivel de colegio, no sienten “apoyo social al usar el teléfono celular para comunicarse. Ellos sienten apoyo social a través de redes más amplias y con una audiencia mucho más grande” (Social media affecting teens' concepts of friendship, intimacy section, para. 8).

De esta manera, Dakin (2014) advierte que la nueva generación de adolescentes ve la intimidad de una manera más abierta. Esta generación está dispuesta a hacer declaraciones personales de su vida privada a cientos de personas en su red social.

Kinnaman (2013) entiende que la tecnología también ha cambiado la fe de la así llamada generación del milenio. Se descubrió que 7 de cada 10 adolescentes leen la Biblia por medio de una pantalla. Es interesante destacar que 1 de cada 3 no creyentes usan el Internet para buscar un templo o una sinagoga para asistir. El estudio también reveló los hábitos de la generación del milenio cuando se trata de satisfacer necesidades espirituales. Prácticamente 6 de cada 10 creyentes (59\%), en contraste con 3 de cada 10 no creyentes, realizan sus búsquedas online para satisfacer necesidades espirituales. De esta manera Kinnaman (2013) concluye diciendo que:

La generación del milenio ha llevado la discusión y la exploración de su fe a las redes online. Una de las tendencias más positivas al respecto, es que la generación del milenio quiere integrar la fe de manera holística, en todas la áreas de su vida, incluyendo la tecnología.” (What the Research Means section, para. 3). 
Este fenómeno plantea un desafío sin precedentes a la hora de testificar, y debe ser analizado con más cuidado.

McDonald (2013) ofrece algunas pautas cuando se trata de testificar a esta generación que está conectada online a su red de amigos las 24 horas. A continuación se comentarán las más destacadas.

1. El testimonio online debe ser consistente. El mensaje, el video o la foto deben ser consistentes con el resto de lo que se ha colocado anteriormente. Si antes de poner el video cristiano en Facebook se colocó una foto de un concierto de Rock and Roll, el mensaje se diluye, se hace confuso y pierde su influencia.

2. Se debe compartir comentarios en las páginas de otros. Si se desea que los amigos de Facebook compartan algún comentario, video o artículo relacionado con la fe; es importante que el creyente participe lo mejor que pueda en las páginas, los comentarios o los videos de sus amigos.

3. Se deben pegar en la página aspectos consistentes a la fe de manera constante y no esporádica. Un comentario perdido en el mes, entre otros comentarios generales, no producirán el interés deseado.

4. Conectarse a todas las redes sociales que se tenga. Para poder alcanzar más público con el testimonio online, es importante conectarse a todas las redes que poseemos para que el mensaje llegue a más personas.

5. Pegar en el momento preciso. Se entiende que hay momentos de mayor concurrencia a la red. En la mañana temprano y por la tarde a última hora son los mejores momentos porque son los espacios cuando la gente más revisa sus redes sociales. 
Abraham (2012) compila los consejos de varios autores que aseveran que con la cantidad de millones de usuarios pegados a la red, los cristianos deben usar la red social como una herramienta evangelística de testificación. Proponen (a) que se lo haga compartiendo un simple testimonio personal con un alto contenido de honestidad; (b) que usen una versión de la Biblia que sea clara y adaptada al lenguaje actual; (c) que el testimonio sea lo más personal que se pueda; (d) que dar gracias a Dios a diario brinda ánimo, confianza y esperanza a los que leen; (e) que sean realistas escribiendo como la persona que siempre ha sido; y finalmente (f) que ofrezcan orar por aquellos que están enfermos o atravesando un momento de pesar. Entre los cientos de amigos y familiares, siempre se encontrará a alguien con problemas.

De esta manera se puede observar un cambio significativo en la manera como la sociedad se comunica y se interrelaciona. De aquí la importancia de que el nuevo creyente pueda entender la magnitud y el poder de su testimonio personal y cibernéticos. Los amigos y familiares en las redes sociales contrastarán la nueva vida en Cristo con la vieja vida online.

\section{El espíritu santo como compañero en la testificación}

Esta sección intentará resaltar la importancia del Espíritu Santo en el proceso de la testificación. De acuerdo a lo investigado, el Espíritu Santo acompañó siempre la misión de Dios para sus testigos desde el momento de la creación.

Green (2004) afirma que desde el principio, Dios comenzó a revelarse a si mismo a los profetas por medio del Espíritu Santo con una misión específica. Kim (2012) entiende que la misión del Espíritu de Dios ha sido la de devolverle la esperanza de vida a los hombres. Esta idea, reafirma el análisis que hace Green (2004) con respecto al 
origen hebraico de la palabra Espíritu; ruach; denotando así la fuerza de la palabra como aliento de vida de parte de Dios para los hombres. "El Espíritu Santo tiene la energía y el poder para recrear; por medio de Cristo otorga vida y transformación” (Kim, 2012, para. 8).

De igual manera, el libro de Isaías presenta claramente cómo la testificación habría de confirmarse en su totalidad por medio de un compañerismo mutuo entre el Espíritu de vida y Cristo: “El espíritu de Dios el Señor está sobre mí. Sí, el Señor me ha ungido; me ha enviado a proclamar buenas noticias a los afligidos, a vendar a los quebrantados de corazón, a anunciar libertad a los cautivos, y liberación a los prisioneros; a proclamar el año de la buena voluntad del Señor, y el día de la venganza de nuestro Dios; a consolar a todos los que están tristes” (Isa. 61:1-2).

Así, se puede inferir que el Espíritu Santo tiene un rol prominente en la testificación de la nueva vida que la Divinidad tiene para el ser humano. Fue Cristo mismo el que más tarde indicó no iniciar la práctica de la testificación sin su presencia y poder; "pero recibiréis poder, cuando haya venido sobre vosotros el Espíritu Santo, y me seréis testigos en Jerusalén, en toda Judea, en Samaria, y hasta lo último de la tierra” (Hechos 1:8).

\section{Acompaña con poder para testificar}

La misión de testificar dada por Jesús a los discípulos era más que el ejercicio de una técnica. Davidson (2013) asevera que era necesaria la manifestación de un poder prometido por Jesús. Por medio de la persona del Espíritu Santo el aumento de seguidores estaba garantizado. De acuerdo a Jensen (2009) es el Espíritu Santo el verdadero testigo de Jesús. Sin embargo, él capacita y le permite al creyente en Cristo 
Jesús que practique la testificación. Por medio de su poder, el testigo observará resultados, aún “en medio de cualquier oposición” (Jensen 2009, para, 7).

Robinson y Wall (2006) aclaran que el poder que otorga el Espíritu Santo tiene el propósito específico de hacer avanzar la misión de la iglesia; “que es la de proclamar la victoria de Dios en Cristo sobre los poderes de la muerte, hasta el punto de crear una nueva comunidad en la que los creyentes están juntos y comparten todas las cosas” (p. 124).

Sonnenberg (2008) presenta la idea de que el Espíritu capacita poderosamente al creyente para la tarea de comunicarle a otros, la nueva vida que esta disponible para aquellos que aceptan el favor divino. Ese poder no es menor, ni diferente al que tuvo Cristo en esta tierra. Stronstad (2012) resalta la importancia de entender que el creyente recibirá el mismo poder que tuvo Jesús para poder ejecutar su ministerio terrenal.

Jensen (2009) entiende que el creyente que testifica encontrará en el camino algún tipo de antagonismo (2 Timoteo 3:10-13), pero es por medio del poder del Espíritu de Dios que el testigo soportará la “inevitable oposición y hostilidad que recibirá por hablar la verdad de Cristo Jesús” (para, 8).

Es importante destacar, como lo identifica Sweet (2010), que el testigo es alguien que ha revivido espiritualmente al redescubrir la autoridad de las Escrituras, a Cristo como supremo en su vida, y al Espíritu Santo el único poder que actúa para "manifestar a Cristo en el contexto de una cultura” (p. Loc. 220 of 3594). 


\section{Acompaña con poder para convertir}

De acuerdo a las Escrituras, es el Espíritu Santo quien dirige el convencimiento de una persona a reconocer su condición de pecaminosidad. El apóstol Juan dice: "Y cuando él venga, convencerá al mundo de pecado, de justicia y de juicio” (Jn. 16:8).

Wallenkampf (2006) asevera que es él quien persuade al mundo al arrepentimiento y la conversión. En general, “obra por medio de los creyentes que estaban dispuestos a ser guiados por el Espíritu y a llevar a cabo sus órdenes” (p. 57). Fue el Espíritu de Dios quien en realidad llevó a tres mil personas al arrepentimiento (Hch 2:41). De esta manera, como lo explica Wallenkampf (2006), “fue tal la experiencia de los creyentes después del Pentecostés, que se transformaron en instrumentos humanos dirigidos por el Espíritu” (p. 58). Por medio de él, los creyentes deciden alcanzar a los que no son salvos, confiados en el poder de convencimiento del Espíritu Santo.

Robinson y Wall (2006) entienden que es el Espíritu Santo, el agente principal en la función de la testificación y la conversión. “El Espíritu Santo está irrevocablemente unido a la promesa del plan de salvación divino” (p. 127). Lange y Shaff (2008) aseguran que es el Espíritu de Dios quien trabaja internamente en los pecadores para traerlos al reconocimiento y al arrepentimiento de su vieja vida.

Woods (2011) afirma que de todos los pecados a los que el Espíritu llama al arrepentimiento y la conversión, el más importante de todos, es “el pecado de fallar en creer en Cristo Jesús” (p. 1). De esta manera, él busca ayudar al no creyente a entender que ha cometido un error en no reconocer a Cristo en su vida. Así, por medio del Espíritu Santo, el no creyente comprende que necesita la justicia o perdón de Cristo. Además, le 
ayuda a comprender que habrá un juicio que determinará el resultado de su conversión. De esta manera, como lo expresa Gangel (2000), el mundo entero será desafiado y sacudido por el poder del Espíritu Santo a través del trabajo de sus testigos. 


\section{CAPÍTULO IV}

\section{PROGRAMA DE ENTRENAMIENTO PARA NUEVOS CREYENTES}

El objetivo de este programa es entrenar a los nuevos creyentes para desarrollar en ellos la práctica de la testificación a familiares y amigos no creyentes en el territorio de la AWC.

El capítulo está divido en dos partes. En la primera, se intentará describir la realidad del territorio y el perfil de la Asociación del Oeste de Allegheny, en la segunda se presentará de descripción del programa de entrenamiento y su implementación para poder ser efectivos en el trabajo de la testificación de los nuevos creyentes.

\section{Realidad del territorio y perfil de la Asociación del Oeste de Allegheny}

Breve reseña histórica de AWC

La Asociación de Allegheny fue establecida el 26 de Septiembre de 1945, lo cual marcó un hito histórico más en la formación de las Asociaciones así llamadas “regionales”.

Sin embargo, en dos comités ejecutivos realizados, uno el 26 de Julio y el otro el 9 de Octubre de 1966, se recomendó la división de la gran Asociación de Allegheny, formando así dos grandes administraciones regionales. A una se la llamó Asociación del Este de Allegheny (AEC) y a la otra se la llamó Asociación del Oeste de Allegheny (AWC), siendo los estado de Ohio y West Virginia los principales territorios de acción. 
Además, la Asociación cubre una parte del sur del estado de Virginia, siendo la ciudad de Charlottesville el área de población más importante, y una franja del oeste del estado de Pennsylvania, donde las ciudades de Pittsburgh y Erie, son los centros de población más destacados. De esta manera, el 1 de Enero de 1967, ambas Asociaciones, AEC y AWC inician oficialmente sus actividades (Allegheny West Conference, 2014). Para ese entonces, AWC contaba con 44 iglesias y 7,144 miembros, y la presencia de adventistas hispanos era casi inexistente (Allegheny West Conference, 2014).

Breve reseña del arribo de hispanos a Ohio

En 1860, 328.249 inmigrantes de diferentes partes del mundo vivían en Ohio. En 1900, el número de inmigrantes de diversas nacionalidades se elevó a 456.734. Sólo unos pocos hispanos residían en las principales ciudades de Ohio, incluyendo Cleveland, Cincinnati y Columbus. La mayoría se desempeñaban en dos trabajos principales: fábricas y agricultura. Luego comenzaron a llegar otros inmigrantes hispanos que establecieron empresas para suministrar productos hispanos tradicionales para la creciente población ("Hispanic Ohioans - Ohio History Central," n.d.).

Es importante aclarar que de acuerdo a la agencia oficial de censo de los Estados Unidos, se determina como hispanos a individuos de origen mexicano, mexicanoamericano, chicanos, puertorriqueños, cubanos, o de algún otro país de Latinoamérica de habla hispana o de trasfondo hispano (Richards, 2014).

Varios estudios concuerdan en que hubo un aumento significativo de la inmigración hispana a los Estados Unidos a partir de la década de 1960. La mayoría de los inmigrantes procedían de América Central y del Sur, con la esperanza de más oportunidades económicas. Para 1980 había más de 120.000 hispanos en Ohio. Las 
comunidades hispanas crecieron de manera exponencial en las zonas urbanas de Cleveland, Columbus y Toledo entre los años 1980 y 1990. Para el año 2006, cerca de 264.000 residentes de Ohio dijeron ser de linaje hispano. ("Hispanic Ohioans - Ohio History Central," n.d.).

De acuerdo con el Censo 2010, la comunidad hispana creció a más de 350.000, representando de esta manera un 3.4\% de la población de Ohio (Richards, 2014). Este número representa un aumento del 63.4 \% desde el año 2000 y la triplicación de la población hispana desde 1980 ("State and County Databases | Pew Research Center's Hispanic Trends Project," n.d.).

Breve reseña del arribo de hispanos a Virginia y West Virginia

En 1607, los ingleses fundaron Virginia. Esta fue la primera de sus trece colonias americanas. La tierra que ahora llamamos West Virginia, era parte de Virginia. Años más tarde, exploradores entraron desde Virginia a West Virginia. Para principios de 1700’s, varios grupos de colonizadores se asentaron finalmente en West Virginia (Kummer \& Capstone Press, 1998, p. 21).

Sin embargo, estudios confirman que los hispanos llegaron a Virginia unos 500 años antes, casi medio siglo previo que los ingleses desembarcaran en Jamestown en el 1607. En 1524, Lucas Vásquez de Ayllón, zarpó de la Española, República Dominicana y llegó al Río Guandape, lo que hoy se conoce como el James River y la Bahía de Chesapeake. En el 1526, Vázquez fundó el asentamiento de San Miguel de Guandape; un número de eruditos e historiadores creen que estaba muy cerca a lo que hoy se conoce como Jamestown, VA. Hoy en día, cerca de 400.000 hispanos viven en Virginia y sus 
raíces ancestrales provienen de España, Puerto Rico, Cuba y Sudamérica ("Hispanics and Latinos in Virginia - Virginia Is For Lovers," 2011).

En West Virginia, la comunidad latina es considerablemente menor. Los hispanos representan el 1.2\% de la población de WV, este es el menor porcentaje de latinos de un estado en la nación. Sin embargo, de acuerdo al último censo, la presencia latina creció un 81.4 \% en sólo 10 años, llegando a 22,268 en el 2010 (WV Gazette, 2012).

Breve Reseña del Arribo de Hispanos a Pennsylvania

De acuerdo a los historiadores, todo comienza con Francisco de Miranda, un revolucionario venezolano que llegó a Philadelphia en el 1780. Miranda peleó junto con “The Founding Fathers” por la independencia de los Estados Unidos. No obstante, el mayor arribo de los latinos al área, se produjo entre 1940 y 1980 (Global Philadelphia, 2013).

El crecimiento latino, así como en otras partes de la región, ha sido significativo. Entre el 2000 y el 2010 el crecimiento latino fue del 58\%, de 267,358 a 422,232 (Hispanic Chamber of Commerce, n.d.).

Es importante destacar el crecimiento explosivo de los hispanos en los condados así llamados del Allegheny, donde el crecimiento ha sido exponencial (Barcousky, 2011); entre el 2000 y el 2010 el crecimiento fue del 71\%, de 11,166 a 19.070, convirtiendo a los latinos en el 1.6\% de toda la población (Barcousky, 2011). 
Pioneros del adventismo hispano en AWC

El primer grupo hispano comenzó a tomar forma a finales del año 2002 en la ciudad de Columbus, OH. Un grupo de 7 personas, mayormente caribeños de República Dominicana y Puerto Rico, comenzaron a reunirse y para principios del 2003 formalizaron lo que luego se llamó la Iglesia Adventista del 7mo día Hispana Manantial de Vida (Grupo Misión). En el año 2005, unos 15 hispanos, mayormente de origen puertorriqueño, pidieron ayuda para establecer un grupo hispano en Erie, PA. Ese mismo año se formalizó la Iglesia Adventista del 7mo día, Templo de Erie (Grupo Misión). En el año 2006, un grupo latino se concentró en la ciudad de Cincinnati, OH. El grupo estaba compuesto mayormente por latinos de origen mexicano y guatemalteco. A diferencia de los otros dos centros de adoración, este de Cincinnati creció con mayor rapidez y para principios del año 2008 cobra el estatus de iglesia. Luego se la conoce como la Iglesia Adventista del 7mo día Central de Cincinnati.

Estos fueron los comienzos de la obra hispana en AWC. No cabe duda de que la enormidad del territorio que abarca, la distancia entre las grandes ciudades con mayor influencia hispana y la falta de liderazgo hispano en la Asociación fueron determinantes para que el crecimiento sea lento. Por más de 30 años, el establecimiento de iglesias hispanas en el territorio de AWC fue prácticamente inexistente.

\section{Descripción del programa de entrenamiento para recién bautizados}

Basados en la realidad de un vasto territorio de más de 106,000 millas cuadradas, la enorme distancia entre las ciudades importantes de crecimiento hispano y el poco liderazgo en los centros de adoración ya establecidos; se tuvo que tomar la decisión de crear una estrategia de trabajo donde cada miembro de iglesia, con historia dentro del 
adventismo o recién bautizado, tome la responsabilidad de convertirse en un pionero de la obra en AWC y avanzar en el crecimiento local y la plantación de otras iglesias en la zona.

\section{Misión y visión estratégica}

A finales del 2009 y durante la convención de liderazgo para toda la Asociación de AWC, se invitó a los líderes hispanos para ser entrenados y además para trazar una estrategia de evangelismo y testificación que facilite el avance del crecimiento de la obra hispana con mayor rapidez.

La declaración de Misión del ministerio multicultural de AWC, que reza de la siguiente manera: "Proclamar a todas las comunidades el evangelio eterno en el contexto del mensaje de los tres ángeles de Apocalipsis 14:6-12, llevándolos a aceptar a Jesús como su salvador personal” (Allegheny West Conference, n.d.); fue crucial para mantener el enfoque de lo que se intentaría lograr en los próximos cuatro años.

Durante la convención de liderazgo a fines del 2009, se llegó a la conclusión de que una estrategia simple, consistente y claramente enfocada en la misión, sería la que daría mayor beneficio a las iglesias locales y a la Visión de AWC: "Plantar iglesias de todas las culturas que tenemos en nuestro territorio, mientras creamos una imagen favorable de la misión de la iglesia, la vida y las actividades por las cuales muchos se convertirán en seguidores de Cristo” (Allegheny West Conference, n.d.).

De esta manera se creó una estructura con cuatro pilares denominados; CREO, CONOZCO, CELEBRO Y COMPARTO. Estas cuatro columnas corresponden a cuatro actividades que tendrían la función de marcar el rumbo, brindar un blanco o un estilo de 
vida para los pocos miembros de AWC y sus cuatro centros de adoración o iglesias en formación y crecimiento.

\section{Primera columna - CREO}

Se determinó que en el mes de Febrero de cada año iniciaríamos nuestro ciclo anual de vida haciendo de la columna CREO el encuentro crucial para asentar las bases del éxito que buscaríamos alcanzar el resto del año. Por ser la columna CREO la base de nuestra estrategia de crecimiento, dedicaremos un poco más de espacio para explicar sus objetivos y su implementación.

\section{Objetivos}

El propósito de este evento de tres días es traer a todos los recién bautizados de nuestros centros de predicación de los últimos tres años a un encuentro donde se ayudará al nuevo creyente o recién bautizado a comprender cómo vive, cómo estudia, cómo ora, cómo adora y cómo testifica una nueva criatura en Cristo (2 Co. 5:17). Es importante tener en cuenta que, de acuerdo a los autores investigados, los nuevos creyentes son los que tienen el mayor potencial de testificación por tener amigos y familiares que no están aún relacionados con su nueva fe.

El entrenamiento a los recién bautizados o nuevos creyentes en sus primeros años es esencial para desarrollar en ellos hábitos que los ayudarán inmediatamente a permanecer en la nueva fe aún a pesar de las batallas espirituales que experimentan todos los creyentes. Estas herramientas también los ayudarán a ser cristianos más estables y testigos más dispuestos a compartir su nueva fe en Cristo Jesús. 
Menzer y Broschat, (n.d.) explican la importancia de dedicar tiempo, espacio y una metodología práctica para que el nuevo creyente adquiera las herramientas necesarias de crecimiento espiritual. Estas son las áreas de crecimiento que Menzer propone:

1. Oración: Es importante mostrarles y enseñarles a los nuevos creyentes cómo orar, los motivos por los cuales orar, el tiempo que se debe dedicar a la oración y la fortaleza espiritual que resulta de la práctica de la oración personal para comunicarse con Dios. En 1 de Tesalonicenses, el apóstol Pablo ora por los nuevos discípulos y de esta manera les enseña la importancia de la oración para la vida de todo nuevo seguidor de Cristo.

2. Estudio de la Palabra: En el segundo capítulo de Tesalonicenses, Pablo menciona la importancia de haber compartido la Palabra con todos ellos. Es vital desde el comienzo que los nuevos creyentes comprendan que el estudio de la Palabra de manera consistente produce una fe más sólida. El estudio de las Escrituras es el nuevo alimento del creyente.

3. Desarrollo de relaciones: Es importante proveer actividades para que el nuevo creyente entienda que no está solo. Hay muchos otros que como él, han tomado la decisión de iniciar una nueva vida y tienen un grupo y un espacio donde pueden compartir sus nuevas experiencias mientras desarrollan amistad con los otros creyentes.

4. Camaradería con otros creyentes: Parte del desarrollo del nuevo creyente es la capacidad de relacionarse con otros creyentes para encontrar apoyo, amistad y soporte para la nueva vida en Cristo. El nuevo creyente tiene que aprender a comunicarse, a compartir momentos de estudio bíblico, de oración y de camaradería con otros creyentes como él. 
5. Cómo compartir a Jesús: Usualmente, los nuevos creyentes están emocionados o se encuentran viviendo lo que las Escrituras llaman el primer amor (Apocalipsis 2:4). Por esta razón es más fácil para ellos compartir con otros de manera natural este cambio de vida. También es importante destacar el caudal de amigos y familiares, muchos seguramente no creyentes todavía, con los cuales ellos pueden compartir su nueva fe. Esto los ayudará a desarrollar la práctica o hábito de la testificación desde muy temprano. Además descubrirán que compartir la fe ayuda a mantener el calor interno de la vida espiritual.

\section{Descripción de CREO}

El programa CREO fue un fin de semana a comienzos del año.

En Febrero del año 2010 realizamos en AWC el primer fin de semana de entrenamiento “CREO” para recién bautizados; 57 nuevos creyentes se hicieron presentes para iniciar el sueño de transformar la cultura de un ministerio hispano extremadamente joven e inexperto. Este grupo de nuevos creyentes se transformarían en nuestros soldados de avanzada para crecer con mayor rapidez.

El ideal fue traer a nuestro entrenamiento la mayor cantidad de los recién bautizados de nuestros tres centros de predicación. Los tres pastores de medio tiempo que tenía la Asociación en su momento, fueron determinantes para que la asistencia fuera significativa.

Durante este fin de semana se intentaría que los participantes comprendan: Qué es la iglesia, cuál es su función dentro de ella, cómo desarrollar el hábito de estudiar la Biblia y de orar diariamente; cuáles son sus talentos y cómo los pueden usar dentro de la iglesia; cómo funciona el apoyo financiero al avance y la predicación del mensaje del 
advenimiento de Cristo al mundo; y cómo servir, testificar y traer a un amigo a los pies de Cristo, ya sea a un grupo pequeño o a la iglesia para una actividad evangelística. Preparación del lugar

El lugar de reunión fue preparado con mesas, como si estuviéramos en una gran sala de aprendizaje. En cada mesa se colocó el material necesario para que cada persona se sintiera atendida y sin necesidad de nada. No se requirió ropa formal, más bien casual. El objetivo era preparar un ambiente cordial donde todos se sintieran cómodos, sin las exigencias que podría tener la asistencia un templo.

Desde el comienzo, las personas de la mesa de registración demostraban intencionalmente mucho afecto y afirmación hacia cada uno de los participantes. En esa mesa de bienvenida se colocaron todos los materiales exclusivos para cada recién bautizado que se había registrado previamente. El material con el nombre de cada uno contenía el programa, libros, sílabos y un pequeño regalo para cada uno de ellos.

Se colocó música de fondo para crear una atmósfera espiritual, de paz y recogimiento. Se colocó también otra mesa con una variedad de aperitivos saludables y de alta calidad para que nuestros nuevos creyentes puedan degustar e iniciar de manera natural conversaciones con otros nuevos creyentes que comenzaban a llegar al lugar.

\section{La estructura del programa}

El entrenamiento fue dividido en 4 segmentos, los cuales se describen en los párrabos que siguen:

1. Primer Segmento - Viernes de tarde: El objetivo era producir un ambiente de adoración y alabanza por medio de la música y videos ilustrativos. Luego se desafió a los recién bautizados a experimentar lo que significa pasar una hora en oración con Jesús. 
Desde la primera noche dedicaríamos 15 minutos de reloj para orar. Para muchos de ellos, era la primera vez que se arrodillaban por tanto tiempo. El énfasis de la oración de la primera noche fue "Mi vida nueva en Cristo Jesús”. El objetivo fue que cada uno de ellos experimente 15 minutos contándole a Dios lo que significó para ellos el nuevo nacimiento que habían experimentado.

La temática del primer segmento tiene que ver con historia y conocimiento de la gran familia adventista, expectativas, opciones de servicio dentro de la iglesia y la responsabilidad que cada uno tiene hacia Dios y hacia esta nueva familia espiritual.

2. Segundo Segmento - Sábado de mañana: Nuevamente la alabanza y adoración fueron parte del inicio de esta segunda etapa. Así como el viernes de noche, en esta ocasión se les pidió a los participantes que oraran 15 minutos de reloj bajo el lema "Yo y mi casa serviremos al Señor” (Josué 24:15). La temática principal del segundo segmento tenía que ver con crecimiento espiritual. Nos enfocamos en enseñar el por qué y cuáles son las herramientas básicas que ayudan a un nuevo creyente a mantenerse firmes en la fe.

3. Tercer Segmento - Sábado de tarde: La actividad regresaba con la alabanza y la adoración intencionalmente preparada para que las personas sintieran el gozo de la adoración. Ya por la tarde permitimos testimonios personales no solamente de lo que habían experimentado hasta ese momento, sino también de lo que significaba para ellos haberle entregado la vida a Jesús. Se volvió a tener 15 minutos de oración donde se enfatizó la oración por el nuevo compromiso de servicio a la iglesia. Se los invitó a orar para que sus dones y sus talentos fueran puestos al servicio de Dios. Ya para ese entonces llevaban 45 minutos de oración y comunicación personal con el Señor. 
Los seminarios de esta sección, tenían la intención de animarlos a participar y servir activamente en la iglesia local. La idea incluía el estimularlos para que pudieran dar su testimonio personal sin temor y analizar la capacidad de expresión en público de los nuevos creyentes. De esa manera podríamos ir descubriendo talentos para los centros locales de predicación, o sea, nuestras futuras iglesias. Recordemos que para este momento, todos los recién bautizados han experimentado 45 minutos de oración personal. De acuerdo a lo que muchos de ellos nos expresaron, esta es la primera vez en sus vidas que habían practicado la oración de manera intencional y por tanto tiempo.

El tema central de la tarde, tuvo que ver con los dones personales y encuestas de talentos para que cada nuevo creyente pudiera regresar a sus iglesias con una mejor comprensión de sus habilidades y colocarlas al servicio de la iglesia local. También hubo momentos de intercambio de ideas en grupos de tres o cuatro. De esta manera se les mostró la importancia y el valor de reunirse con personas a estudiar, conversar o simplemente analizar ideas en grupos pequeños. Se utilizó este momento para recalcar la importancia de practicar el estudio de la Biblia y la camaradería en grupos pequeños de apoyo a la iglesia local.

4. Cuarto segmento: Domingo de mañana: Nuevamente preparamos el ambiente con alabanzas y muchas palabras de afirmación por haber llegado al final del encuentro de nuevos creyentes. Se volvió a invitar a los participantes a dedicar 15 minutos de oración, sólo que esta vez les entregamos en sus manos un simple marcador de Biblia con el lema de la Asociación para ese año. En la parte posterior del marcador de Biblia se les pidió que escribieran el nombre de 5 personas, especialmente de amigos o familiares, o 
simplemente personas por las cuales ellos dedicarían 15 minutos de oración, con los cuales completarían una hora de oración personal con Dios durante todo el retiro.

Como esto significaba un evento casi histórico en la vida de muchos de ellos, les entregábamos un certificado a cada uno por haber pasado una hora con Dios por primera vez durante un fin de semana. Esto se convirtió en un momento significativo para la mayoría de ellos. Se observaron expresiones de satisfacción, como así también de lágrimas de gozo y felicidad por el resultado de haber tenido un profundo encuentro con Dios.

El objetivo de los seminarios del domingo era para inspirarlos y desafiarlos a orar, servir, compartir y traer a sus amigos y familiares a los pies del Señor. El domingo se convirtió, eventualmente, en una mañana de desafíos para traer nuevos creyentes a los pies de Cristo Jesús. El compromiso ante Dios, escrito y en oración, era traer cinco personas a los pies del Señor en el próximo año. Pero la razón principal de esta temática era ayudar a cada uno de los nuevos creyentes a convertirse de manera natural y desde el comienzo en seguidores, misioneros, discípulos fieles y obedientes de Cristo Jesús.

\section{Segunda columna - CONOZCO}

Al terminar la primera columna CREO, se invitó a los recién bautizados a dar el siguiente paso que estaba directamente relacionado con grupos pequeños de estudios de la Biblia.

\section{Objetivo}

El objetivo en esta instancia era que cada uno de ellos saliera del retiro con el compromiso de llegar a sus iglesias y participar de grupos pequeños de crecimiento 
espiritual y también, como medio para invitar a sus amigos y familiares a participar de una actividad que los pre-conectara con la iglesia.

Para comprometer a los recién bautizados con esta nueva columna de crecimiento espiritual, se les entregó todos los materiales de estudios para grupos pequeños y un calendario de participación dividido en dos etapas. La primera etapa concluiría cerca de tres meses después, en el campestre hispano de AWC. La segunda etapa concluiría al final del año.

En esta etapa de conocimiento, el nuevo creyente reforzaría su conocimiento de la palabra de Dios. Esto lo ayudaría en su crecimiento espiritual y a la vez practicaría la testificación invitando a amigos y familiares a conocer las Escrituras.

Tercera columna - CELEBRO

El cuarto fin de semana de mayo se fijó como fecha de celebración durante el campestre hispano de AWC. En el año 2010 fue la primera vez que se realizaba un campestre hispano de tres días con una programación completa de viernes a domingo.

\section{Objetivo}

La meta en esta etapa era de vital importancia para el crecimiento en la vida del nuevo creyente, de las iglesias y de la Asociación.

Se desafió a todos los nuevos creyentes y también al resto de los miembros de la Asociación a asistir a este evento de celebración espiritual. Para darle la importancia que esta actividad merecía, se contó con el apoyo de los pastores para cerrar todos los centros de predicación y traer a los miembros a la actividad. 
El objetivo para los recién bautizados fue el de traer a sus amigos y familiares que estuvieron estudiando la Biblia en los grupos pequeños (columna CONOCER), a un fin de semana de alabanza, presentación de la palabra y camaradería cristiana.

Una parte destacada de este evento fue el reconocimiento que se le dio a los “pioneros” de la AWC durante el sábado de mañana. Se les explicó que este reconocimiento en forma de placa se daba una vez en la vida a esa persona. Se determinó que un pionero era todo creyente involucrado intencionalmente en el crecimiento de su iglesia local. El siguiente año, ellos eran los encargados de animar a otros a que se convirtieran en pioneros y agentes de crecimiento en sus iglesias.

El mayor desafío lo tuvieron los pastores locales y las juntas de iglesias para determinar quiénes serían ese año las dos o tres personas destacadas como pioneros y agentes de crecimiento en sus iglesias locales. Se intentó hacer un fuerte hincapié en identificar y seleccionar a nuevos creyentes comprometidos para este reconocimiento.

\section{Cuarta columna - COMPARTO}

Esta etapa final se la denominó “COMPARTO”. En ella, se intentaría cosechar el resultado de todo un año de entrenamiento, capacitación, reconocimiento e involucramiento del nuevo creyente para la testificación.

\section{Objetivo}

La meta principal era crear semanas de cosecha intencionalmente organizadas para que cada iglesia o centro de predicación pudiera utilizar esas actividades de impacto como formas de evangelismo para las iglesias locales. También se organizó cada año una actividad metropolitana general de impacto en la comunidad que se realizó desde el 
primer año y también los siguientes tres años en diferentes partes del territorio de AWC. Se tuvo el privilegio de utilizar los servicios del Pr. Alejandro Bullón durante cuatro años consecutivos para esta actividad y los resultados fueron contundentes.

\section{Resultados del programa de entrenamiento}

En el año 2009, AWC contaba con tres centros de predicación y un grupo pequeño en formación para convertirse en un grupo-misión. Sólo uno de los tres centros reconocidos había recibido el estatus de iglesia de acuerdo a los reglamentos de la Asociación. Para ese entonces, la Asociación contaba solamente con dos pastores de medio tiempo.

Para el año 2013, el ministerio hispano de AWC había triplicado sus centros de predicación y adoración. Ahora contaba con 11 centros claros y definidos y tres grupos de reunión con potencial a convertirse en grupos-misión. Tres de estos diez centros ya eran iglesias organizadas oficialmente de acuerdo a los estatutos y reglamentos de AWC.

En el año 2010 se realizó el primer Campestre de tres días sólo para la comunidad adventista hispana de AWC. Los pastores Raúl Rodríguez y José Espósito, ambos dirigentes y evangelistas de la Asociación de Potomac, fueron los ponentes invitados para lanzar una programa agresivo de evangelización y testificación en el territorio. Por primera vez en la historia del adventismo hispano en AWC, 158 delegados se hicieron presentes y fueron parte del primer Campestre Hispano de celebración. En el año 2013 la asistencia a nuestro evento de celebración o campestre hispano se había triplicado con una asistencia de más de 500 personas. En esta ocasión, los pastores Roger Hernández, Henry Barrios y Samuel Moreno, fueron los expositores principales. 
En el año 2009 se registraron 28 bautismos hispanos en toda la Asociación. Para fines del 2013 el número de bautismos fue de 168.

Para fines del año 2009 el diezmo en AWC fue de $\$ 57.750 .00$. A fines del año 2013 el diezmo había aumentado a \$148,468.00.

En la siguiente tabla podremos observar el crecimiento cuantitativo desde que se implementó el programa de crecimiento: CREO - CREZCO - CELEBRO COMPARTO.

Tabla 4

Crecimiento Cuantitativo de AWC Entre 2009 y 2013

\begin{tabular}{ccccc}
\hline Año & Membresía & Iglesias & Bautismos & Diezmos \\
\hline 2009 & 112 & 4 & 28 & $57,750.00$ \\
2010 & 215 & 6 & 37 & $75,800.00$ \\
2011 & 285 & 8 & 73 & $98,500.00$ \\
2012 & 360 & 10 & 91 & $124,300.00$ \\
2013 & 475 & 12 & 168 & $148,468.00$ \\
\hline
\end{tabular}

En esta tabla se observa el crecimiento cuantitativo de la Asociación a lo largo de cinco años desde que se inició la primera reunión con los pocos líderes que tenía la Asociación. Desde el año 2010 se observó un crecimiento constante, estable e integral. El último año de la implementación del programa se puede advertir un crecimiento significativo al menos en las columnas de membresía, bautismos y diezmos. La plantación de iglesias fue estable. Se obersvó un crecimiento moderado, pero constante que estubo directamente relacionado con el liderazgo con el cual se podía contar. 
También hubo un crecimiento en la participación de los recién bautizados al retiro espiritual de los nuevos creyentes. Y también el involucramiento de los mismos en los grupos pequeños y en la participación activa como "pioneros-misioneros” en sus iglesias locales.

Tabla 5

Participación de los Nuevos Creyentes en el Programa de Crecimiento de AWC

\begin{tabular}{ccccc}
\hline Año & Bautismos & $\begin{array}{c}\text { Nuevos creyentes } \\
\text { registrados a } \\
\text { CREO }\end{array}$ & $\begin{array}{c}\text { Grupos pequeños } \\
\text { en AWC }\end{array}$ & $\begin{array}{c}\text { Pioneros-misioneros } \\
\text { honrados en } \\
\text { CELEBRO }\end{array}$ \\
\hline 2009 & 28 & & 12 & 22 \\
2010 & 37 & 36 & 18 & 36 \\
2011 & 73 & 45 & 26 & 48 \\
2012 & 91 & 56 & 28 & 62 \\
2013 & 168 & 71 & & \\
\hline
\end{tabular}

En la tabla 2 podemos observar el aumento en la participación de los nuevos creyentes en el retiro CREO. La participación de ellos se ve reflejada en la cantidad de grupos pequeños que fueron aumentando con los años. También observamos un incremento paulatino de aquellos que fueron honrados durante nuestro campestre anual de CELEBRACIÓN, entendiendo que la mayoría de esos pioneros-misioneros eran nuevos creyentes que aumentaban su participación de manera significativa en las iglesias locales.

El iniciar un modelo de entrenamiento para nuevos creyentes con objetivos claros de crecimiento cualitativos y cuantitativos por medio del programa de crecimiento CREO 
- CONOZCO - CELEBRO Y COMPARTO, produjo beneficios positivos para el avance y el crecimiento de la Asociación de AWC.

Los nuevos creyentes fueron educados, inspirados, afirmados y desafiados desde el comienzo de su nuevo caminar en Cristo Jesús. Este programa intencional de crecimiento hizo que ellos se enfocaran en la misión convirtiéndose en testigos y misioneros, adoptando una visión de propósito para sus vidas y un compromiso más significativo y participativo en la iglesia local. 


\section{CAPÍTULO V}

\section{RESUMEN, CONCLUSIONES Y RECOMENDACIONES}

Esta sección tiene el fin de realizar un resumen de los aspectos más significativos descubiertos durante el transcurso de esta investigación. Se prestará un breve resumen de lo que se observó durante la investigación teórica y práctica. También se expondrán las conclusiones más relevantes y las recomendaciones que se debe tener en cuenta cuando se realice un programa de entrenamiento para nuevos creyentes.

\section{Resumen}

Tanto el Antiguo Testamento como el Nuevo Testamentos nos dan excelentes ejemplos, instrucciones, y escenarios para ayudarnos en un plan del entrenamiento para la testificación. El entrenamiento, está fundamentado claramente en principios bíblicos y con un claro apoyo en los escritos de Ellen G. White. A lo largo de la investigación se descrubrió que la Palabra de Dios nos da ejemplos que se usaron para formar una comprensión de la mentoría y el entrenamiento.

El entrenamiento para la testificación de Cristo Jesús tiene un origen divino. De alguna manera, así lo explica Roehl (1999), él comenta que hay encuentros divinos cuando se cruzan las relaciones de un entrenador, un líder, y el Espíritu Santo. Desde el principio de la Creación, el propósito de Dios ha sido que tengamos relación unos con otros, y el entrenamiento fluye mejor de las buenas relaciones. 
Esa comprensión de entrenamiento cobra un valor significativo en la vida de Jesús y su métodología para combinar la enseñanza teórica y práctica. Sobre todos los entrenadores, Jesús es supremo. La relación que tuvo con otros, especialmente con sus discípulos, nos indica muchas actitudes y actividades que podemos asimilar e imitar en el entrenamiento.

La relación de Jesús como maestro e instructor a sus discípulos muestra la importancia de dedicar tiempo para analizar ideas relacionadas con el reino de Dios, lo que significa cruzar barreras para la testificación y las batallas que tiene un testigo. Además se descubrió excelencia en la forma cómo Cristo dirigió a la práctica la instrucción teórica.

Los Discípulos de Cristo, como nuevos aprendices, se transformaron en sobresalientes testigos de las buenas nuevas de salvación porque fueron instruidos, inspirados, afirmados, supervisados y enviados a una misión clara por Cristo Jesús.

De la misma manera, la participación del Espiritu Santo fue y es vital para dar fuerza, inspiración y poder sobrenatural que acompaña al instruido no solamente en la comprensión de la instrucción, sino en la razón de la misama. En otras palabras, sin el Espíritu Santo, es imposible comprender la enormidad de lo que significa la tarea de testificación al mundo, mucho menos la realización o la práctica de la misma.

En la literatura contemporanea se observó la clara intencionalidad que tienen las iglesias de mayor crecimiento en la instrucción a sus nuevos conversos. El énfasis es evidente ya que se descubrió que por un proceso casi natural e involuntario, mientras más tiempo pasa una persona dentro de una iglesia, más relación comienza a tener con su nueva familia en Cristo. Así, de esta manera, se pierde la relación con otros no creyentes 
y por ende la posibilidad de testificación y de crecimiento de iglesia de manera más natural.

Es por eso la importancia de entrenar rápidamente al nuevo creyente. Este último todavía tiene la mayoría de sus amigos y familiares fuera de la fe, pero por estar relacionado aún con ellos, tiene más posibidades de testificación que aquellos que ya tienen muchos años dentro de una iglesia.

En la práctica se descubrió que los nuevos creyentes están dispuesto a aprender y a ser entrenados si se les ofrece el tiempo, el material, el ambiete correcto y se les permite, aún cometiendo errores, iniciarse en la testificación y el liderazgo en las iglesias locales.

El nuevo creyente en general, tiene una actitud que facilita el entrenamiento, está entusiasmado por haber recibido el perdón de sus pecados, tiene una pasión especial y se encuentra feliz porque acaba de aceptar a Cristo como Señor y Salvador. Por estas razones y otras, está dispuesto a ser instruido y desafiado para testificar a otros de su fe en Cristo Jesús.

\section{Conclusiones}

Del análisis Bíblico, como de los comentarios sobre instrucción y crecimiento de iglesia de Elena G. De White y de la variedad de autores, pastores y comentaristas contemporáneos, extraemos principios que coniciden en que es de vital importancia la instrucción inmediata a una persona que toma la decisión de entregarse a Cristo y bautizarse. Esto ayudará al crecimiento espiritual de esa persona, lo fortalecerá en su nueva fe y también aportará ayuda extra a cualquier iglesia en su crecimiento cuantitativo y cualitativo. 
El programa de crecimiento implementado en la Asociación del Oeste de Allegheny, confirmó la importancia que tiene la instrucción para la testificación de los nuevos creyentes. Además, arrojó luz en cuanto a cuáles serían los factores que podrían favorecer más el crecimiento de iglesias, especialmente en lugares con poco liderazgo de experiencia.

Toda la literatura revisada confirma que el entrenamiento inmediato con un alto contenido de práctica es de vital importancia para el crecimiento personal del nuevo creyente y por ende de la iglesia local donde servirá como discípulo y misionero contemporaneo.

También se observó la necesidad de proveer para el entrenamiento, maestros que posean claridad en el contenido teórico de información bíblica, pero además cierta comprensión de lo que está experimentando el nuevo creyente en su nueva vida. Un maestro experimentado ayudará a este nuevo discípulo a cómo practicar dentro y fuera de la iglesia su nueva realidad. Todo esto es crucial para que este pueda visualizar lo que Dios y la iglesia local esperan de él de ahora en más.

Los resultados observados por el programa de entrenamiento para recién bautizados en AWC, ratificó la importancia de no descartar a ningún ser humano. Todos son valiosos para el reino de Dios y aportan mucho, especialmente en el área de crecimiento numérico por medio de la testificación, cuando primero nos avocamos a ellos para su crecimiento cualitativo. Dios es poderoso y el Espíritu de Dios sigue utilizando todo tipo personas de diferentes razas y con variadad de habilidades. Cualquier ser humano, rendido a Cristo, entrenado y habilitado puede continuar la obra que El mismo encomendó a sus doce aprendices más de 2,000 años atrás. 
En el trascurso de esta investigación se pudo observar que nuestra satisfacción como entrenadores es que veamos la obra del Señor como líderes que ayudan a otros líderes a descubrir cómo Dios está obrando en ellos, y que los ayude a ser transformados a la imagen de Jesús para que puedan participar con Cristo en su misión redentora y de testificación al mundo.

\section{Recomendaciones}

Luego de analizar con detenimiento los resultados de la experiencia que se obtuvo por medio del programa de entrenamiento para nuevos creyentes en la Asociacion del Oeste de Alleheny, este autor va a proveer algunas recomendaciones que podrían tener el potencial de maximzar la implementación de algo similar en otros lugares.

Es importante crear una cultura de entrenamiento para la testificación a nuevos creyentes en cada iglesia local además de un programa de entrenamiento y crecimiento a niveles superiores en la estrucutra de la iglesia.

Que las escuelas de discipulado ya establecidas en muchas asociaciones tengan las adaptaciones necesarias para ofrecer ciertos módulos o clases que puedan satifacer la necesidad de aquellos que han sido recientemente bautizados y que por ende tienen necesidades más básicas. Sin embargo, estos últimos también tienen un mayor potencial de rendimiento en la testificación por las relaciones que aún mantienen con los de afuera.

Durante el entrenamiento a los nuevos creyentes, sería beneficioso pertimir algún tiempo para realizar simulacros de práctica de testificación entre ellos. Esto permitiría evaluar lo que se debe y lo que no se debe hacer en una interacción donde la testificación está de por medio. 
Hay que evaluar de manera más cualitativa la participación de los nuevos creyentes en las iglesias locales. Para esto, es crucial convencer a pastores y líderes locales de la importancia de proveer espacios y permitir la paricipación de los nuevos creyentes en toda la dinámica de la iglesia local.

Que las iglesias puedan crear más actividades sensibles a las visitas; de esta manera los nuevos creyentes podrían maximizar su capacidad de invitación a amigos y familiares que no han entrado aún en contacto con la iglesia.

Permitir que el nuevo creyente participe por tres años consecutivos en este tipo de entrenamientos. De esa manera hay más seguridad de que adopte las prácticas y los hábitos de un discípulo activo de Cristo. Durante la actividad es importante desafiar constantemente al nuevo creyente de que el siguiente año, debiera venir acompañado de una o más personas como resultado de su trabajo de testificación con otros.

Este trabajo ha tenido como propósito ayudar al crecimiento de una Asociación que no tuvo presencia hispana en su territorio por más de 30 años hasta el 2009, cuando se presentó una nueva propuesto de crecimiento.

El crecimiento significativo experimentado en AWC, luego de la implemtación del programa de entrenamiento a los nuevos creyentes, puede servir como modelo para ser utilizado en otros lugares y así beneficiar el fortalecimiento espiritual de aquellos que van aceptando a Cristo y al mismo tiempo ayudar al crecimiento del campo local por medio del trabajo de testificación de estos nuevos discípulos de Cristo Jesús. 


\section{APÉNDICE}

ALGUNAS FOTOGRAFÍAS Y PRESENTACIONES DE LOS SEMINARIOS

1. Pr. Alejandro Bullón (al centro) acompañando a algunos pioneros de la capacitación

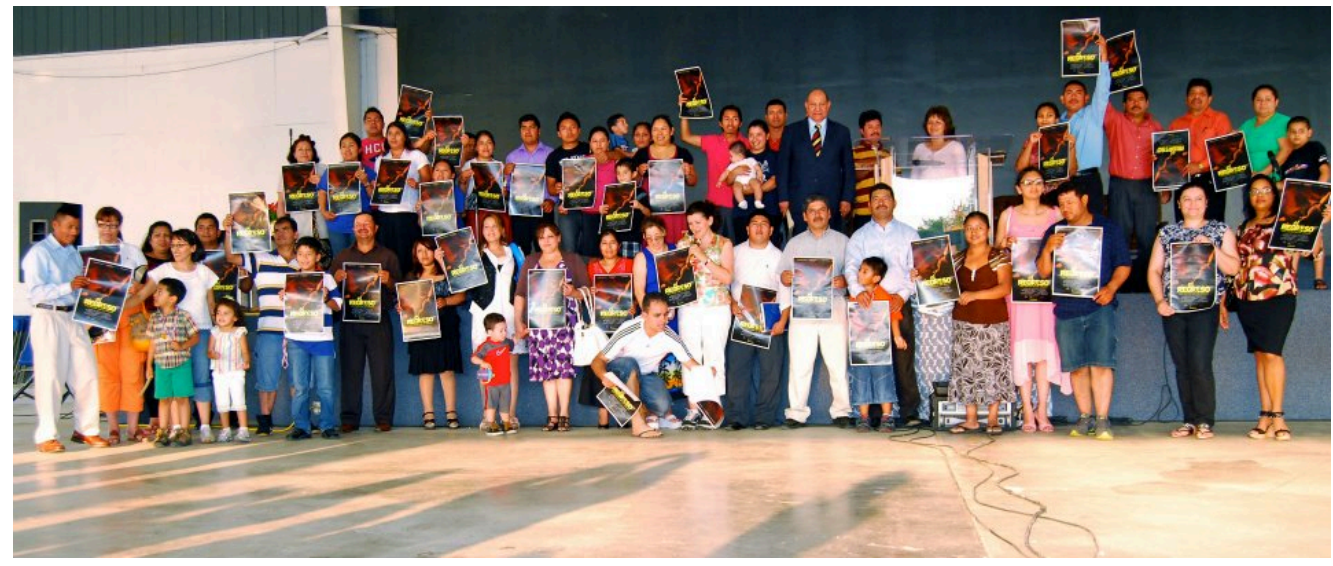

2. Primer Encuentro de Nuevos Creyentes

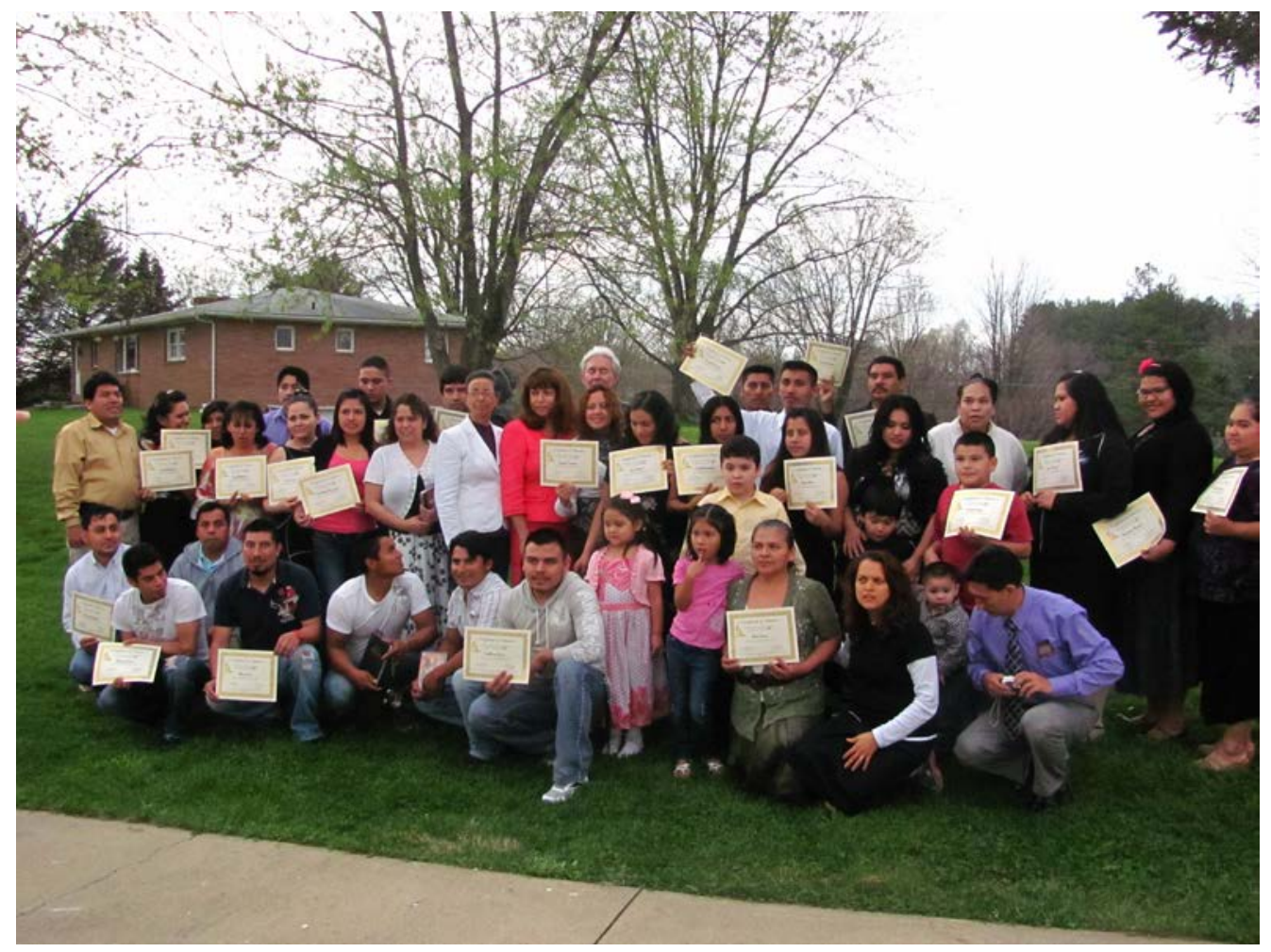


3. Materiales para el alumno del seminario Soy Discípulo, el cual fue uno de los seminarios y talleres que fueron llevados a cabo durante la capacitación para los nuevos conversos.

(Diapositiva 1)

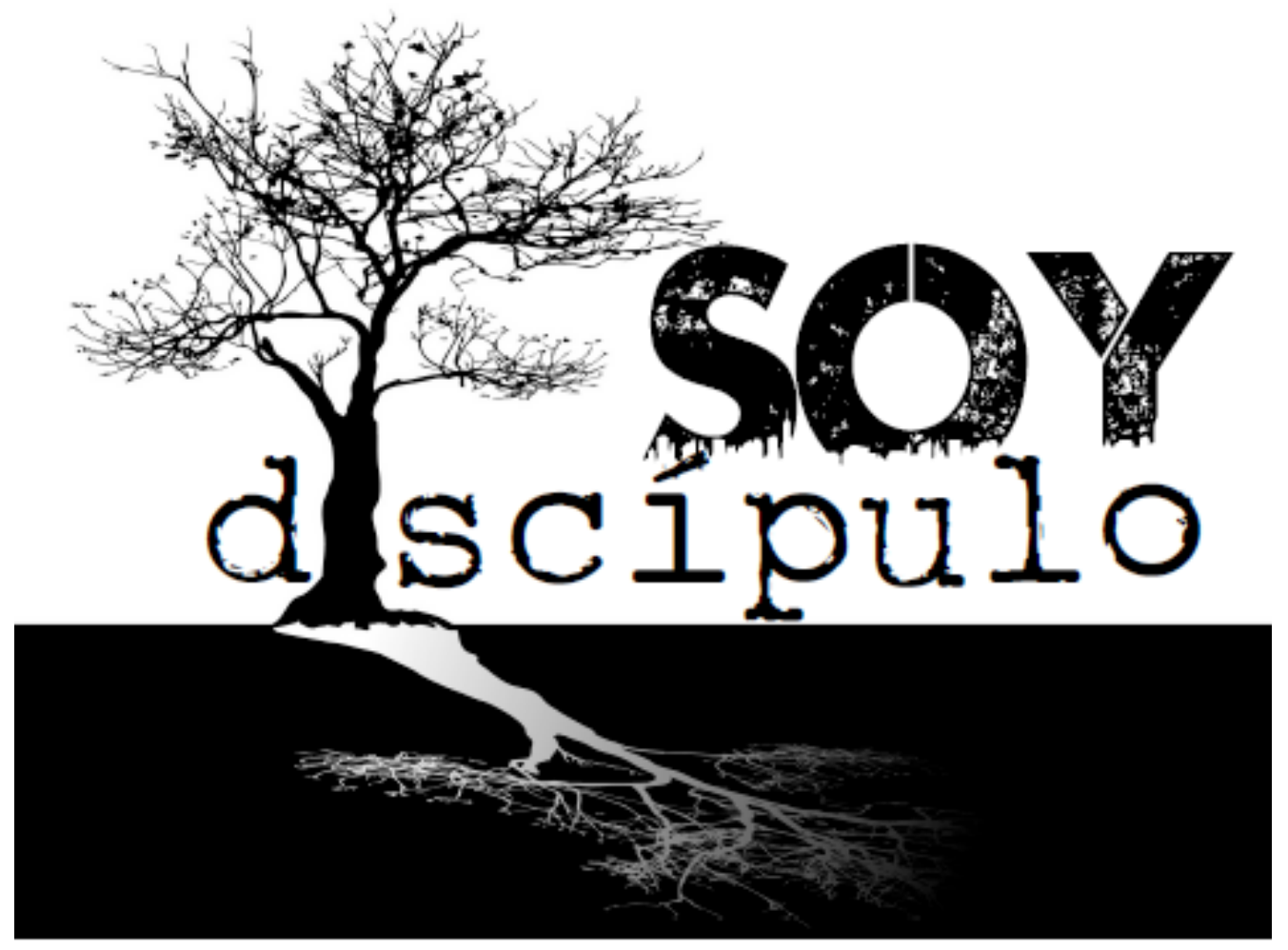

Pr. Walter Castro 
(Soy Discípulo, Diapositiva 2)

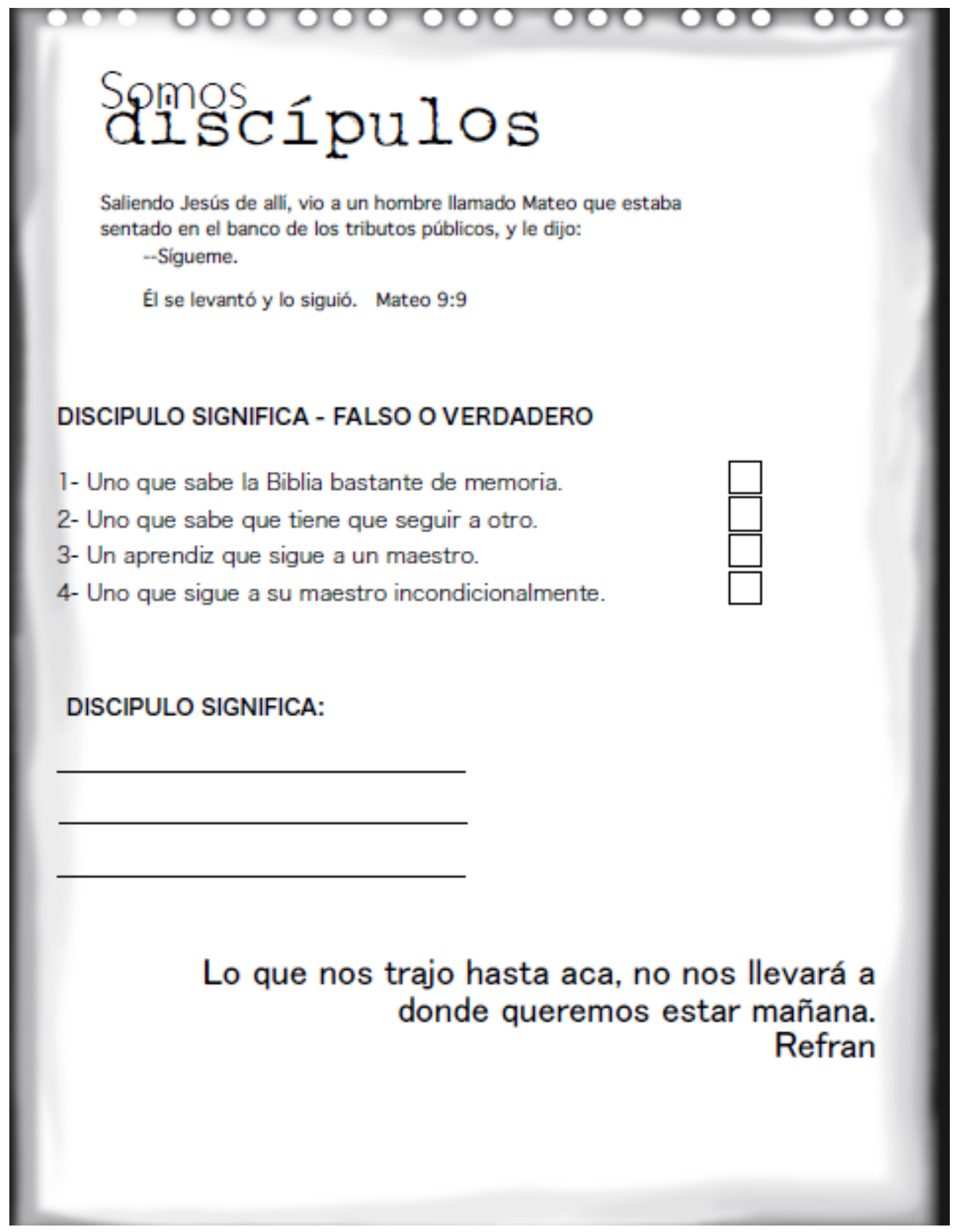


(Soy Discípulo, Diapositiva 3)

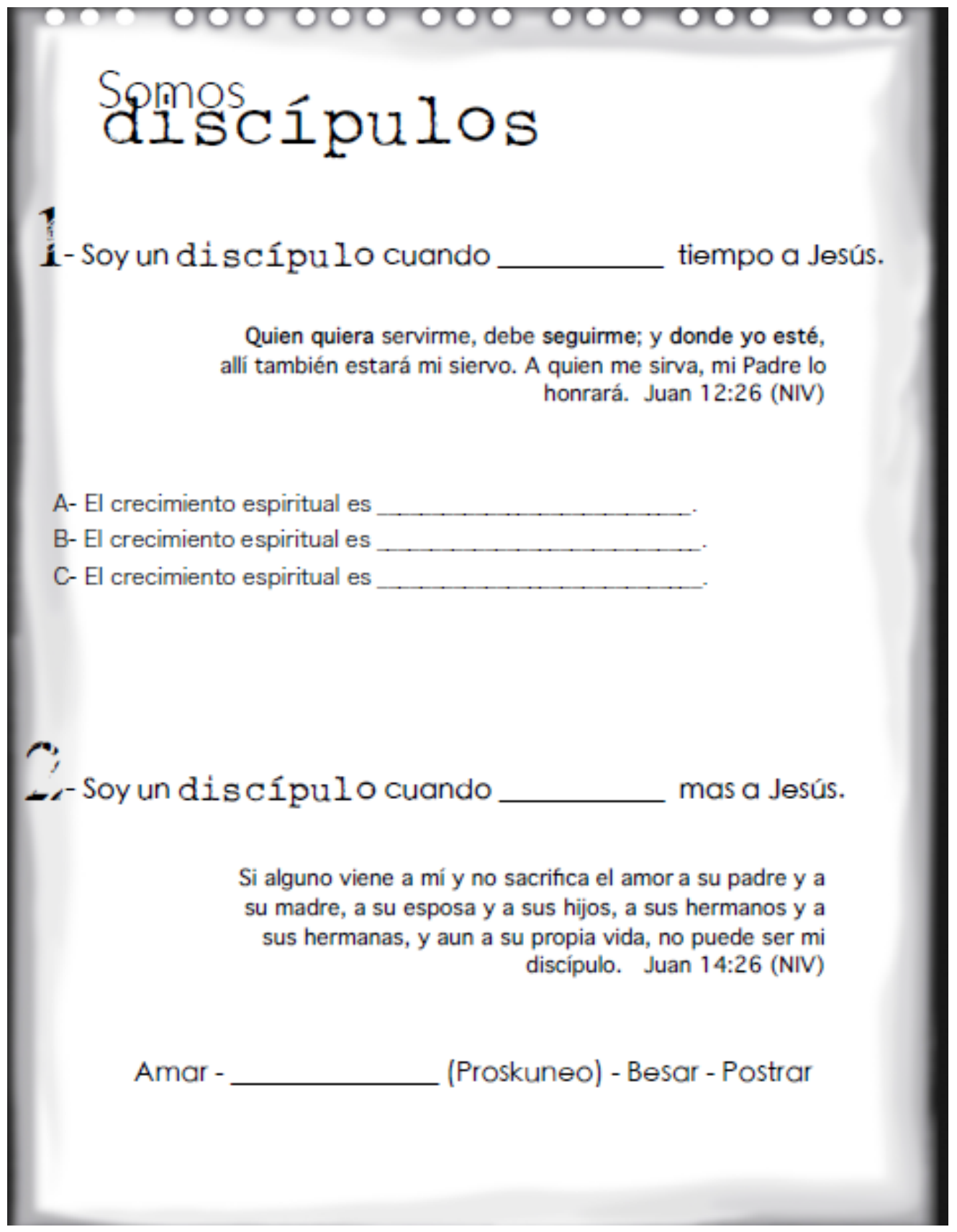


(Soy Discípulo, Diapositiva 4)

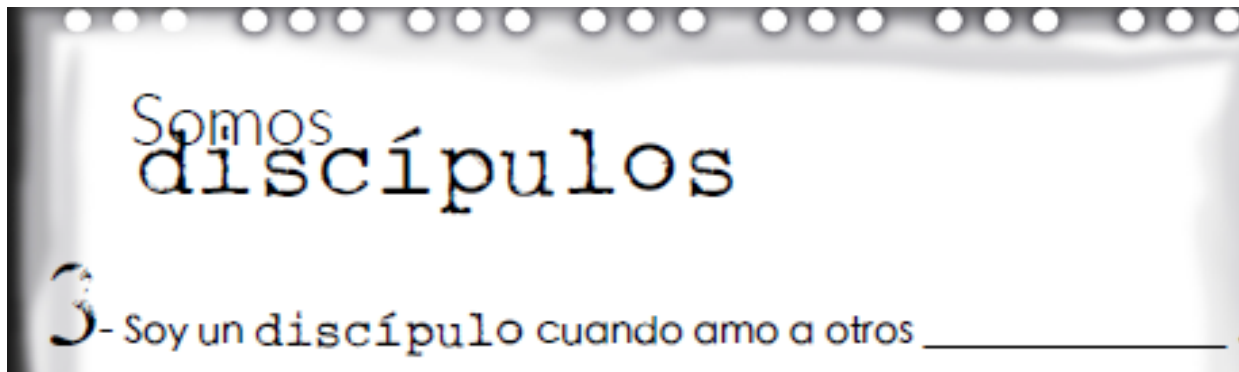

En esto conocerán todos que sois mis discípulos, si tenéis amor los unos por los otros. Juan 13:35 (RV-95)

\section{es rempor ne cambia:}

Iglesias impulsadas por $\longrightarrow$ impulsadas por

2. Soy un discípulo cuando lo que Jesús dice.

Jesús les dijo a los judios que habían creído en él:

- Si ustedes obedecen mis enseñanzas, serán verdaderamente mis discípulos; ${ }^{32}$ y conocerán la verdad, y la verdad los hará libres. Juan 8:31-32 (TLA)

A- Es un proceso

B- Se mide por la y no por el

C- Se basa en la 
(Soy Discípulo, Diapositiva 5)

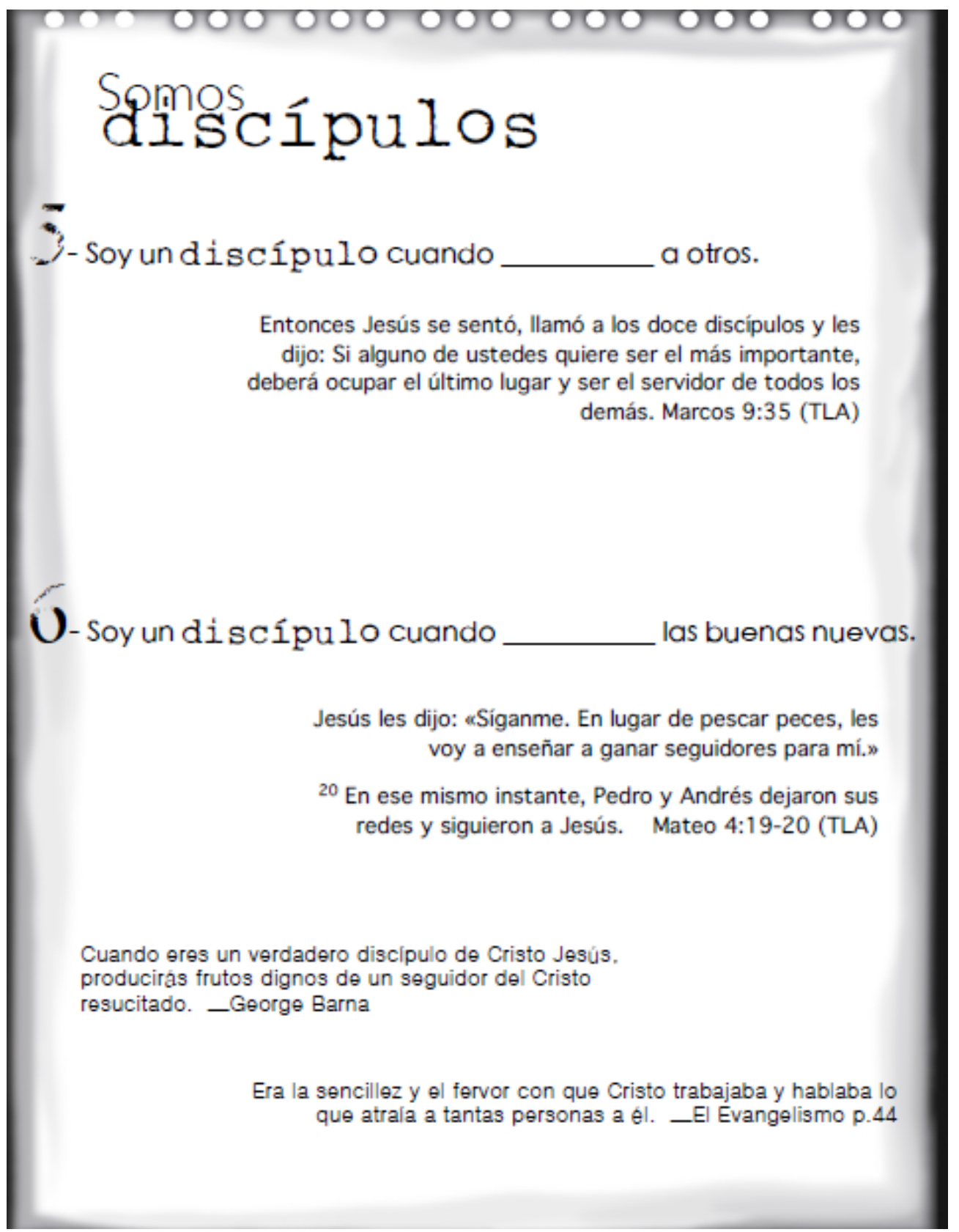


4. Materiales para el alumno del seminario De Enano a Gigante, otra de las herramientas de capacitación para los nuevos conversos.

(Diapositiva 1)

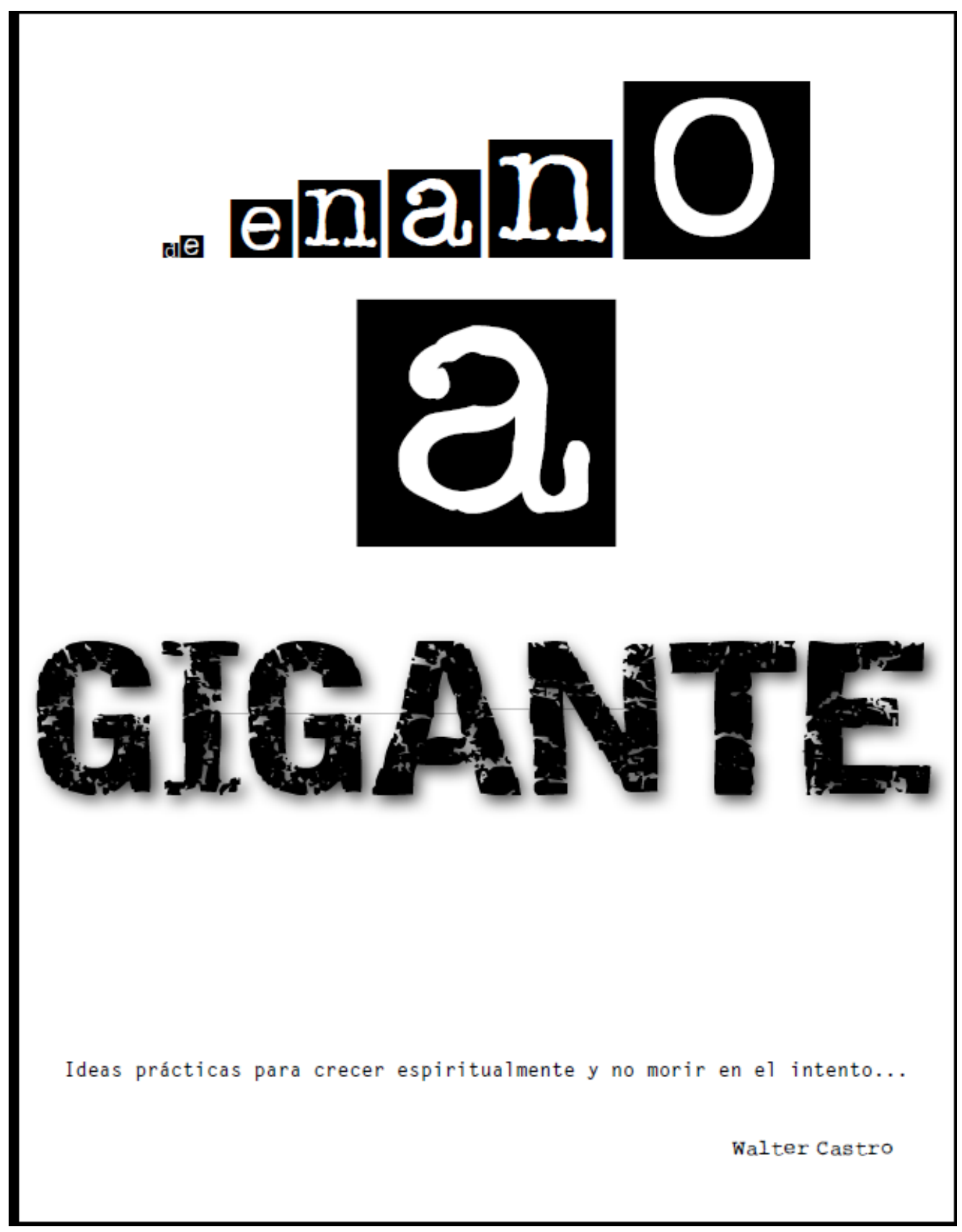


(De Enano a Gigante, Diapositiva 2)

enano chaparro petizo corto mediolitro

para que ya no seamos niños fluctuantes, arrastrados para todos lados por todo viento de doctrina, por los engaños de aquelos que emplean con astucia artimañas engañosas.

Efesios 4:14

MITO

VERDAD

El crecimiento es automático $\longrightarrow$ Es una elección

Puede ser instantaneo $\longrightarrow$ Es gradual

Yendo a la Iglesia $\longrightarrow$ Desarrollando hábitos

Puedo por mi mismo $\longrightarrow$ No puedes sin los demás

Se mide por las creencias $\longrightarrow$ Por creencias y comportamiento

Tu actitud en la Iglesia $\longrightarrow$ Tu actitud en la calle y en tu casa

\section{El Crecimiento Espiritual es:}

Estarás tan cerca de Cristo. como lo quieras estar.

hasta que todos $\underline{\text { leguemos }}$ a estar unidos por la fe $y$ el conocimiento del Hijo de Dios; hasta que _._-__-__ a ser un hombre perfecto, a la medida de la estatura de la plenitud de Cristo:

Efesios 4:13 (RVC)

giggante

errandulan

altate

torre

espigâ 
(De Enano a Gigante, Diapositiva 3)

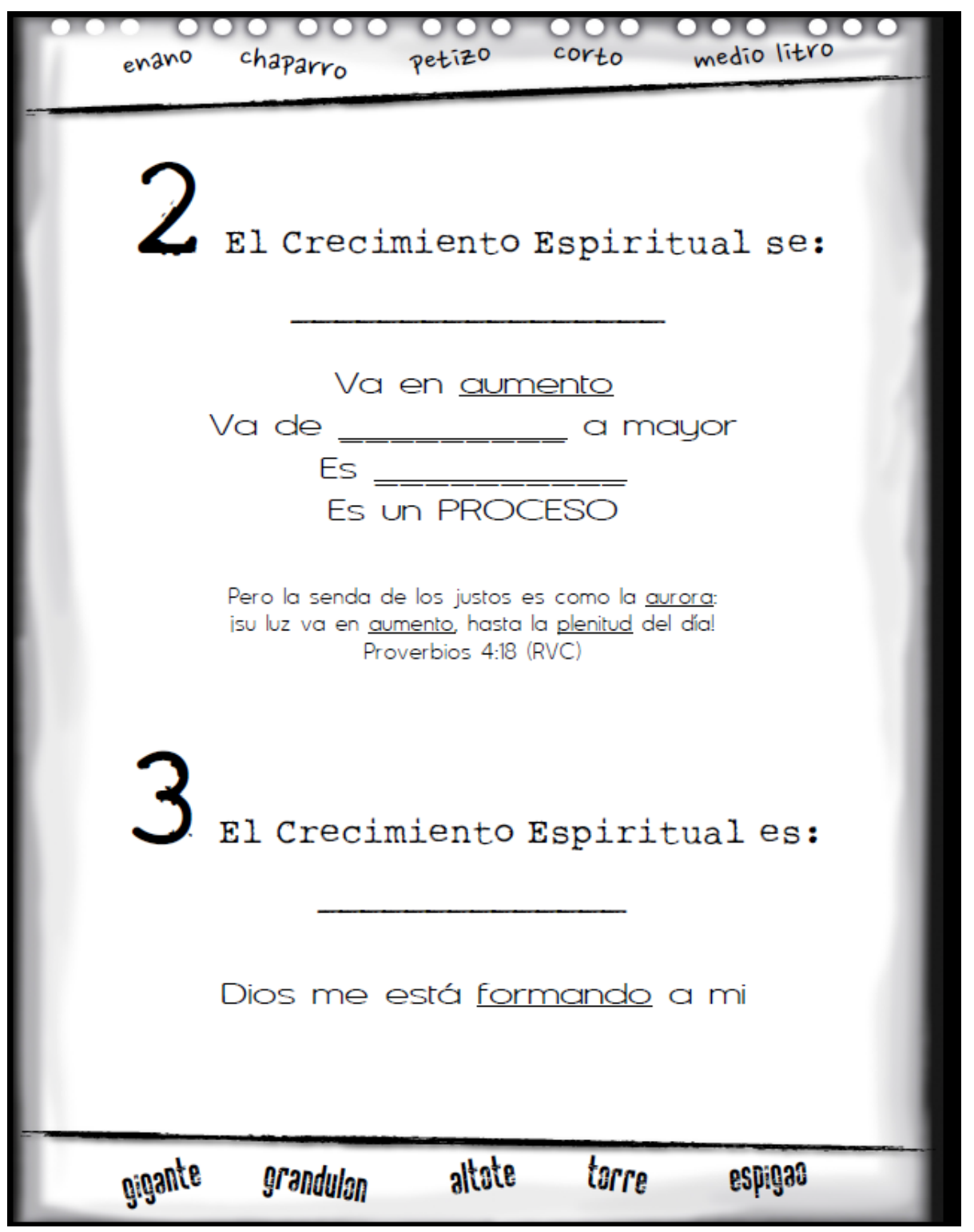


(De Enano a Gigante, Diapositiva 4)

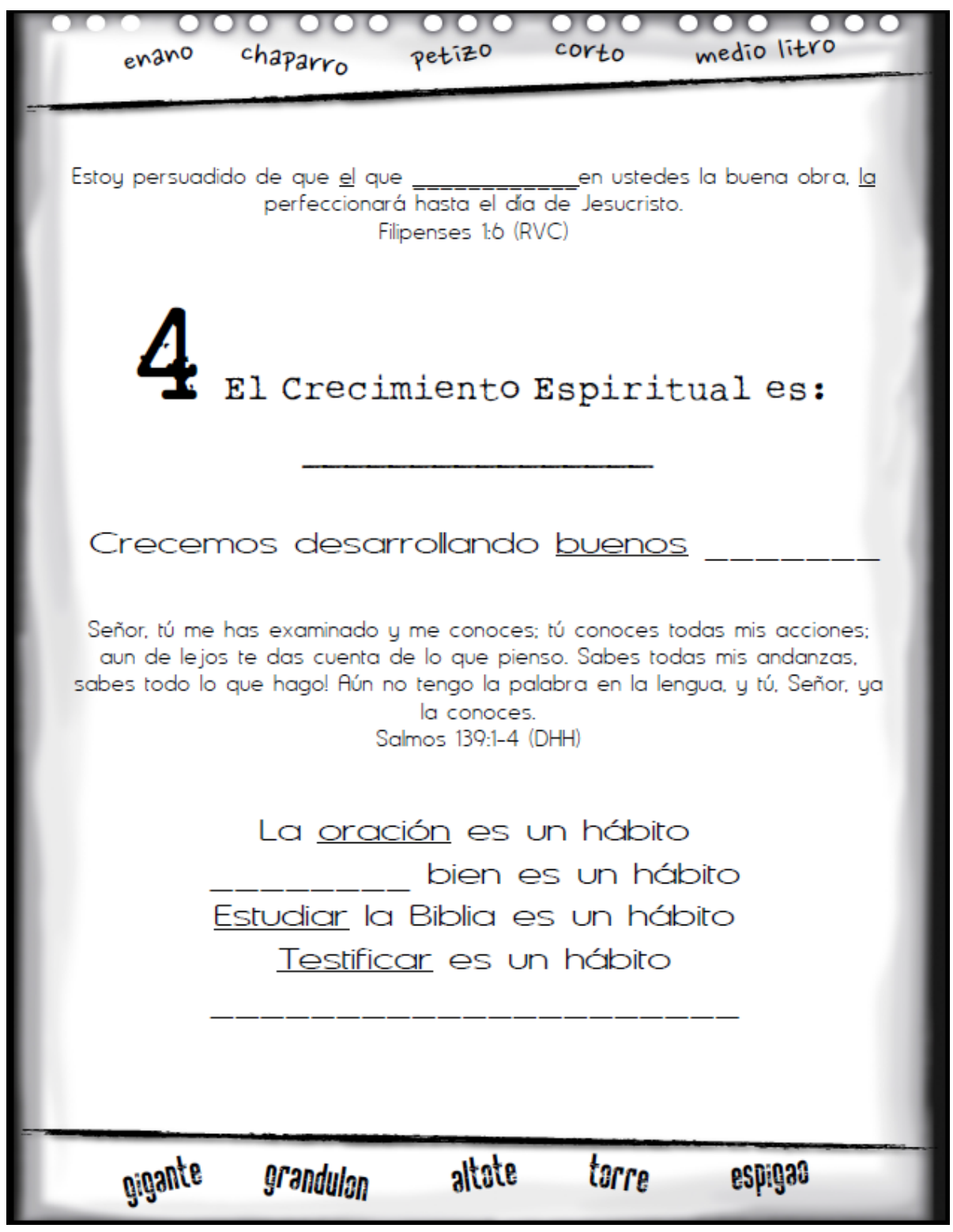


(De Enano a Gigante, Diapositiva 5)

El Crecimiento Espiritual es :
Nenano puedo crecer solo
Necesito a mi nedio litro


(De Enano a Gigante, Diapositiva 6)

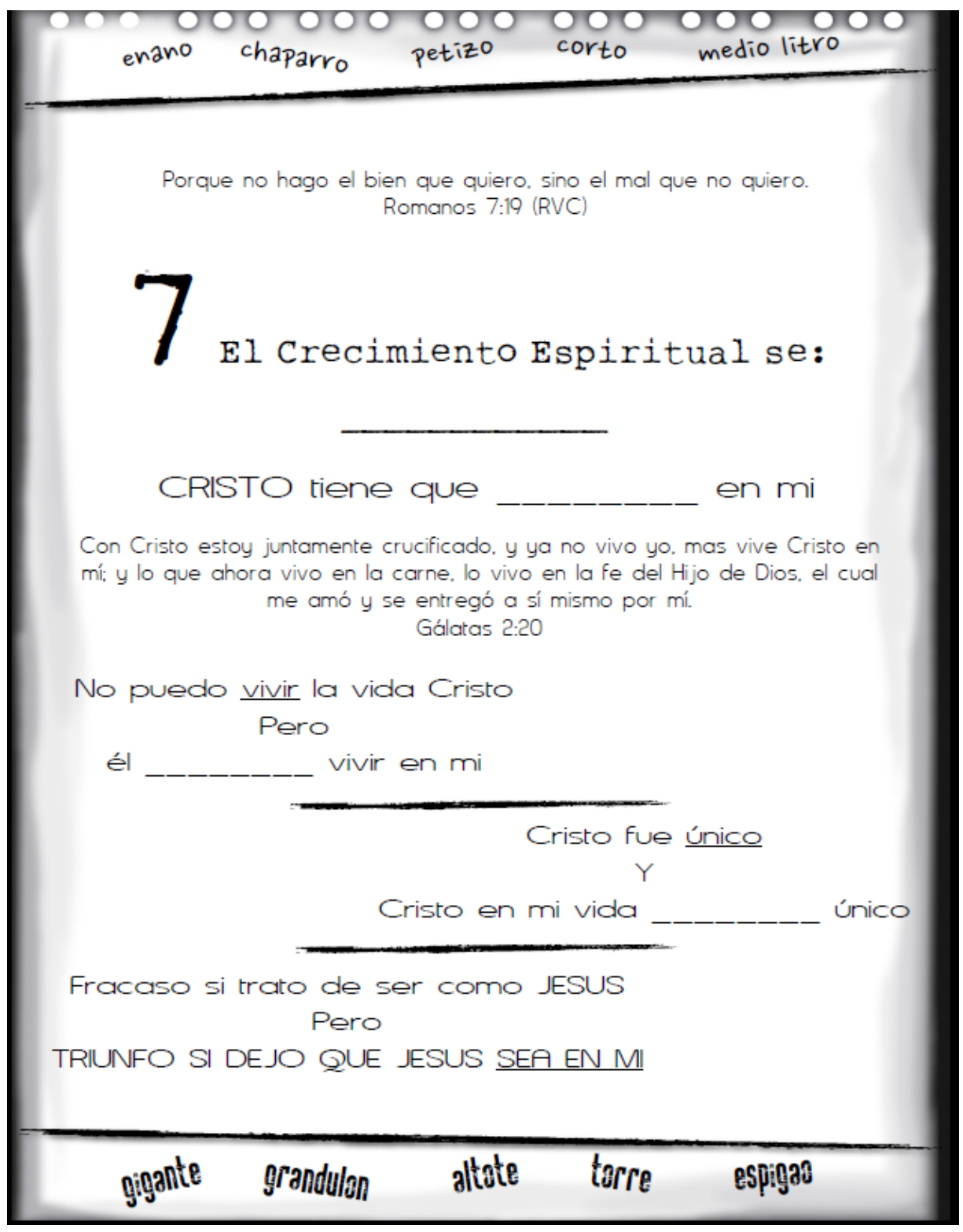


5. Materiales para el alumno del seminario La Peor Batalla de un Líder, un tercer instrumento usado en la capacitación descrita en este proyecto.

(Diapositiva 1)

...con sencillez y sinceridad de Dios..., nos hemos conducido en el mundo,

2 Corintios 2:12

LA PEDR BATALLA

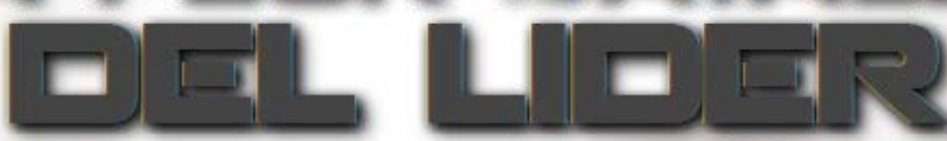

Pr. Walter Castro 
(La Peor Batalla de un Líder, Diapositiva 2)

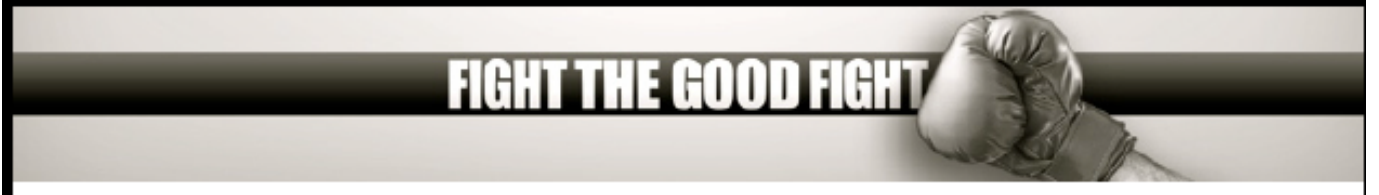 \\ 3REALDADES SOBRE EL LIDERAZGO}

1 Liderazgo es

2. El fundamento del Liderazgo es

3 Lideramos gente que en nosotros.

(Efesios 5:3)

\section{1 - NUNCA TE CONSIDERES}

Por eso, que nadie se sienta seguro de que no va a pecar, pues puede ser el primero en pecar. 1 Corintios 10:12 BLS

Puedo evitar la Tentación:

Puedo evitar la Tentación:

Nunca digas:

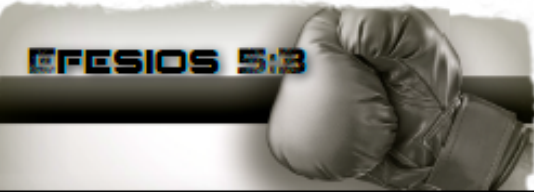


(La Peor Batalla de un Líder, Diapositiva 3)

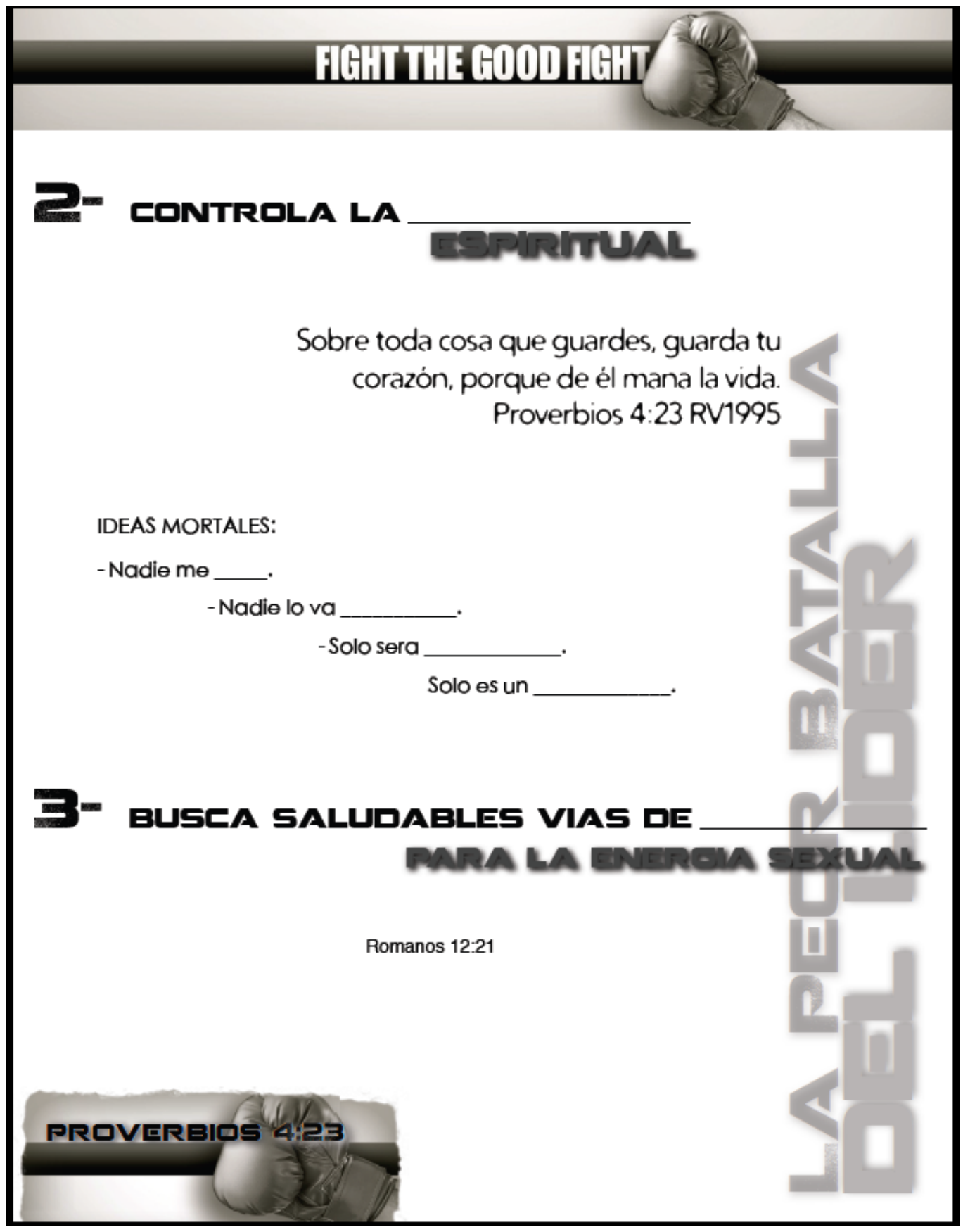


(La Peor Batalla de un Líder, Diapositiva 4)

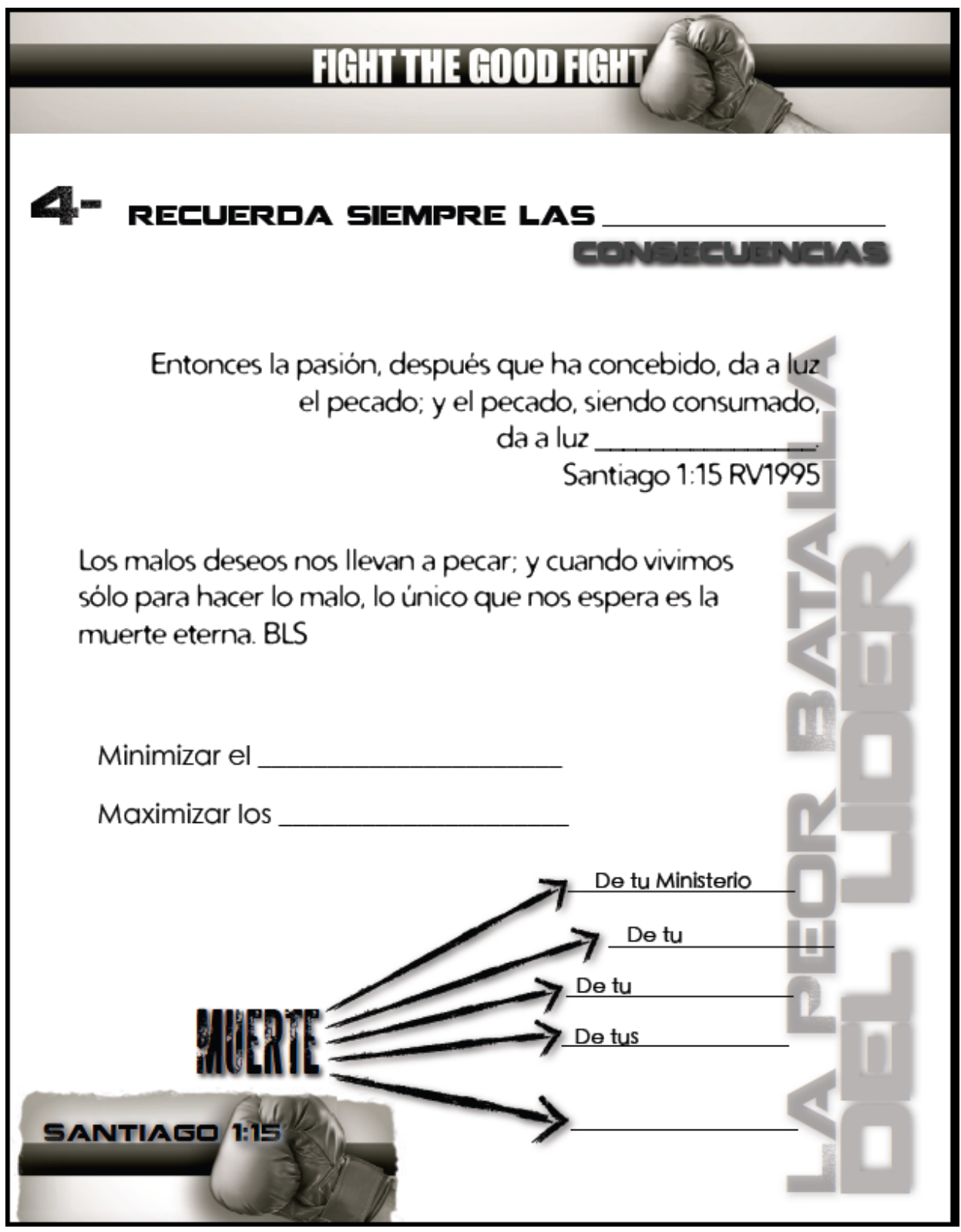




\section{LISTA DE REFERENCIAS}

Abraham, F. (2012). 10 Ways to evangelize on facebook. Retrieved from http://www.charismamag.com/spirit/evangelism-missions/8917-10-ways-toevangelize-on-facebook

Allegheny West Conference. (n.d.). About us. Retrieved November 14, 2014, from http://www.awconf.org/article/5/about-us

Allegheny West Conference. (n.d.). Allegheny West Conference : Multicultural. Retrieved November 21, 2014, from http://alleghenywest.adventistchurchconnect.org/article/42/departmentsministries/multicultural

Abraham, W. (1989). The logic of evangelism. Grand Rapids, MI: Eerdmans.

Allen, C. (1969). The broadman Bible commentary. Nashville, TN: Broadman Press.

Asociación General de los Adventistas del Séptimo Día. (1984). Testificando por Cristo. Miami, FL: Departamento de actividades laicas.

Arn, W. (1979). The Pastors Church Growth Handbook. Pasadena, CA: Church Growth.

Arndt, W. \& Wilbur, G. F. (eds). (1964). A Greek-Enlgish lexicon of the New Testament and other early christian literature. Chicago, IL: University of Chicago Press.

Anderson, L. Duane. (n. d.), Crossing barriers for evangelism. Retrieved November 14, 2014, from http://www.aibi.org/training/cbfevan.pdf

Anderson, L. (1992). A church for the 21st century. Minneapolis, MN: Bethany.

Anderson, J., \& Rainie, L. (2010). Millennials will make online sharing in networks a lifelong habit | Pew research center's internet \& american life project. Retrieved from http://www.pewinternet.org/2010/07/09/millennials-will-make-onlinesharing-in-networks-a-lifelong-habit/

Ausejo, S. de. (1981). Diccionario de la Biblia. España: Editorial Herder.

Barcousky, L. (2011). Hispanic population shows modest climb in region, Pittsburgh Post-Gazette. Retrieved from http://www.postgazette.com/local/region/2011/03/10/Hispanic-population-shows-modest-climbin-region/stories/201103100734

Barna, G. (1995). Evangelism that works. Ventura, CA: Regal Books. 
Barna, G. (2000). Growing true disciples. Ventura, CA: Issachar Resources

Barna, G. (2000). Re-churching the unchurched. Ventura, CA: Issachar Resources.

Barnes, S. (2012). Intimacy requires commitment. Retrieved from www.sethbarnes.com/?filename=intimacy-requires-commitment

Baumgartner J. H. (1960). Meet the Twelve. Minneapolis, MN: Augsburg.

Bechtle, M. (2006). Evangelism for the rest of us: Sharing Christ within your personality style. Grand Rapids, MI: Baker Books.

Benner, D. G., \& Hill, P. C. (eds.). (1999). Baker encyclopedia of psychology \& counseling. Grand Rapids, MI: Baker Books.

Bisagno, J. R. (2002). Principle preaching: How to create and deliver purpose driven sermons for life applications. Nashville, TN: Broadman \& Holman.

Black, B. W. (1995). The Spiritual Gifts Handbook. Neptune, NJ: Loizeaux Brothers.

Bogaert, P. (1993). Diccionario Enciclopedico de la Biblia. España: Editorial Herder.

Borchert, G. L. Dynamics of Evangelism. Waco, TX: Word Books.

Botha, E. J. (1991). Jesus and the Samaritan Woman. Netherlands: E.J. Brill.

Bretherton, L. (2006). Hospitality as holiness: Christian witness amid moral diversity. England: Ashgate.

Bright, B. (1998). Testificando sin temor. Miami, FL: Unilit.

Bright, B. (n.d.). Witnessing and prayer. Retrieved on December 31, 2014 from http://www.cru.org/train-and-grow/classics/10-basic-steps/7-the-christian-andwitnessing.5.html

Browser Media, Socialnomics, \& MacWorld (2014). Social networking statistics | Statistic brain. Retrieved from http://www.statisticbrain.com/social-networkingstatistics/

Bruce A. B. (1983). Training of the twelve. New York, NY: A. C. Armstrong and Son.

Bugg, C. B. (2003). Witness of a fragile servant: A personal look at preaching. Macon, GA: Smyth \& Helwys.

Bullón, A. (2010). Sharing Jesus is everything. Nampa, ID: Pacific Press. 
Burg G. M. (2000). The NIV Application Commentary. Grand Rapids, MI: Zondervan.

Burrill, R. (1993). Revolution in the church. Fallbrook, CA: Hart Research Center.

Burrill, R. (2011). Revolution in the church of the 21 century. Fallbrook, CA: Hart Research Center.

Byungjoon, M. (2010). Evangelism 101: How to witness the gospel to non-believers. South Korea: Hot Books.

Byung-Yang M. (1995). Stewardship training for the maturity of the church (Unpublished master’s thesis). Hanshin University, Osan, South Korea.

Campbell, J. B. (1987). Rethinking evangelism, a theological approach. Philadelphia, PA: Westminster Press.

Callahan, K. L. (1983). Twelve keys to an effective church. San Francisco, CA: Harper and Row.

Chan, F., \& Beuving, M. (2012). Multiply: Disciples making disciples. Colorado Springs, CO: David C Cook.

Chang, Yijoon. (2011). Equipping the laity through discipleship training in a Korean Church (Unpublished doctoral dissertation). Asbury Theological Seminary, Wilmore, KY.

Christian, D. C. (1992). El líder: Dones y funciones. Miami, FL: Asociación Publicadora Interamericana.

Christensen, M. J. (2000). Equipping the saints: Mobilizing laity for the ministry. Nashville, TN: Abingdon Press.

Chronic, D. (2009). What do we mean by ‘Evangelism? Retrieved from http://www.wordmadeflesh.org/the-cry/the-cry-vol-9-no-4/evangelism/

Coleman, R. E. (1973). They meet the master: A study manual on the personal evangelism of Jesus. Huntington Valley, PA: Christian Outreach.

Coleman, R.E. (1986). Evangelism on the cutting edge. Old Tappan, NJ: Fleming Revell.

Coleman, R. E. (1996). The master plan of evangelism. Grand Rapids, MI: Baker Books House Company. 
Collins, Martin. (1997). You are my witnesses. Retrieved from http://www.bibletools.org/index.cfm/fuseaction/Library.sr/CT/ARTB/k/310\#ixzz2 8QUBVdDv

Collinson, S. W. (2004). Making Disciples. United Kingdom: Paternoster.

Colson, H., \& Rigdon, R. (1969). Understanding your church's curriculum. Riverside, CA: Broadman Press.

Cooter E. (2013). Ministry Matters ${ }^{\mathrm{TM}}$ | Articles | Fresh expressions: Evangelism for our culture. Retrieved from http://www.ministrymatters.com/all/article/entry/4004/fresh-expressionsevangelism-for-our-culture

Cox, D. (1998). Think big, think small groups. Watford, England: Personal ministries.

Cox, D. (2001). Future church. England: The Stanborough.

Crandall, R. K. (1999). The contagious witness. Nashville, TN: Abingdon.

Dakin, P. (2014). Social media affecting teens' concepts of friendship, intimacy - Health. Retrieved from http://www.cbc.ca/news/health/social-media-affecting-teensconcepts-of-friendship-intimacy-1.2543158

Daniel, L. (2006). Tell it Like it is: Reclaiming the practice of testimony. Herndon, VA: Alban Institute.

Davidson, D. (2013). Intimacy with God as an inviting aspect of pentecostalism's word, deed, and power expression of the good news gospel. Asian Journal of Pentecostal Studies, 16(1), 61-75.

http://search.ebscohost.com/login.aspx?direct=true\&db=a9h\&AN=91567461\&sit $\mathrm{e}=$ ehost-live

Dunavant, D. (2006). From membership to discipleship. Lincoln, NE: AdventSource.

Dunbar, A. C. (1992). The bible instructor: A manual for the training of lay Bible instructors. (Unpublished doctoral dissertation). Andrews University, Berrien Springs, MI.

Dupont, J. (1967). The salvation of the gentiles. New York, NY: Paulist Press.

Early, D., \& Wheeler, D. (2010). Evangelism is: How to share Jesus with passion and confidence. Nashville, TN: B\&H Academic Publishing Group. 
EMarketer (2013). Social networking reaches nearly one in four around the World eMarketer. Retrieved from http://www.emarketer.com/Article/Social-NetworkingReaches-Nearly-One-Four-Around-World/1009976\#wWVAOsm8zku31IOO.99

Emis, L. (1978). The lost art of disciple making. Grand Rapids, MI: Zondervan.

Espasa-Calpe (2005). Capacitar. Retrieved from http://www.wordreference.com/definicion/capacitar

Finley, M. (2010). Reavívanos otra vez. Nampa, ID: Pacific Press.

Fitch, F. (2007). Evangelism or witness?: The necessary turn for the missional church. Retrieved from http://www.reclaimingthemission.com/?p=115

Foote, G. (1953). The transformation of the twelve. Nashville, TN: Abingdon Press.

Fontaine, M. (2014). Serve one another in love. Retrieved from http://www.thefamilyinternational.org/en/viewpoints/views-issues/12/

Galloway, D. E. (1986). 20/20 Vision: How to create a successful church with Lay pastors and cell groups. Portland, OR: Scott.

Gangel, K. O. (2000). John (Vol. 4). Nashville, TN: Broadman \& Holman.

George, C. F., \& Bird, W. (1994). The coming church revolution: Empowering leaders for the future. Grand Rapids, MI: F.H. Revell.

Global Philadelphia. (2013). 200 Years of latino history in Philadelphia: An illuminating profile of a small populace in the Delaware Valley. Retrieved from http://globalphiladelphia.org/news/200-years-latino-history-philadelphiailluminating-profile-small-populace-delaware-valley

Graham, B. (2009). Make Your Life a Witness for Christ. Retrieved from http://www.christianpost.com/news/make-your-life-a-witness-for-christ-40068/

Gray, D., \& Gray, M. (2003). You are My Witness: Sharing Jesus in the 21st Century: a Practical Training Guide. Keene, TX: Seminars Unlimited.

Green, M. (2004). Thirty Years That Changed the World. Grand Rapids, MI: Eerdmans.

Hall, D. A. (2008). The Witnessing Church. Lincoln, CA: Begin Again Living Ministries.

Harris, R. G. Mission in the Gospels. United Kingdom: Epworth.

Hendrix J., \& Householder, L. (1977). The Equipping of Disciples. Nashville, TN: Broadman Press. 
Henrichsen, W. A. (1976). El discípulo se hace, no nace. España: Clie.

Hispanic chamber of commerce. (n.d.). Hispanics in the region - Greater Philadelphia Hispanic Chamber of Commerce, Philadelphia, PA. Retrieved from http://philahispanicchamber.org/about_us/Hispanics_in_the_Region.aspx

Hispanics and latinos in Virginia. (2011). Virginia Is for lovers. Retrieved from http://www.virginia.org/HispanicsandLatinosinVirginia/

Horn S. H. (1960). Seventh-day Adventist Bible dictionary. Washington, DC: Review and Herald.

Hunter, K. R. (1994). Foundations for church growth. Corunna, IN: Church growth center.

Hunt, J. (1993). Let it grow. Grand Rapids, MI: Baker.

Hunt, J., \& Mays. (2010). L. Disciple-Making Teachers. Loveland, CO: Vital Ministry.

Hunter, T. (2009). Christianity beyond belief. Downers Grove, IL: Inter Varstiy Press.

Hull, B. (1990). The disciple-making church. Grand Rapids, MI: Fleming H. Revell.

Hull, B. (1990). New century disciplemaking, applaying Jesus' ideas for the future. Grand Rapids, MI: Fleming H. Revell.

Hull, B. (1999). The disciple-making pastor. Grand Rapids, MI: Fleming H. Revell.

Hull, B. (2007). The disciple-making pastor: Leading others on the journey of faith. Grand Rapids, MI: Baker Books.

Hybels, B., \& Mittelberg, M. (1994). Becoming a contagious Christian. Grand Rapids, MI: Zondervan.

Jensen, P. (2009). Power to witness. Retrieved from http://phillipjensen.com/articles/power-to-witness/

Jones, S. J. (2003). The evangelistic love of God \& neighbor: A theology of witness and discipleship. Nashville, TN: Abingdon.

Juárez, A. \& Acosta, P. F. (1987). Arte de ganar almas. Mexico: Pacific Press de Mexico.

Kammerdiener, D. R. (1975). El crecimiento de la iglesia. El Paso, TX: Casa Bautista de Publicaciones. 
Kaung, S. (2014). El ministerio del nuevo pacto - aguas vivas. Retrieved from http://www.aguasvivas.cl/multimedia-archive/el-ministerio-del-nuevo-pacto/

Kim, K. (2012). Introducing the new statement on mission and evangelism. International review of mission, 101(2), 316-321.

Kinnaman, D. (2013). How technology is changing millennial faith. Retrieved from https://www.barna.org/barna-update/millennials/640-how-technology-ischanging-millennial-faith\#.Uw1_M16prcI

Knight, G. R. (1994). The abundant Bible amplifier: Matthew. Boise, ID: Pacific Press.

Kuhne, G. W. (1977). Dinámica de evangelismo. España: Clie.

Kuhne, G. W. (1980). La dinámica de adiestrar discípulos. Nashville, TN: Editorial Caribe.

Kummer, P. K. (1998). West Virginia. Mankato, MN: Capstone High/Low Books.

Knowles, G. E. (1981). How to help your church grow. Washington, DC: Review and Herald.

Laurie, G. (2002). New believer's guide to effective christian living. Carol Stream, IL: Tyndale House.

Lange, J. P., \& Schaff, P. (2008). A commentary on the Holy Scriptures: John. Bellingham, WA: Logos Bible Software.

Little, P. E. (2006). How to give away your faith. Grove, IL: Inter Varstiy Press.

Logan, R. E. (1989). Beyond church growth. Grand Rapids, MI: Fleming H. Revell.

Logan, R. E. The master plan of evangelism. Grand Rapids, MI: Fleming H. Revell.

Long, T. G. (2004). Testimony: Talking uurselves into being christian. San Francisco, CA: Jossey-Bass.

Long, T. G. (2005). The witness of preaching. Louisville, KY: Westminster John Knox.

Lorch L. (2013). Nurturing new believers. Retrieved from http://powertochange.com/experience/spiritual-growth/nurturing/

Malphurs, A. (2009). Strategic disciple making: A practical tool for successful ministry. Grand Rapids, MI: Baker Books. 
Mallory, S. (2001). The equipping church: Serving together to transform lives. Grand Rapids, MI: Zondervan.

Mallory, S., \& Smith, B. (2001). The equipping church guidebook. Grand Rapids, MI: Zondervan.

Mann, L., y Mendoza, W. (1996). El discipulado, transferencia de vida. España: Clie.

Manson, T. W. (1959). The teaching of Jesus. England: University Press.

Marsh, C. M. (1997). Evangelism is--. Louisville, KY: Geneva Press.

Marshall, H., \& Peterson, D. (1998). Witness to the gospel. United Kingdom: William B. Eerdmans.

Martin, F. (2006). Ancient christian commentary on scripture. Downers Grove, IL: Inter Varsity Press.

Maynard-Reid, P. U. (1997). Complete evangelism the Luke-Acts model. Scottdale, PA: Herald Press.

McClendon, J. (2000). Witness. Nashville, TN: Abingdon.

McClung, F. (1990). Basic discipleship. Downers Grove, IL: Inter Varsity Press.

Mccumber, W. E. (1975). Beacon Bible exposititions, Matthew. Kansas City, MO: Beacon Hill Press.

McDonald, A. (2013). The protestant standard: 10 Tips for using Facebook effectively in Christian witness. Retrieved from http://protestantstandard.blogspot.com/2013/05/10-tips-for-using-facebook-effectively.html

McDonald, G. (2004). The disciple making church: From dry bones to spiritual vitality. Grand Haven, MI: FaithWalk.

McGavran D., \& Hunter, G. (1986). Creative leadership series. Nashville, TN: Abingdon Press.

Mhando, H. (2000). A strategy for pastors to mobilize and equip lay members for evangelism in Tanzania (Unpublished doctoral dissertation). Andrews University, Berrien Springs, MI.

Miano, T., \& Slick, M. (n.d.). How to witness to friends and family | Witnessing to family. Retrieved December 3, 2014 from http://carm.org/how-witness-familyfriends 
Miles, D. (1982). Master principles of evangelism. Nashville, TN: Broadman Press.

Menzer, H., \& Broschat, B. (n.d.). Helping new believers grow. Retrieved December 3, 2014, from http://www.cru.org/train-and-grow/mentoring/helping-newbelievers.html

Newman, R. (2011). Bringing the gospel home: Witnessing to family members, close friends, and others who know you well. Wheaton, IL: Crossway.

Norton, R. (2001). La persuasión cristiana, el arte de ganar almas. Berrien Springs, MI: Kerygma.

Norton, R. (2005). Evangelism principles \& practice. Berrien Springs, MI: Kerygma.

Ola, J. A. (1989). Training for evangelism among the Yorubas of Nigeria (Unpublished doctoral dissertation). Andrews University, Berrien Springs, MI.

Ogden, G. (1998). Discipleship essentials: A guide to building your life in christ. Downers Grove, IL: InterVarsity.

Ogden, G. (2003). Transforming discipleship: Making disciples a few at a time. Downers Grove, IL: InterVarsity Press.

Ohio History Central. (n.d.). Hispanic Ohioans. Retrieved December 3, 2014 from http://www.ohiohistorycentral.org/w/Hispanic_Ohioans?rec=3257

Ortlund, R. C. (1977). Señor, haz de mi vida un milagro. España: Clie.

Pew Hispanic. (n.d.). State and County Databases. Retrieved November 21, 2014, from http://www.pewhispanic.org/states/state/oh/

Pfeiffer, C. F., \& Harrison, E. F. (1962). The Wycliffe Bible commentary. Chicago, IL: Moody Press.

Phillips, K. (2008). Id y haced discípulos. Eugene, OR: Wipf and Stock.

Poe, H. L. (2001). Christian witness in a postmodern world. Nashville, TN: Abingdon.

Rand, R. (1988). Won by one. Ventura, CA: Regal Books.

Real Academia Española. (2011). Diccionario de la lengua española. Retrieved from http://lema.rae.es/drae/?val=testificar

Redford, D. (2007). The New Testament church: Acts-Revelation (Vol. 2). Cincinnati, $\mathrm{OH}$ : Standard. 
Richards, J. S. (2014). Hispanics lead population growth in Ohio. Retrieved from http://www.dispatch.com/content/stories/local/2014/06/26/hispanics-lead-statepopulation-increases.html.

Richardson, R. (2006). Reimagining evangelism. Downers Grove, IL: IVP Books.

Robinson, S. J. (2004). Opening up 1 Timothy. Leominster, MA: Day One Publications.

Robinson, A. B., \& Wall, R. W. (2006). Called to be church: The book of Acts for a new day. Grand Rapids, MI: W.B. Eerdmans.

Roehl, T. (2008). El fundamento bíblico del entrenamiento. Retrieved from http://ag.org/enrichmentjournal_sp/201202/201202_028_Biblical_foundations.cf $\mathrm{m}$

Samaan, P. G. (1995). El método de Cristo para testificar. Argentina: Casa Editora.

Samaan, P. G. (1999). Christ's Way of making disciples. Hagerstown, MD: Review and Herald.

Schuller, R. H. (1975). Su iglesia tiene posibilidades. España: Clie.

Schuller, R. H. (1976). Serás lo que quieras ser. Miami, FL: Vida.

Schneider, F. (2000). Evangelism for the fainthearted. Grand Rapids, MI: Kregel.

Schwarz, C. A. (1996). Las 8 características básicas de una iglesia saludable. España: Clie.

Schwarz, C. A. (1999). Cambio de paradigma en la iglesia. España: Clie.

Schwarz, C. A. (2001). Los 3 colores del ministerio. España: Clie.

Schwarz, C. A. (1999). Desarrollo natural de la iglesia en la práctica. España: Clie.

Shrum, K. (2010). What evangelism is not. Retrieved from http://www.christianpost.com/news/what-evangelism-is-not-46967/

Sisson, R. (1984). Prepárate para evangelizar: Un programa de evangelización personal. El Paso, TX: Casa Bautista.

Sjogren, S. (2001). 101 ways to reach your community. Colorado Springs, CO: Navpress Books. 
Sjogren, S. (2007). Conspiracy of kindness: A unique approach to sharing the love of Jesus. Ventura, CA: Regal Books.

Skreslet, S. H. (2006). Picturing christian witness: New Testament images of disciples in mission. Grand Rapids, MI: William B. Eerdmans.

Smith, A. (2014). 6 new facts about Facebook. Retrieved from http://www.pewresearch.org/fact-tank/2014/02/03/6-new-facts-about-facebook/

Smith, A. (1958). The twelve christ chose. New York, NY: Harper \& Brothers.

Social Media. (2013). Networking reaches nearly one in four around the world. Retrieved from http://www.emarketer.com/Article/Social-Networking-Reaches-Nearly-OneFour-Around-World/1009976\#wWVAOsm8zku31IOO.99

Sonnenberg, K. (2008). Preaching as spirit directed witness. Retrieved from http://scholars.wlu.ca/cgi/viewcontent.cgi?article=1873\&context=etd

Stein, R. H. (1992). Luke. Nashville, TN: Broadman \& Holman.

Steinborn, M. J. (1987). Can the pastor do It alone? Ventura, CA: Regal Books.

Stedman, R. (1976). Body life. Glendale, CA: Regal Books.

Stotts, J. R. (2010). The radical disciple, Downers Grove, IL: Inter Varsity Press.

Stout, K. B. (1983). Developing, implementing, and testing a training program for lay pastoral ministry in selected churches of the Columbia Union Conference of Seventh-day Adventists (Unpublished doctoral dissertation). Andrews University, Berrien Springs, MI.

Strobel, L., \& Mittelberg, M. (2009). The unexpected adventure: taking everyday risks to talk with people about Jesus. Grand Rapids, MI: Zondervan.

Stronstad, R. (2012). The charismatic theology of St. Luke: Trajectories from the Old Testament to Luke-Acts. Grand Rapids, MI: Baker Academic.

Strogatz, S. (2012). Friends you can count on. Retrieved from opinionator.blogs.nytimes.com/2012/09/17/friends-you-can-count-on/

Sweet, L. I., \& Viola, F. (2010). Jesus manifesto: Restoring the supremacy and sovereignty of Jesus Christ. Nashville, TN: Thomas Nelson.

Tangeman, G. E. (1996). The disciple making church in the 21st Century. Washington, PA: Christian Literature Crusade. 
Towns, E. L. (1990). An inside look at 10 of today's most innovative churches. Ventura, CA: Regal.

Trueblood, E., \& Newby, J. R. (1979). The best of Elton Trueblood: An anthology. Nashville, TN: Impact Books.

Wagner, C. P. (1971). Strategies for church growth. Ventura, CA: Regal.

Wagner, C. P. (1980). Su iglesia puede crecer. España: Clie.

Wagner, C. P. (1980). Sus dones espirituales. España: Clie.

Wagner, C. P. (1981). Church growth and the whole gospel: A biblical mandate. San Francisco, CA: Harper \& Row.

Wagner, C. P. (1982). Your spiritual gifts can help your church to grow. Ventura, CA: Regal Books.

Wagner, C. P. (1984). Leading your church to growth. Ventura, CA: Regal.

Wagner, C. P. (1986). Spiritual power and church growth. Altamonte Springs, FL: Strong.

Walker, J. (2012). Reaching the unchurched requires relationships. Retrieved from http://pastors.com/reaching-the-unchurched-requires-relationships/

Wallenkampf, A. (2006). Renovados por el Espíritu. Doral, FL: Asociación Publicadora Interamericana.

Warren, R. (2013). God Calls Us to a Life of Service. Retrieved from http://ministrytodaymag.com/index.php/ministry-outreach/service/19872-godcalls-you-to-serve-others

Weld, W., \& McGavran, D. (1971). Principios del crecimiento de la iglesia. South Pasadena, CA: William Carey.

Weber, S. K. (2000). Matthew (Vol. 1). Nashville, TN: Broadman \& Holman.

Webster, D. (1959). What is Evangelism? Unidet Kingdom: The Hichway Press.

White, E. G. (1978). El evangelismo. Argentina: Casa Editora Sudamericana.

Wilson, R. (2009). JesusWalk - Beginning the journey: Discipleship and spiritual formation. Los Angeles, CA: JesusWalk. 
Wilson, R. (2014). Witness - Sharing your faith. Retrieved from http://www.jesuswalk.com/beginning/8_witness.htm

Willima F., \& Shepherd, L.E. (1999). Share Jesus without fear. Nashville, TN: B\&H.

Willis, A. T., \& Brown, S. W. (1998). MasterLife: developing a rich personal relationship with the Master. Nashville, TN: Broadman \& Holman.

Wilkers, G. G. (1996). El liderazgo de Jesús. Nashville, TN: LifeWay Press.

Wilkings, M. J. (1992). Following the Master. Grand Rapids, MI: Zondervan.

Wilkings, M. J. (1995). Discipleship in the ancient world and Matthew's gospel. Grand Rapids, MI: Baker Books.

Wilkinson, B. (2000). The prayer of Jabez: Breaking through to the blessed life. Sisters, OR: Multnomah.

Wood, C. (2003). Character witness: How our lives can make a difference in evangelism. Downers Grove, IL: InterVarsity.

Woods, A. (2011). The work of the Holy Spirit among the unsaved. Retrieved from http://www.spiritandtruth.org/teaching/documents/articles/66/66.pdf?x=x

WV Gazette. (2012). State sees increases in Hispanic population. Retrieved from http://www.wvgazette.com/News/201203220040

Youssef, M. (1986). The leadership style of Jesus. Wheaton, IL: Victor Books.

Zackrison, J. W. (1993). Church growth, the great commission model, a new way of life for your Church. Lincoln, NE: Church Resources.

Zuck, R. B. (1998). Vital missions issues: Examining challenges and changes in world evangelism. Grand Rapids, MI: Kregel Resources. 


\section{CURRICULUM VITAE}

Walter Castro

620 N. Bear Lake Rd.

Apopka, FL 32703

USA

Tel. 703.231.6642

e-mail: castrowal@gmail.com

\section{Education}

- 2005-

Doctor of Ministry (in progress)

- 1999-2001 Andrews University.

Berrien Springs, MI. Master of Divinity.

- 1990-1995 River Plate University.

Argentina. Bachelor in Theology.

\section{Languages English \\ Spanish}

\section{Work experience}

- 2013-present Volunteer Lay Pastors Director/Ministerial Associate, Florida Conference of Seventh-day Adventists

- 2009-2013 Multilingual and Church Planting Director Allegheny West Conference of Seventh-day Adventists

- 2005-2009 Senior District Pastor, Vienna Hispanic SDA Church and Bristow Hispanic SDA Church Potomac Conference of Seventh-day Adventists, VA

- 2001-2005 Senior District Pastor, Annandale Hispanic and Burke Hispanic SDA churches. Potomac Conference of Seventh-day Adventists, VA

- 1999-2001 Sent by Potomac Conference the Seminary Youth Pastor for the Berrien Springs Hispanic SDA Church

- 1998-1999 Senior District Pastor, 
Hampton Hispanic SDA Church

Potomac Conference of Seventh-day Adventists, VA

- 1996-1998 Literature Evangelist Director

Pennsylvania Conference of Seventh-day Adventists, VA

- 1995-1996 Literature Evangelist Assistant

Greater New York Conference of Seventh-day Adventists, NY

\section{Special Skills:}

- Computer Skills: Mac Os, Windows, Key Notes, Power Point, Pages, Basic Web Design, Etc...

- Language Skills: Spanish (first language), English (second language)

- Communication: I have 8 years of experience in the elaboration of Christian radio programs for both, Christian and non-christian communities.

- Evangelism: I have been involved in evangelism since the beginning of my ministry. I have done evangelism in my own churches; in Central, South America and also in Europe. God has always blessed by adding new people through baptism.

- Youth: Although I have been asked three times to take the position of the Youth Director for the Hispanic Ministry and rejected due to my love and duty to the local church, I have never disconnected myself from the youth department. In 2008, we developed a new ministry called HUGE Ministry; with the intention to support the spiritual needs of College and University Students.

- Discipleship: For the past 11 years, I have been directly involved in the organization of mayor lay training events for the Hispanic community in US. In January 2009, the Potomac Conference trained more than 1,700 lay leaders, small groups leaders and more than 250 young adults. God had giving me the opportunity to be part of the organizing committee all my ministry. Our focus as been always on evangelism and witnessing. For the past 6 years, my passion is towards our yearly New Believers. I have created a training curriculum to train our new believers during the first two years after their baptism. The main goal is to help them to love the Lord, the Church, the Mission and to develop a passion for witnessing to their closest friends and family.

- Multiculturalism: For the past 13 years, my ministry has been among multicultural churches. As a Multilingual Ministry Director for AWC, I enjoyed serving among people from more than 18 different types of cultures and nationalities. This experience has enriched my ministry and I have received a glance of the Kingdom of God.

- Church Planting: For the past 10 years I have been heavily involved in Church Planting. I've been working closely with the Church Planting Department of North American Division and Pr.Tom Evans (NADEI). Together have done the training, the coaching and the follow up of the new churches recently planted throughout the AWC territory. Similar initiatives are taking place in my recently assigned responsibility as Volunteer Lay Pastors Director for the Florida Conference of Seventh-day Adventists. 